\title{
In search of new diagnostic modalities and techniques in ventilator-associated pneumonia
}

Citation for published version (APA):

Schnabel, R. M. (2016). In search of new diagnostic modalities and techniques in ventilator-associated pneumonia. [Doctoral Thesis, Maastricht University]. https://doi.org/10.26481/dis.20160414rs

Document status and date:

Published: 01/01/2016

DOI:

$10.26481 /$ dis.20160414rs

Document Version:

Publisher's PDF, also known as Version of record

\section{Please check the document version of this publication:}

- A submitted manuscript is the version of the article upon submission and before peer-review. There can be important differences between the submitted version and the official published version of record.

People interested in the research are advised to contact the author for the final version of the publication, or visit the DOI to the publisher's website.

- The final author version and the galley proof are versions of the publication after peer review.

- The final published version features the final layout of the paper including the volume, issue and page numbers.

Link to publication

\footnotetext{
General rights rights.

- You may freely distribute the URL identifying the publication in the public portal. please follow below link for the End User Agreement:

www.umlib.nl/taverne-license

Take down policy

If you believe that this document breaches copyright please contact us at:

repository@maastrichtuniversity.nl

providing details and we will investigate your claim.
}

Copyright and moral rights for the publications made accessible in the public portal are retained by the authors and/or other copyright owners and it is a condition of accessing publications that users recognise and abide by the legal requirements associated with these

- Users may download and print one copy of any publication from the public portal for the purpose of private study or research.

- You may not further distribute the material or use it for any profit-making activity or commercial gain

If the publication is distributed under the terms of Article $25 \mathrm{fa}$ of the Dutch Copyright Act, indicated by the "Taverne" license above, 


\section{In search of new diagnostic modalities and techniques in ventilator-associated pneumonia}


${ }^{\circledR}$ Copyright Ronny Schnabel, Maastricht 2016

Layout: Tiny Wouters

Cover picture: Bernd Schnabel

Printed by: Datawyse | Universitaire Pers Maastricht

ISBN: 9789461595430 


\section{In search of new diagnostic modalities and techniques in ventilator-associated pneumonia}

ter verkrijging van de graad van doctor aan de Universiteit Maastricht, op gezag van de Rector Magnificus, Prof. dr. L.L.G. Soete

volgens het besluit van het College van Decanen, in het openbaar te verdedigen op donderdag 14 april 2016, om 10:00 uur

door

Ronny Schnabel

geboren op 23 juni 1974 te Görlitz, Duitsland 


\title{
Promotor
}

Prof. dr. P. Roekaerts

\section{Co-promotor}

\author{
Dr. D. Bergmans
}

\section{Beoordelingscommissie}

Prof. dr. L. Zimmermann (voorzitter)

Prof. dr. L. Blanch, Universitat Autònoma de Barcelona

Prof. dr. J. Kesecioglu, UMC Utrecht

Prof. dr. S. Olde Damink

Prof. dr. E. Wouters 
It might be well for all of us to remember that, while differing widely in the various little bits we know, in our infinite ignorance we are all equal.

Karl Popper, Conjectures and Refutations 



\section{Contents}

$\begin{array}{lll}\text { Chapter } 1 \quad \text { General introduction } & 9\end{array}$

Chapter 2 Alternative diagnosis in the putative ventilator-associated pneumonia patient not meeting the diagnostic bronchoalveolar lavage criteria

Chapter 3 Candida pneumonia in ICU?

Chapter 4 Mimivirus is not a frequent cause of ventilator-associated pneumonia in critically ill patients.

Chapter 5 Clinical course and complications following diagnostic bronchoalveolar lavage in critically ill mechanically ventilated patients

Chapter 6 Electronic nose analysis of exhaled breath to diagnose ventilator-associated pneumonia

Chapter 7 Analysis of volatile organic compounds in exhaled breath to diagnose ventilator-associated pneumonia

Valorisation

Acknowledgements

Curriculum Vitae

List of publications 



\section{Chapter 1}

General introduction 



\section{General introduction}

Ventilator-associated pneumonia (VAP) is a nosocomial infection that can complicate mechanical ventilation. ${ }^{1}$ VAP is defined as a new-onset pneumonia that occurs in patients receiving mechanical ventilation for more than 48 hours. ${ }^{2}$ It is associated with increased length of ventilation, increased length of stay in the intensive care unit and in the hospital, additional health care costs and an attributable mortality risk of $13 \%$. 3,4 VAP is generally divided into early onset ( $<5$ days) or late onset ( $\geq 5$ days) after hospitalisation. ${ }^{1}$ VAP in the early course of mechanical ventilation has been thought to be caused by microorganisms present in the upper respiratory tract like Streptococcus pneumoniae, Staphylococcus aureus and Hemophilus influenzae. These bacteria can reach the lower respiratory tract when the natural barrier is bridged by intubation, the mucociliary clearance is disturbed and microaspirations occur. ${ }^{5,6}$ In late-onset VAP nosocomial pathogens like Enterobacteriaceae and Pseudomonas aeruginosa are found more frequently. ${ }^{6-8}$ Colonisation of the upper respiratory tract could result from transmission of digestive tract bacteria or exogenous contamination via the hands of personnel. Longer periods of hospital admission and antibiotic treatment prior to mechanical ventilation were associated with increased multi drug resistant (MDR) bacteria causing VAP. ${ }^{9}$ However, recent studies have challenged these traditional classifications. ${ }^{1}$ The identity of pathogens causing early- and late-onset VAP were found to be more similar with $S$. aureaus, $P$. aeruginosa, $K$. pneumonia and $E$. coli as the most frequent organisms. ${ }^{10}$ The rates of MDR pathogens also appear to be more equal. ${ }^{11}$ Thus, empirical antibiotic treatment based on the time of onset might result in inadequate microbial coverage in the early-onset VAP or overtreatment in late-onset VAP. ${ }^{1}$ Non-bacterial pathogens like respiratory viruses and fungi might also have a role in the development and severity of VAP. ${ }^{12-14}$ Therefore, a fast and appropriate diagnostic strategy is mandatory. The ultimate goal of the diagnostic procedure is to prescribe antimicrobial drugs as fast as possible only to those patients with real bacterial pulmonary infection. A diagnostic technique with low sensitivity would leave patients untreated and increase morbidity and mortality. ${ }^{15,16}$ In contrast, a diagnostic modality with high sensitivity but low specificity would lead to unnecessary use of antibiotics and promote the development of multi drug resistance. With regard to the best diagnostic approach of VAP no consensus has been reached yet. ${ }^{17}$ The Center of Disease Control (CDC) definition of VAP requires that patients be ventilated for more than 48 hours and meet clinical, radiographic and microbiologic criteria. The clinical suspicion of VAP has been based on criteria depicted in Table 1.1.18 
I. Three or more positive out of the following

1. Rectal temperature $>38^{\circ} \mathrm{C}$ or $<35.5^{\circ} \mathrm{C}$

2. Blood leukocytosis $(>10.000 / \mu \mathrm{l})$ and/or left shift or blood leukopenia $(<3.000 / \mu \mathrm{l})$

3. More than ten leukocytes in Gram stain of tracheal aspirate (in high-flow field)

4. Positive culture of tracheal aspirate

and

II. New, persistent, or progressive infiltrate on chest radiograph

(The most recent surveillance definition from $C D C$ does not include radiographic evidence in the definitions of a possible or probable VAP. ${ }^{19}$ The present studies were designed before this adjustment in the definition.)

Clinical criteria alone are of limited diagnostic value in definitively establishing the diagnosis of VAP. An autopsy study comparing the presence of an infiltrate on chest radiograph and clinical criteria (leucocytosis, purulent secretions, fever) with postmortem findings only found a $69 \%$ sensitivity and $75 \%$ specificity in the diagnosis of VAP. ${ }^{20}$ The clinical pulmonary infection score (CPIS) was developed as a tool to facilitate the diagnosis of VAP. It combines six clinical assessments (temperature, blood leukocyte count, volume and purulence of tracheal secretions, oxygenation, pulmonary radiographic findings, semiquantitative culture of tracheal aspirate) each worth between 0 and 2 points. A value $\geq 6$ is a threshold to identify patients with VAP. ${ }^{21,22}$ However, using CPIS did not increase the accuracy in the clinical diagnosis of VAP. The sensitivity and specificity was approximately $65 \% .{ }^{23}$ Despite an apparent straightforward calculation of CPIS there is a substantial inter-observer variability. ${ }^{24}$ In patients with clinical suspicion of VAP respiratory samples for further microbiological analysis are therefore collected to confirm or reject the diagnosis. These samples can be obtained by several techniques. Incidence of VAP thereby depends on the chosen diagnostic modality and varies widely between 4 and $42 \%{ }^{25}$ Flexible fibreoptic bronchoscopy (FFB) with bronchoalveolar lavage (BAL) from the presumed site of infection is an invasive technique. It is thought to be a specific diagnostic approach with cytological analysis and quantitative microbiological culture of lavage fluid to identify patients with a true pulmonary infection to tailor antibiotic therapy. It aims at prevention of unnecessary use of antibiotics with associated risks of toxicity and development of multi-resistance. ${ }^{26-28}$ However, there is evidence from studies that showed similar outcome and overall use of antibiotics when clinical diagnostic criteria added by non-quantitative culture results from less invasive tracheal aspirations were used in the diagnosis of VAP. ${ }^{29,30}$ These findings challenged the warrant of more invasive techniques in the diagnostic workup. Nevertheless, direct visualisation of the airway by FFB could deliver additional clinical information and guide the selection of lung areas where specimens are taken. ${ }^{31,32}$ The information provided by BAL analysis is broader than from tracheal aspirates. This could benefit the diagnosis of bacterial VAP ${ }^{33}$ but also support the diagnosis of alternative infectious causes ${ }^{34}$ or other respiratory 
diseases. ${ }^{35}$ Furthermore, it has been demonstrated that BAL and endotracheal aspirates do not deliver interchangeable results in the diagnosis of VAP. ${ }^{36}$

The studies described in the present thesis were conducted in the Department of Intensive Care Medicine of the Maastricht University Medical Centre+, a tertiary unit that consists of two 9- bed units for medical and surgical patients with together 800 admissions per year and one 9-bed unit for cardiothoracic surgery patients with about 900 admissions per year. Considering all pro en con arguments, the standard strategy in the diagnosis of VAP has been FFB and BAL in clinically suspicious ventilated patients. Based on quantitative BAL analysis the average VAP incidence was found to be 3.5 episodes of VAP per 1,000 ventilator days. [Figure 1.1]

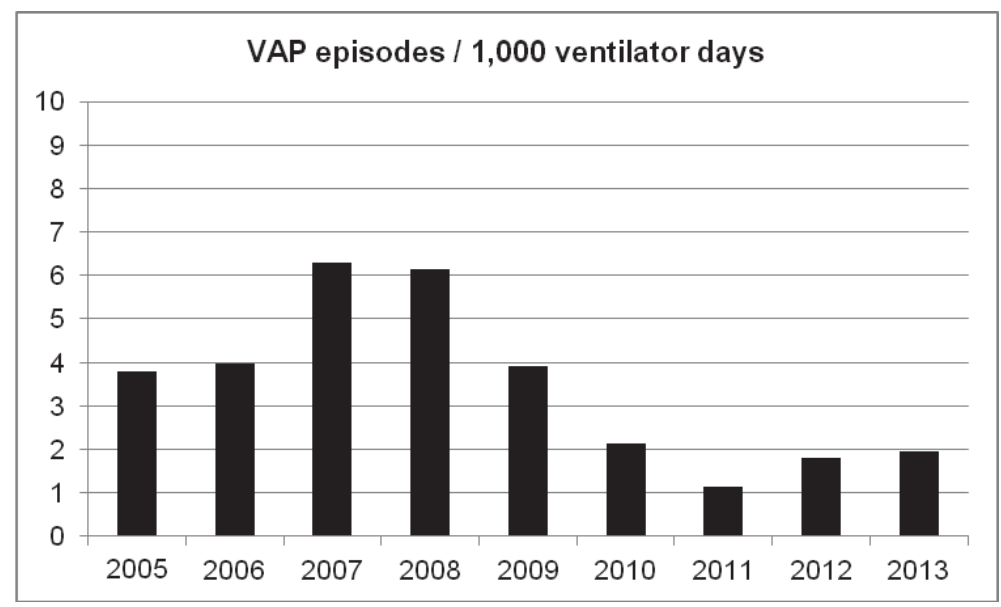

Figure 1.1 VAP episodes per 1,000 ventilator days

Of all patients with a clinical suspicion of VAP who underwent BAL between 2005 and 2013 in only $10-39 \%$ (with an average of $24 \%$ ) bacterial pneumonia could be confirmed by BAL analysis. [Figure 1.2] 


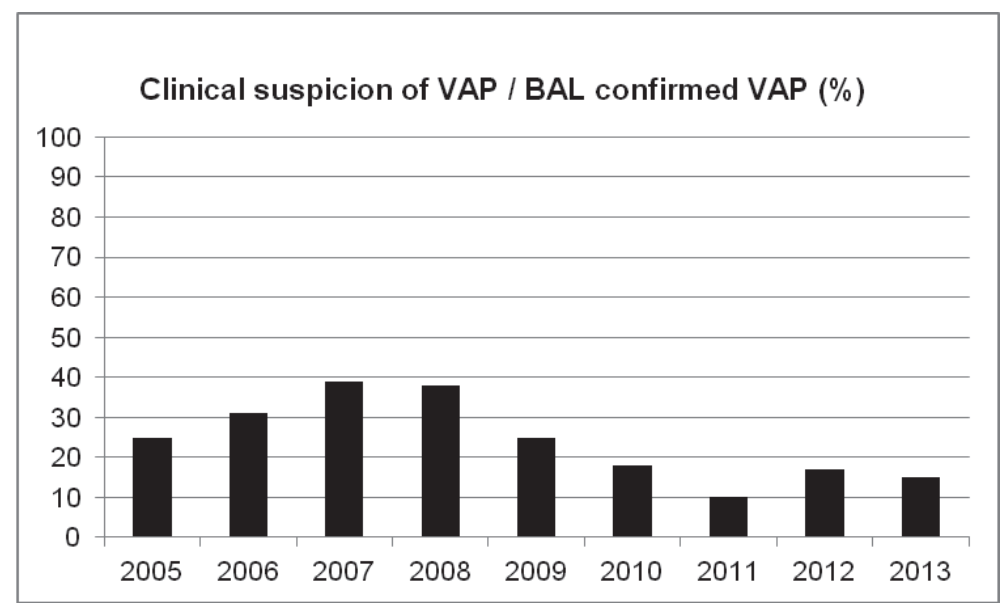

Figure 1.2 Percentage of BAL-confirmed VAP of all clinically suspicious patients

Obviously, in critically ill mechanically ventilated patients clinical signs are unspecific for pneumonia and could be mimicked by numerous alternative diagnoses. ${ }^{37}$ A potential delay in revealing the etiology of underlying alternative diagnoses in the putative VAP patient could cause harm. Knowledge of the most frequent alternative diagnoses and development of a diagnostic algorithm would be beneficial.

The first part of the present thesis deals with diagnostic modalities in patients clinically suspected to have VAP without a confirmation of bacterial pneumonia in BAL results.

In Chapter 1 the question is raised: What are alternative diagnoses in the putative ventilator-associated pneumonia patient not meeting lavage-based diagnostic criteria?

Whereas the role of bacteria in the etiology of VAP has been established, little is known about the presence of fungi and viruses in nosocomial pneumonia. Candida species are the most common isolated yeasts in critically ill patients but the significance is still argued. ${ }^{14,38,39}$ Fungi probably rarely cause nosocomial pneumonia. Candida pneumonia as a clinical entity has been questioned altogether. ${ }^{40}$ Histopathology could establish the definitive diagnosis. This is often not feasible in patients. As opposed to bacterial VAP there are no quantitative diagnostic cut-off values for fungal presence in BAL fluid.

In chapter $\mathbf{2}$ of the present thesis the question is raised: Does candida pneumonia exists in critically ill patients?

Respiratory viruses may have a role in VAP. Herpes simplex virus and cytomegalovirus can be reactivated and could cause pneumonia during the course of mechanical ventilation in critically ill patients. ${ }^{41}$ Human metapneumovirus has also been detected in BAL fluid analysis and could be a causative agent of pulmonary infection. ${ }^{42}$ It has been further suggested that Acanthamoeba polyphaga mimivirus (APMV) could play a 
role as a respiratory pathogen in ICU patients. APMV is a giant virus which belongs to the amoeba-associated microorganisms. It was discovered after an investigation of a pneumonia outbreak with no clear causative agent. ${ }^{43}$ Earlier studies have suggested that a positive serology could be associated with an increased duration of mechanical ventilation and ICU length of stay. ${ }^{44,45}$

In chapter 3 the assessment of APMV in bronchoalveolar lavage fluid of critically ill mechanical ventilated patients is described to answer the question: Is Acanthamoeba polyphaga mimivirus a respiratory pathogen in critically ill ventilated patients?

In the second part of the thesis, the focus is on diagnostic techniques in VAP. Bronchoscopic BAL from the presumed site of infection with cytological analysis and quantitative microbiological culture of the lavage fluid has been established as a diagnostic standard. ${ }^{26-28}$ Benefits should thereby outweigh potential hazards caused by the invasiveness of this diagnostic technique. Studies concerning the safety of bronchoscopic diagnostic techniques in critical care patients were small in size and differed in patient population, setting, applied diagnostic technique and length of observation. $^{46-53}$

In chapter $\mathbf{4}$ of the present thesis a study is described to establish the clinical course and complications following diagnostic bronchoalveolar lavage in critically ill mechanically ventilated patients.

The starting point in search for new diagnostic techniques in VAP is the assumption of an ideal method. It should meet all demands depicted in Table 1.2. The ideal diagnostic modality would combine high accuracy with speed and would carry no risks and hazards for patients.

Table 1.2 Characteristics of an ideal diagnostic technique in ventilator associated pneumonia

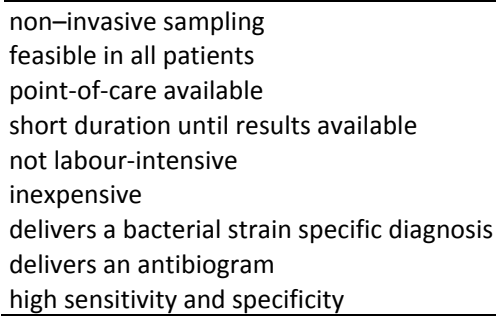

Exhaled breath analysis has been introduced into respiratory medicine as a new diagnostic strategy. It is based on the assumption that every disease is associated with alterations in the normal physiology and metabolism. Some of these changes can be disease specific and used in diagnostics. ${ }^{54}$ Exhaled breath is composed of air (nitrogen, oxygen, carbon dioxide, water vapour, inert gasses) and thousands of other low abundant volatile organic compounds (VOCs). ${ }^{54}$ The occurrence of certain VOCs in exhaled breath as a result of alterations in various pathways could distinguish a disease 
state. ${ }^{54}$ These compounds can be detected in collected exhaled breath by various technical modifications of gas chromatography coupled with mass spectrometry (GC-MS). ${ }^{55}$ Molecules are thereby carried with an inert gas through a column where they are separated according to their volatility and interaction with the stationary phase of the column. During mass-spectrometry components are fragmented into charged particles, carried through an electromagnetic field, quantitatively detected and identified in a mass-spectra library. ${ }^{56-58}$ Endogenous VOCs are produced by biological processes, excreted into the blood, after which they will easily diffuse into the lungs where they are exhaled. ${ }^{59}$ Each individual carries a characteristic microbiom of VOCs. ${ }^{60}$ The spectrum of VOCs can be altered by environmental, behavioural and nutritional influences. But also disease processes and inflammatory reactions by the immune system can change the VOCs in exhaled breath. VOCs can also be released by microorganisms as metabolic products during growth, as signalling molecules or as a defence mechanism. ${ }^{61}$ However, there is no single VOC that is solely produced by one strain of microorganisms. Therefore, analysis of 5-20 well-defined VOCs might be necessary to provide sufficient discriminative power between different microorganisms. Thereby, sophisticated computation and statistical analysis are applied. ${ }^{62}$ Intriguingly, microorganisms known for their strong specific odour were targeted first in exhaled breath studies among them Mycobacterium tuberculosis, Pseudomonas aeruginosa and fungi. ${ }^{63}$ VOC profiles could differentiate exhaled breath from patients with tuberculosis. ${ }^{64,65}$ Pseudomonas aeruginosa is an important pulmonary pathogen particularly in patients with cystic fibrosis (CF). Breath samples were able to classify patients with CF and Pseudomonas colonization correctly. ${ }^{66,67}$ Aspergillus fumigatus is a fungal pathogen causing invasive bronchopulmonary aspergillosis that forms a threat particularly for immunocompromised patients. Volatile compounds were identified to support the diagnosis of aspergillosis and could be used to monitor treatment efficacy. ${ }^{68-70}$ Discriminating VOC profiles have not only been determined for certain pathogenic microorganisms but also for various respiratory diseases such as chronic obstructive pulmonary disease (COPD), asthma, tuberculosis and cystic fibrosis. ${ }^{65,66,71-73}$ However, little is known about the applicability of VOC profiling for detection of pneumonia in a clinical setting. It has been demonstrated in vitro that the six most frequently involved bacteria can be identified by VOC analysis in the headspace of a bacterial culture medium. Pseudomonas aeruginosa, Staphylococcus aureus, Escherichia coli and Klebsiella pneumoniae could be identified correctly based on the headspace analysis of cultured bacteria. ${ }^{62}$ VOCs of Streptococcus pneumoniae and Haemophilus influenzae cultures were analysed by GC-MS at different time points during cultivation. Characteristic volatile biomarkers were detected for both bacterial species. ${ }^{74}$ A systematic review of 31 studies indicated metabolites that are produced mainly by one strain of bacteria and could possibly serve as a volatile biomarker for this specific strain. ${ }^{75}$ At present, pneumonia-specific VOCs have been solely identified in 
headspace of bacterial cultures. Thereby the focus has been on VOCs produced by microorganisms and by metabolic processes inside the bacterial culture medium.

In chapter $\mathbf{5}$ of the present thesis a study is described to analyse volatile organic compounds directly in exhaled breath to diagnose ventilator-associated pneumonia.

The advantage of GC-MS as an analytical tool in exhaled breath analysis is the opportunity of direct measurement and identification of VOCs. Numerous statistical methods are established to analyse VOC spectra. However, the technique is expensive, laborious and needs technical knowledge and operator skills. It is not easily applicable as a bed-side diagnostic tool and monitor, although there are new developments in portable systems. ${ }^{57}$ Therefore, the clinical applicability of GC-MS is limited for the time being.

A different approach in exhaled breath analysis is the electronic nose methodology (e-nose). Generally, e-noses consist of an array of nanosensors. When these sensors are exposed to a mixture of VOCs, a change in their electrical resistance is induced, leading to the production of a 'breath-print'. This breath-print represents the complex mixture of exhaled VOCs and can be used for pattern-recognition algorithms in multiple diseases. ${ }^{58}$ E-noses have been long applied for industrial purposes like environmental monitoring, pesticide detection and aroma detection. ${ }^{76}$ They are portable, easy to operate and potentially applicable at the bed-side. In the field of diagnostic medicine, studies have demonstrated that e-nose technology can be used to identify patients with colorectal cancer ${ }^{77}$, head and neck cancer $^{78}$, tuberculosis $^{79}$, cystic fibrosis ${ }^{80}$, chronic obstructive lung disease and asthma. ${ }^{81}$ It has been previously suggested that e-nose could be used to diagnose patients suffering from pneumonia. ${ }^{82}$ In vitro studies have demonstrated that e-nose sensors are able to discriminate between potential pathogens by analyzing the air above a bacterial culture medium. ${ }^{83}$ Comparison of the predictive value of e-nose to the clinical pulmonary infection score (CPIS) found e-nose capable of distinguishing between infected and uninfected state. ${ }^{84}$ It has never been confirmed, whether e-nose technology is able to identify patients with VAP when measuring directly in exhaled breath samples. But only if preliminary invasive sampling and the need for culturing sample material could be eliminated from the diagnostic process, e-nose could be a truly non-invasive, easily operated and fast diagnostic tool at the bedside.

Chapter 6 describes a study that deals with the question whether electronic nose technology can identify patients with ventilator-associated pneumonia by measuring directly in exhaled breath.

If non-invasive in vivo diagnosis by e-nose would be feasible, an on-site diagnostic tool could be made available. Rapid, non-invasive detection of patients who develop VAP could fasten adequate antibiotic treatment. 


\section{Outline of the thesis}

1. What are alternative diagnoses in the putative ventilator-associated pneumonia patient not meeting lavage-based diagnostic criteria?

2. Does candida pneumonia exists in critically ill ventilated patients?

3. Is Acanthamoeba polyphaga mimivirus a respiratory pathogen in critically ill ventilated patients?

4. What is the clinical course following diagnostic bronchoalveolar lavage in critically ill mechanically ventilated patients? What complications occur?

5. Can ventilator-associated pneumonia be diagnosed directly from exhaled breath by gas chromatography - mass spectrometry?

6. Can ventilator-associated pneumonia be diagnosed directly from exhaled breath by electronic nose technology? 


\section{References}

1 Nair GB, Niederman MS. Ventilator-associated pneumonia: present understanding and ongoing debates. Intensive care medicine 2015;41:34-48.

2 Horan TC, Andrus M, Dudeck MA. CDC/NHSN surveillance definition of health care-associated infection and criteria for specific types of infections in the acute care setting. American journal of infection control 2008;36:309-32.

3 Melsen WG, et al. Attributable mortality of ventilator-associated pneumonia: a meta-analysis of individual patient data from randomised prevention studies. The Lancet infectious diseases 2013;13: 665-71.

4 Warren DK, et al. Outcome and attributable cost of ventilator-associated pneumonia among intensive care unit patients in a suburban medical center. Critical care medicine 2003;31:1312-7.

5 Zolfaghari PS, Wyncoll DL. The tracheal tube: gateway to ventilator-associated pneumonia. Critical care 2011;15:310.

6 Hunter JD. Ventilator associated pneumonia. BMJ 2012;344:e3325.

7 American Thoracic Society; Infectious Diseases Society of America. Guidelines for the management of adults with hospital-acquired, ventilator-associated, and healthcare-associated pneumonia. American journal of respiratory and critical care medicine 2005;171:388-416.

8 Chastre J, Fagon JY. Ventilator-associated pneumonia. American journal of respiratory and critical care medicine 2002;165:867-903.

9 Trouillet JL, et al. Ventilator-associated pneumonia caused by potentially drug-resistant bacteria. American journal of respiratory and critical care medicine 1998;157:531-9.

10 Gastmeier $\mathrm{P}$, et al. Early- and late-onset pneumonia: is this still a useful classification? Antimicrobial agents and chemotherapy 2009;53;2714-8.

11 Restrepo $\mathrm{MI}$, et al. Comparison of the bacterial etiology of early-onset and late-onset ventilatorassociated pneumonia in subjects enrolled in 2 large clinical studies. Respiratory care 2013;58:1220-5.

12 Traen S, et al. Is acyclovir effective among critically ill patients with herpes simplex in the respiratory tract? Journal of clinical virology : the official publication of the Pan American Society for Clinical Virology 2014;60:215-21.

13 Wood GC, Mueller EW, Croce MA, Boucher BA, Fabian TC. Candida sp. isolated from bronchoalveolar lavage: clinical significance in critically ill trauma patients. Intensive care medicine 2006;32:599-603.

14 Delisle MS, et al. The clinical significance of Candida colonization of respiratory tract secretions in critically ill patients. Journal of critical care 2008;23:11-7.

15 Iregui $\mathrm{M}$, Ward S, Sherman G, Fraser VJ, Kollef $\mathrm{MH}$. Clinical importance of delays in the initiation of appropriate antibiotic treatment for ventilator-associated pneumonia. Chest 2002;122:262-8.

16 Luna CM, et al. Impact of BAL data on the therapy and outcome of ventilator-associated pneumonia. Chest 1997;111:676-85.

17 Kalanuria AA, Zai W, Mirski M. Ventilator-associated pneumonia in the ICU. Critical care 2014;18;208.

18 CDC definitions for nosocomial infections. American journal of infection control 1989;17;42-3.

19 Raoof S, Baumann MH. An official multi-society statement: ventilator-associated events--the new definition. Annals of the American Thoracic Society 2014;11:99-100.

20 Fabregas $\mathrm{N}$, et al. Clinical diagnosis of ventilator associated pneumonia revisited: comparative validation using immediate post-mortem lung biopsies. Thorax 1999;54:867-73.

21 Pugin J, et al. Diagnosis of ventilator-associated pneumonia by bacteriologic analysis of bronchoscopic and nonbronchoscopic "blind" bronchoalveolar lavage fluid. The American review of respiratory disease 1991;143:1121-9.

22 Fartoukh $\mathrm{M}$, et al. Diagnosing pneumonia during mechanical ventilation: the clinical pulmonary infection score revisited. American journal of respiratory and critical care medicine 2003;168:173-179.

23 Shan J, Chen HL, Zhu JH. Diagnostic accuracy of clinical pulmonary infection score for ventilatorassociated pneumonia: a meta-analysis. Respiratory care 2011;56:1087-94.

24 Zilberberg MD, Shorr AF. Ventilator-associated pneumonia: the clinical pulmonary infection score as a surrogate for diagnostics and outcome. Clinical infectious diseases : an official publication of the Infectious Diseases Society of America 2010;51 Suppl 1:S131-5. 
25 Ego A, Preiser JC, Vincent JL. Impact of diagnostic criteria on the incidence of ventilator-associated pneumonia. Chest. 2015;147:347-55.

26 Fagon JY, et al. Invasive and noninvasive strategies for management of suspected ventilator-associated pneumonia. A randomized trial. Annals of internal medicine 2000;132:621-30.

27 Shorr AF, Sherner JH, Jackson WL, Kollef $\mathrm{MH}$. Invasive approaches to the diagnosis of ventilatorassociated pneumonia: a meta-analysis. Critical care medicine 2005;33:46-53.

28 Fagon JY. Diagnosis and treatment of ventilator-associated pneumonia: fiberoptic bronchoscopy with bronchoalveolar lavage is essential. Seminars in respiratory and critical care medicine 2006;27:34-44.

29 Canadian Critical Care Trials Group. A randomized trial of diagnostic techniques for ventilator-associated pneumonia. The New England journal of medicine 2006;355:2619-30.

30 Berton DC, Kalil AC, Teixeira PJ. Quantitative versus qualitative cultures of respiratory secretions for clinical outcomes in patients with ventilator-associated pneumonia. The Cochrane database of systematic reviews 2014;10:CD006482.

31 Meduri GU, Chastre J. The standardization of bronchoscopic techniques for ventilator-associated pneumonia. Chest 1992;102:557S-64S.

32 Timsit JF, et al. Usefulness of airway visualization in the diagnosis of nosocomial pneumonia in ventilated patients. Chest 1996;110:172-9.

33 Kirtland $\mathrm{SH}$, et al. The diagnosis of ventilator-associated pneumonia: a comparison of histologic, microbiologic, and clinical criteria. Chest 1997;112:445-57.

34 Linssen CF, et al. Herpes simplex virus load in bronchoalveolar lavage fluid is related to poor outcome in critically ill patients. Intensive care medicine 2008;34:2202-9.

35 Linssen KC, et al. Reactive type II pneumocytes in bronchoalveolar lavage fluid. Acta cytologica 2004;48:497-504.

36 Scholte JB, et al. Endotracheal aspirate and bronchoalveolar lavage analysis: interchangeable diagnostic modalities in suspected ventilator-associated pneumonia? Journal of clinical microbiology, 2014;52:3597-604.

37 Meduri GU, et al. Causes of fever and pulmonary densities in patients with clinical manifestations of ventilator-associated pneumonia. Chest 1994;106:221-35.

38 Delisle MS, et al. Impact of Candida species on clinical outcomes in patients with suspected ventilatorassociated pneumonia. Canadian respiratory journal : journal of the Canadian Thoracic Society 2011;18: 131-6.

39 Hamet $\mathrm{M}$, et al. Candida spp. airway colonization could promote antibiotic-resistant bacteria selection in patients with suspected ventilator-associated pneumonia. Intensive care medicine 2012;38:1272-9.

40 Meersseman W, et al. Significance of the isolation of Candida species from airway samples in critically ill patients: a prospective, autopsy study. Intensive care medicine 2009;35:1526-31.

41 Luyt CE, Brechot N, Chastre J. What role do viruses play in nosocomial pneumonia? Current opinion in infectious diseases 2014;27:194-9.

42 Vanspauwen MJ, van Mook WN, Bruggeman CA, Bergmans DC, Linssen CF. Human metapneumovirus in bronchoalveolar lavage fluid of critically ill patients with suspected pneumonia. Intensive care medicine 2012;38:728-9.

43 Kutikhin AG, Yuzhalin AE, Brusina EB. Mimiviridae, Marseilleviridae, and virophages as emerging human pathogens causing healthcare-associated infections. GMS hygiene and infection control 2014;9:Doc16.

44 La Scola B, Marrie TJ, Auffray JP, Raoult D. Mimivirus in pneumonia patients. Emerging infectious diseases 2005;11:449-52.

45 Vincent $A$, et al. Clinical significance of a positive serology for mimivirus in patients presenting a suspicion of ventilator-associated pneumonia. Critical care medicine 2009;37:111-8.

46 Trouillet JL, et al. Fiberoptic bronchoscopy in ventilated patients. Evaluation of cardiopulmonary risk under midazolam sedation. Chest 1990;97:927-33.

47 Montravers, P, Gauzit R, Dombret MC, Blanchet F, Desmonts JM. Cardiopulmonary effects of bronchoalveolar lavage in critically ill patients. Chest 1993;104:1541-7.

48 Steinberg KP, et al. Safety of bronchoalveolar lavage in patients with adult respiratory distress syndrome. The American review of respiratory disease 1993;148:556-61.

49 Bauer TT, et al. Effects of bronchoalveolar lavage volume on arterial oxygenation in mechanically ventilated patients with pneumonia. Intensive care medicine 2001;27:384-93. 
50 Chou MY, Ou CY, Chen CW. Alterations in respiratory mechanics in mechanically ventilated patients following bronchoalveolar lavage. Journal of the Formosan Medical Association = Taiwan yi zhi 2009;108:704-12.

51 Estella, A. Effects on respiratory mechanics of bronchoalveolar lavage in mechanically ventilated patients. Journal of bronchology \& interventional pulmonology 2010;17:228-31.

52 Estella A. [Analysis of 208 flexible bronchoscopies performed in an intensive care unit]. Medicina intensiva / Sociedad Espanola de Medicina Intensiva y Unidades Coronarias 2012;36:396-401.

53 Turner JS, Willcox PA., Hayhurst MD, Potgieter PD. Fiberoptic bronchoscopy in the intensive care unit--a prospective study of 147 procedures in 107 patients. Critical care medicine 1994;22:259-64.

54 Pereira J, et al. Breath analysis as a potential and non-invasive frontier in disease diagnosis: an overview. Metabolites 2015;5:3-55.

55 Sethi S, Nanda R, Chakraborty T. Clinical application of volatile organic compound analysis for detecting infectious diseases. Clinical microbiology reviews 2013;26:462-75.

56 Hübschmann. Handbook of GC/MS: Fundamentals and Applications. Wiley 2008).

57 Santos FJ, Galceran MT. Modern developments in gas chromatography-mass spectrometry-based environmental analysis. Journal of chromatography A 2003;1000:125-51.

58 van de Kant KD, van der Sande LJ, Jobsis Q, van Schayck OC, Dompeling E. Clinical use of exhaled volatile organic compounds in pulmonary diseases: a systematic review. Respiratory research 2012;13:117.

59 Miekisch W, Schubert JK, Noeldge-Schomburg GF. Diagnostic potential of breath analysis--focus on volatile organic compounds. Clinica chimica acta; international journal of clinical chemistry 2004;347: 25-39.

60 Human Microbiome Project Consortium. Structure, function and diversity of the healthy human microbiome. Nature 2012;486:207-14.

61 Thorn RM, Greenman J. Microbial volatile compounds in health and disease conditions. Journal of breath research 2012;6:024001.

62 Boots AW, et al. Identification of microorganisms based on headspace analysis of volatile organic compounds by gas chromatography-mass spectrometry. Journal of breath research 2014;8:027106.

63 Omelianski VL. Aroma-Producing Microorganisms. Journal of bacteriology 1923;8:393-419.

64 Phillips $M$, et al. Volatile biomarkers of pulmonary tuberculosis in the breath. Tuberculosis 2007;87: 44-52, .

$65 \mathrm{Kolk} \mathrm{AH}$, et al. Breath analysis as a potential diagnostic tool for tuberculosis. The international journal of tuberculosis and lung disease : the official journal of the International Union against Tuberculosis and Lung Disease 2012;16:777-82.

66 Robroeks CM, et al. Metabolomics of volatile organic compounds in cystic fibrosis patients and controls. Pediatric research 2010;68:75-80.

67 Savelev SU, et al. Volatile biomarkers of Pseudomonas aeruginosa in cystic fibrosis and noncystic fibrosis bronchiectasis. Letters in applied microbiology 2011;52:610-3.

68 Syhre M, Scotter JM, Chambers ST. Investigation into the production of 2-Pentylfuran by Aspergillus fumigatus and other respiratory pathogens in vitro and human breath samples. Medical mycology 2008; 46:209-15.

69 Chambers ST, Syhre M, Murdoch DR, McCartin F, Epton MJ. Detection of 2-pentylfuran in the breath of patients with Aspergillus fumigatus. Medical mycology 2009;47:468-76.

70 Chambers ST, Bhandari S, Scott-Thomas A, Syhre M. Novel diagnostics: progress toward a breath test for invasive Aspergillus fumigatus. Medical mycology 2011;49 Suppl 1, S54-61.

71 Van Berkel JJ, et al. A profile of volatile organic compounds in breath discriminates COPD patients from controls. Respiratory medicine 2010;104:557-63.

72 Dallinga JW, et al. Volatile organic compounds in exhaled breath as a diagnostic tool for asthma in children. Clinical and experimental allergy 2010;40:68-76.

73 Robroeks CM, et al. Exhaled volatile organic compounds predict exacerbations of childhood asthma in a 1-year prospective study. The European respiratory journal 2013;42:98-106.

74 Filipiak W, et al. Characterization of volatile metabolites taken up by or released from Streptococcus pneumoniae and Haemophilus influenzae by using GC-MS. Microbiology 2012;158:3044-53.

75 Bos LD, Sterk PJ, Schultz MJ. Volatile metabolites of pathogens: a systematic review. PLoS pathogens 2013;9:e1003311. 


\section{Chapter 1}

76 Wilson AD. Diverse applications of electronic-nose technologies in agriculture and forestry. Sensors 2013;13:2295-348.

77 de Meij TG, et al. Electronic nose can discriminate colorectal carcinoma and advanced adenomas by fecal volatile biomarker analysis: proof of principle study. International journal of cancer. Journal international du cancer 2014;134:1132-8.

78 Leunis $\mathrm{N}$, et al. Application of an electronic nose in the diagnosis of head and neck cancer. The Laryngoscope 2014;124:1377-81

79 Bruins $M$, et al. Diagnosis of active tuberculosis by e-nose analysis of exhaled air. Tuberculosis 2013;93: 232-8.

80 Paff $\mathrm{T}$, et al. Exhaled molecular profiles in the assessment of cystic fibrosis and primary ciliary dyskinesia. Journal of cystic fibrosis : official journal of the European Cystic Fibrosis Society 2013;12: 454-60.

81 Fens $\mathrm{N}$, et al. Exhaled breath profiling enables discrimination of chronic obstructive pulmonary disease and asthma. American journal of respiratory and critical care medicine 2009;180:1076-82.

82 Montuschi P, Mores N, Trove A, Mondino C, Barnes PJ. The electronic nose in respiratory medicine. Respiration; international review of thoracic diseases 2013;85:72-84.

83 Humphreys L, et al. Electronic nose analysis of bronchoalveolar lavage fluid. European journal of clinical investigation 2011;41:52-8.

84 Hanson CW 3rd, Thaler ER. Electronic nose prediction of a clinical pneumonia score: biosensors and microbes. Anesthesiology 2005;102:63-8. 


\section{Chapter}

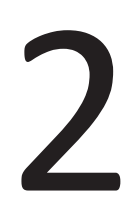

Alternative diagnosis in the putative ventilator-associated pneumonia patient not meeting lavage-based diagnostic criteria 


\section{Abstract}

\section{Objective}

The clinical picture of ventilator-associated pneumonia (VAP) can be mimicked by other infectious and non-infectious diseases. Aim of this study was to determine the alternative diagnoses and to develop a diagnostic flowchart in patients suspected of VAP not meeting the diagnostic bronchoalveolar lavage (BAL) criteria.

\section{Methods}

Adult intensive care patients with a clinical suspicion of VAP and negative BAL results were included. The clinical suspicion of VAP was based on the combination of clinical, radiological, and microbiological criteria. BAL was considered positive if cell differentiation revealed $\geq 2 \%$ cells with intracellular organisms and/or quantitative culture results of $\geq 10^{4} \mathrm{cfu} / \mathrm{ml}$. The most likely alternative diagnosis of fever and pulmonary densities was retrospectively determined by two authors independently.

\section{Results}

One hundred ten out of two hundred seven patients with suspected VAP did not meet the diagnostic BAL criteria and required further diagnostic evaluation. In sixty-seven patients an alternative diagnosis for fever could be found. In fifty-one patients an alternative diagnosis of both fever and pulmonary densities could be established. In almost $40 \%$ of patients no alternative diagnosis could be provided. Non-bacterial pneumonia was diagnosed in ten patients with Herpes simplex virus 1 (HSV-1) as the most common pathogen. In eight patients non-infectious pneumonitis was diagnosed.

\section{Conclusion}

Due to the wide range of alternative diagnosis and applied tests the diagnostic work-up proved to be necessarily individualized and guided by repeated clinical assessment. Most frequently found alternative diagnoses were viral pneumonia and non-infectious pneumonitis. 


\section{Introduction}

Ventilator-associated pneumonia (VAP) is the most frequent nosocomial infection in the intensive care unit (ICU). Approximately $10-50 \%$ of patients on mechanical ventilation develop VAP during their ICU stay depending on the applied diagnostic criteria. ${ }^{1}$ VAP increases the mean ICU length of stay and causes additional costs. Furthermore, several studies suggest attributed mortality of VAP in the non-trauma and non-ARDS patient. ${ }^{2,3}$

A generally accepted gold-standard for the diagnosis of VAP is lacking. VAP has been defined as a combination of clinical, radiological, and microbiological criteria. Each criterion on its own has a high sensitivity, but low specificity for VAP. ${ }^{4}$ During the Memphis Conference in 1992, experts adapted bronchoalveolar lavage (BAL) as a valuable diagnostic strategy for VAP. ${ }^{5}$ Approximately $40 \%$ of patients clinically suspected of VAP, have microbiologically confirmed VAP using the quantitative culture method of BAL fluid. ${ }^{6}$

More recently, cytological BAL fluid analysis has shown to provide contributory data. The presence $\geq 2 \%$ of inflammatory cells in BAL fluid with phagocytized, intracellular microorganisms has a high sensitivity and specificity in diagnosing VAP. ${ }^{7}$ The performance of BAL in patients clinically suspected of VAP is of substantial value. Identification of the responsible organism and its susceptibility pattern is important in optimizing antibiotic therapy. It reduces unnecessary antibiotic use, costs, development of multi resistant pathogens ${ }^{8}$ and possibly morbidity and mortality. ${ }^{9}$

The sensitivity and specificity of quantitative BAL fluid cultures in the diagnosis of VAP is approximately $75-85 \% .{ }^{10}$ Consequently a small part of the microbiologically nonconfirmed VAP will be false negative, while the majority can be marked as true negative. In all those cases an alternative diagnosis must be responsible for the clinical signs of fever, leukocytosis and chest X-ray abnormalities. The importance of identifying those alternative diagnoses is highlighted by the fact that in our own patient population the hospital mortality of patients with a negative BAL (39\%) is as high as in patients with a confirmed VAP (43\%). The aim of our study was to determine the frequency and nature of alternative diagnoses in the VAP-suspected patient with subsequently negative BAL results. We analysed the frequency of the different diagnostic modalities in this patient population in order to create a diagnostic flowchart.

\section{Materials and methods}

This retrospective study was conducted at the Maastricht University Medical Centre+, a tertiary-care, university-affiliated teaching hospital in the Netherlands with 1700 ICU admissions a year. The ICU consists of two 9 bed units for medical and surgical patients and one 9 bed unit for cardiothoracic surgery patients. 
Adult patients ( $\geq 18$ years), admitted to the ICU, with a clinical suspicion of VAP were included. In all patients, mechanical ventilation was initiated on the day of admission. A patient was clinically suspected of VAP after $\geq 48 \mathrm{~h}$ of mechanical ventilation according to the definitions adapted from the Centers for Disease Control and Prevention (CDC) depicted in Table 2.1. (The most recent surveillance definition from CDC does not include radiographic evidence in the definitions of a possible or probable VAP. ${ }^{11}$ The study was conducted before this adjustment in the definition.) Patients were screened daily for VAP using the clinical criteria. BAL was performed on the day of a clinical suspicion of VAP. We considered a clinically suspected episode microbiologically confirmed when the following criteria were met in BAL fluid ${ }^{12,13}$ : presence of $\geq 2 \%$ cells containing intracellular organisms (ICO) and/ or quantitative culture results of $\geq 10^{4}$ colony forming units (cfu) per milliliter of BAL fluid and/or a positive blood culture matching the microorganism of the aspirate and/ or a positive culture of pleura fluid without previous instrumentation. ${ }^{5}$

Table 2.1 Clinical suspicion of VAP criteria $^{4}$

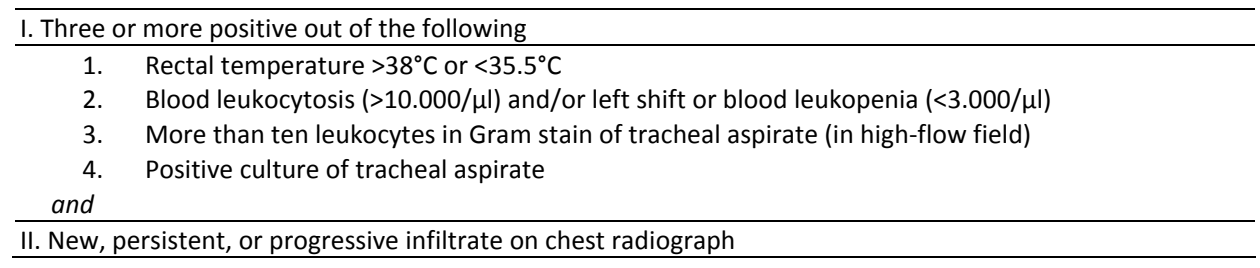

Subsequently patients with a positive BAL result were excluded. For patients with more than one episode of suspected VAP and a negative BAL, only the first BAL was included in the study. Baseline criteria were recorded. Time between ICU admission and BAL was also determined.

Informed consent regarding the use of data for research purposes was obtained from patients or their legal representatives. ${ }^{14}$ Only clinical data were used. No further experimental data were collected. Patients consented to the use of clinical data for scientific analysis according to the admission regulations if they did not opt out. This was approved by our local ethics commission.

Two researchers independently determined whether patients met the criteria for clinically suspected and confirmed VAP; in case of disagreement consensus was established after discussing and common re-analysis of the data.

All additional diagnostic examinations performed before, during or after the time of BAL were recorded. On this basis the most likely alternative diagnosis was determined out of a broad a priori differential diagnostic spectrum including cardio-pulmonary and vascular disease, other infections, malignancies and immunologic diseases. Two authors independently scored the contributory value of the diagnostic results afterwards. In 
case of disagreement consensus was established after re-analysis. All radiographic examinations were analyzed by a radiologist.

\section{Results}

The results are displayed as follows: patient demographics [Table 2.2], the applied diagnostic examinations [Table 2.3], its usefulness in establishing an alternative diagnosis and finally the most likely alternative diagnosis [Figure 2.1]. The left box lists alternative diagnoses explaining fever alone. The right box lists alternative diagnoses explaining pulmonary abnormalities. The box in the middle lists patients in whom an alternative diagnosis was established explaining both fever and pulmonary abnormalities.

Table 2.2 Characteristics of the study population

\begin{tabular}{|c|c|}
\hline Characteristic & $\begin{array}{c}\text { All patients } \\
(n=110)\end{array}$ \\
\hline \multicolumn{2}{|l|}{ Sex } \\
\hline Male (\%) & $70(64)$ \\
\hline Female (\%) & $40(36)$ \\
\hline Age (mean $\pm S D$, range) & $58 \pm 17(18-82)$ \\
\hline Days in hospital (mean $\pm S D$, range) & $62 \pm 46(8-322)$ \\
\hline Days in ICU (mean $\pm S D$, range) & $35 \pm 24(7-168)$ \\
\hline Days in ICU before BAL (mean $\pm S D$, range) & $12 \pm 8(1-40)$ \\
\hline Days in ICU after BAL (mean $\pm S D$, range) & $25 \pm 24(0-159)$ \\
\hline APACHE II score ${ }^{a}$ (mean $\pm S D$, range) & $23 \pm 7(7-40)$ \\
\hline Mortality in ICU (\%) & $36(33)$ \\
\hline Mortality in hospital (\%) & $39(35)$ \\
\hline \multicolumn{2}{|l|}{ Medical specialty (\%) } \\
\hline Medical & $46(42)$ \\
\hline Surgical & $40(36)$ \\
\hline Trauma & $14(13)$ \\
\hline Neurological & $7(6)$ \\
\hline Other ${ }^{b}$ & $3(3)$ \\
\hline \multicolumn{2}{|l|}{ Reason for ICU admission (\%) } \\
\hline Respiratory insufficiency & $14(13)$ \\
\hline Trauma & $12(11)$ \\
\hline Shock & $32(29)$ \\
\hline Cardiopulmonary failure & $13(29)$ \\
\hline Pneumonia & $17(16)$ \\
\hline Neurological disease & $7(6)$ \\
\hline Post-operative & $15(14)$ \\
\hline
\end{tabular}

\footnotetext{
${ }^{a}$ In 11 of 110 patients, APACHE II scores could not be calculated retrospectively. The patients involved did not differ significantly from the other patients in this study. ${ }^{b}$ Including otorhinolaryngology and gynaecology.
} 
Table 2.3 Diagnostic examinations

\begin{tabular}{|c|c|c|c|}
\hline Diagnostic examination & $\begin{array}{l}\mathrm{N}(\%) \text { examination } \\
\text { performed }\end{array}$ & $\begin{array}{c}\text { Day of examination } \\
\text { after BAL } \\
\text { (mean } \pm S D \text {, range) }\end{array}$ & $\begin{array}{c}\mathrm{N}(\%) \text { supported } \\
\text { establishing an } \\
\text { alternative diagnosis }\end{array}$ \\
\hline Repeated bronchoalveolar lavage & $11(10)$ & $7 \pm 4(2-17)$ & $1(9)$ \\
\hline Sputum microbiologic evaluation & 109 (99) & $1 \pm 1(-3-6)$ & 0 \\
\hline Hemoculture & $85(77)$ & $1 \pm 3(-3-11)$ & $10(12)$ \\
\hline Virology blood tests & $23(21)$ & $3 \pm 4(-4-8)$ & $1(9)$ \\
\hline Urine culture & $108(98)$ & $1 \pm 2(-3-7)$ & $4(4)$ \\
\hline $\begin{array}{l}\text { Urinary analysis for pneumococcal and } \\
\text { Legionella antigen }\end{array}$ & $5(5)$ & $0 \pm 1(-1-1)$ & 0 \\
\hline Urinary catheter culture & $9(8)$ & $3 \pm 3(0-8)$ & 0 \\
\hline Central venous catheter culture & $64(58)$ & $2 \pm 3(-3-11)$ & $5(8)$ \\
\hline Pleural fluid culture & $10(9)$ & $2 \pm 4(-2-9)$ & $2(20)$ \\
\hline Pus culture & $9(8)$ & $3 \pm 5(-3-10)$ & $1(11)$ \\
\hline Wound(fluid) culture & $18(16)$ & $2 \pm 3(-1-8)$ & $3(17)$ \\
\hline Drain tip culture & $23(21)$ & $2 \pm 3(-2-8)$ & $2(9)$ \\
\hline Drain fluid culture & $2(2)$ & $1 \pm 1(0-1)$ & 0 \\
\hline Faeces culture & $8(7)$ & $3 \pm 2(0-5)$ & 0 \\
\hline Ascites culture & $5(5)$ & $3 \pm 3(-1-6)$ & $3(60)$ \\
\hline Pathology examination & $19(17)$ & $4 \pm 6(-2-20)$ & $11(58)$ \\
\hline Post-mortem examination & $14(12)$ & $10 \pm 4(4-14)$ & $10(71)$ \\
\hline Echocardiography & $25(23)$ & $3 \pm 5(4-14)$ & $2(8)$ \\
\hline Endoscopy & $4(4)$ & $3 \pm 4(-1-8)$ & $2(50)$ \\
\hline Abdominal echography & $38(35)$ & $2 \pm 3(-2-10)$ & $3(8)$ \\
\hline Doppler ultrasound & $5(5)$ & $5 \pm 5(1-12)$ & 0 \\
\hline Chest radiography & $110(100)$ & $0 \pm 0(0-2)$ & $77(70)$ \\
\hline Sinus radiography & $11(10)$ & $3 \pm 3(-4-8)$ & 0 \\
\hline Abdominal radiography & $2(2)$ & $1 \pm 4(-2-3)$ & 0 \\
\hline Pelvic radiography & $1(1)$ & 2 & 0 \\
\hline Abdominal CT scan & $17(16)$ & $2 \pm 3(-1-11)$ & $3(18)$ \\
\hline Thoracic CT scan & $33(30)$ & $3 \pm 7(-3-34)$ & $22(67)$ \\
\hline Head CT scan & $10(9)$ & $2 \pm 3(-2-7)$ & $5(50)$ \\
\hline Sinus CT scan & $2(2)$ & $3 \pm 6(-2-7)$ & 0 \\
\hline Head MRI & $1(1)$ & 7 & 1 \\
\hline Laparotomy & $1(1)$ & 4 & 1 \\
\hline $\begin{array}{l}\text { Endoscopic retrograde } \\
\text { cholangiopancreatography }\end{array}$ & $1(1)$ & 1 & 1 \\
\hline Cerebrospinal fluid culture & $4(2)$ & $1 \pm 2(0-3)$ & 0 \\
\hline
\end{tabular}

In our study population 207 patients met the clinical criteria for VAP and subsequently underwent BAL. Hundred and ten patients had a negative BAL result and became subject to search for an alternative diagnosis.

Hemoculture was performed in 85 of 110 patients. A second BAL was conducted in 11 of 110 of patients within one week after the initial negative BAL result. In one case repeated BAL led to a diagnosis. In 108 of 110 patients urine was cultured. In 27 of 110 patients this culture was positive and lead to a definite diagnosis in four patients. Sinus radiography was performed in 11 patients and turned out to be suggestive for sinusitis in four, but did not lead to a definite diagnosis in any of these cases. Repeated 
chest X-rays were performed in all 110 patients, resulting in alternative causes of pulmonary infiltrations in $\mathbf{7 7}$ patients albeit not always leading to a definite alternative diagnosis.

\section{Alternative diagnoses explaining fever}

In 67 of 110 patients (61\%) with a negative BAL result an alternative diagnosis causing fever could be established. [Figure2.1] Infectious pneumonia with non-bacterial pathogens was found to be the cause of fever in 10 patients. Herpes simplex virus-1 (HSV-1) was the most commonly identified pathogen, being responsible in seven cases, followed by one case each of cytomegalovirus (CMV), Pneumocystis jiroveci and Candida albicans. HSV-1 pneumonia was diagnosed by a HSV-1 load in BAL exceeding $10^{5}$ genome equivalents (GE) $/ \mathrm{ml}^{15}$ In one case the diagnosis was confirmed by postmortem examination. CMV infection was confirmed by plasma PCR of 100.000 CMV DNA copies $/ \mathrm{mL}$, Candida albicans by a growth of $>10^{5} \mathrm{cfu} / \mathrm{ml}$ ) and Pneumocystis jiroveci by microscopic evidence. In one case repeated BAL lead to the diagnosis of VAP with Proteus mirabilis.

In eight patients non-infectious pneumonitis (NIP) was finally detected as likely cause of fever. Bronchiolitis obliterans with organizing pneumonia (BOOP) $(n=3)$ and drug induced pneumonia $(n=3)$ were the most common diagnoses, followed by one case each of eosinophilic pneumonia and Wegener's granulomatosis. BOOP was diagnosed in two cases by post-mortem examinations and once after lung biopsy. Drug-induced pneumonia was diagnosed by clinical suspicion in one case and pathologic examination of lung tissue in two cases. Suspected drugs were bleomycin, tegretrol, valproinic acid and amiodarone. Eosinophilic pneumonitis was diagnosed by clinical suspicion and blood chemistry.

In nine patients bacteremia was found. In seven of these, the focus could be established: catheter-related bloodstream infection $(n=2)$, infected ascitis $(n=1)$, urosepsis ( $n=3$ ) and one infected hematoma.

Resorption fever was considered in eight patients and found to be most likely caused by neurotrauma $(n=3)$, multitrauma $(n=2)$, lung hemorrhage $(n=1)$, brainstem hemorrhage $(n=1)$ and a postoperative bleeding after thoraco-abdominal aortic aneurysm repair $(n=1)$.

Ischemia was found to be the alternative cause of fever in six patients, five due to intestinal ischemia and one due to an extensive ischemic cerebrovascular accident.

Malignancy was found to be to be the cause of fever in four patients originating from ovarian carcinoma, squamous cell lung carcinoma, adenocarcinoma of the stomach and Morbus Hodgkin. 


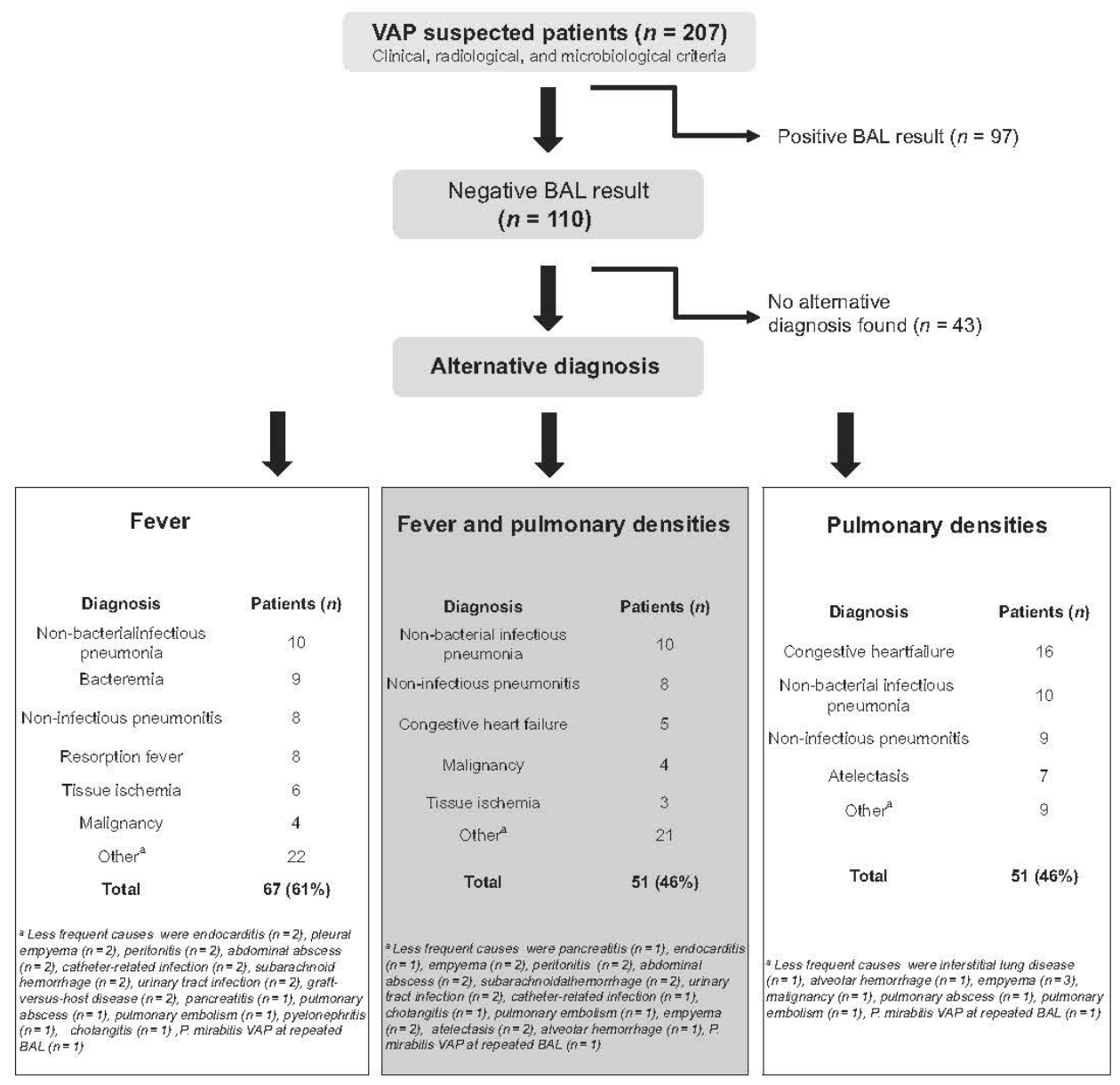

Figure 2.1 Alternative diagnosis in the putative ventilator-associated pneumonia patient not meeting lavage-based diagnostic criteria.

\section{Alternative diagnoses explaining pulmonary abnormalities}

In 51 of 110 patients (46\%) with a negative BAL result an alternative diagnosis of pulmonary densities could be established [Figure 2.1].

Congestive heart failure was considered the cause of pulmonary effusions in 16 patients. Non-bacterial infectious pneumonia $(n=10)$, non-infectious pneumonitis $(n=10)$ and atelectasis $(n=7)$ were other frequent causes of pulmonary abnormalities. 


\section{Alternative diagnoses explaining fever and pulmonary abnormalities}

In 51 of 110 patients (46\%) with a negative BAL result an alternative diagnosis causing both fever and pulmonary densities could be established [Figure 2.1]. Non-bacterial infectious pneumonia $(n=10)$ and non -infectious pneumonitis $(n=8)$ were the most frequent alternative diagnoses next to a broad spectrum of other causes.

Post-mortem examination was performed in 14 patients confirming the following diagnoses: intestinal ischemia, pancreatitis, lung hemorrhage, HSV pneumonia, BOOP, ovarian cancer, infected retroperitoneal hematoma, pulmonary embolism and a case of nonspecific alveolitis associated with graft-versus-host disease.

In 43 patients (39\%) no alternative diagnosis, neither for fever or pulmonary abnormalities (primarily pleural effusions and ARDS) could be established.

\section{Discussion}

Our results reveal that there are multiple alternative diagnoses in patients clinically suspected of VAP with a negative BAL. Hence various additional diagnostic examinations were necessary. Frequent urinary analysis, sputum culture and chest Xray are part of surveillance in our ICU. Repeated BAL after the initial negative BAL was carried out in 11 patients whereby in one case repeated BAL led to the diagnosis of bacterial VAP. Repeated radiographic examinations suggested an alternative cause of pulmonary infiltrations in $\mathbf{7 7}$ patients. Radiologic signs for pneumonia are nonspecific and repeated examinations may lead to a higher specificity. ${ }^{16}$ However, not all alternative cause of pulmonary infiltrations (for instance pleural effusions or ARDS) finally lead to a definite alternative diagnosis. Hemoculture was performed in $77 \%$ around the time of BAL. In our study population fever regarded separately was mainly caused by bacteremia due to hemoresorption and ischemia. Alternative causes of pulmonary densities were mainly identified as pleural effusion, congestive heart failure, non-bacterial infectious pneumonia and noninfectious pneumonitis. Fever and pulmonary densities regarded together were caused by non-bacterial pneumonia and non-infectious pneumonitis in the majority of cases.

Findings about the combination of fever and pulmonary densities in our study are comparable with previous studies by Meduri et al. and Balthazar et al. ${ }^{16,17}$ whereas results about causes of fever regarded solely differ.

Meduri et al. have shown that other infectious and non-infectious diseases can mimic VAP. In 45 of 50 patients clinically suspected of VAP and undergoing a systematic diagnostic protocol one or more alternative diagnoses were obtained. In total 78 sources of fever were identified. VAP was proven in $42 \%$ of cases $(n=19)$. Sinusitis $(n=12)$, catheter-related bloodstream infection $(n=14)$ and urinary tract infections $(n=10)$ accounted for $84 \%$ of the infections. A relevant non-infectious cause of fever 
was pulmonary fibroproliferation $(n=5)$, defined as lack of alternative source of fever with either histological confirmation of diffuse alveolar damage without evidence of pneumonia, or marked pulmonary uptake of ${ }^{67} \mathrm{Ga}$ and resolution of pulmonary densities and fever following treatment with high-dose corticosteroids.

In all patients with fever a cause of pulmonary densities was established. Out of 45 causes, 25 (56\%) were non-infectious: congestive heart failure $(n=7)$, atelectasis $(n=5)$, chemical aspirations $(n=1)$ and ARDS $(n=12)$. An infectious cause besides pneumonia was empyema $(n=1){ }^{16}$

Balthazar et al. performed postmortem lung biopsies in 37 patients with suspected VAP. In $54 \%$ the histopathological diagnosis of pneumonia was made. In $46 \%$ ( $n=17$ ), the following pathological findings were revealed: ARDS $(n=9)$, interstitial fibrosis $(n=3)$, diffuse alveolar damage $(n=3)$, diffuse alveolar edema $(n=2)$ and pulmonary embolism $(n=4) .{ }^{17}$ However, deceased patients are a subgroup of patients not representative for the population in the present study. Moreover, the reproducibility of histopathologic diagnosis of VAP is poor, as demonstrated by Corley et al. ${ }^{18}$

Alternative causes of fever differ between the known literature and our findings. Sinusitis, defined by a CT-scan with an air fluid level or opacification and positive culture of a maxillary aspirate, was the most frequent cause of fever in the study of Meduri et al. However, it always occurred together with another cause of fever. Pneumonia $(n=5)$, catheter-related infection $(n=3)$, urinary tract infection $(n=3)$ were the main concomitant causes. Other studies confirm the high incidence of sinusitis in ICU patients (7.7-11.5\%). ${ }^{19-21}$ In contrast, our study showed no cases of sinusitis. There was no case with sufficient clinical suspicion to further analyze this potential diagnosis. Notably, all our patients are orally intubated or tracheotomized carrying a lower risk of sinusitis than the nasal route of intubation. Another difference is the incidence of urinary tract infection. Meduri et al. stated that urinary tract infections occurred in $20 \%$ $(n=10)$. Seven patients had one or more associated infections: pneumonia $(n=4)$, catheter-related infections $(n=4)$ and sinusitis $(n=3)$. We found urinary tract infection in combination with a positive blood culture as the cause of fever in only $3 \%$. However, Meduri et al. describe only one case of bacteremia with the same organism present in the urine. The other cases are therefore not defined as urosepsis and are probably cases of "asymptomatic bacteriuria". Although bacteriuria is common in ICU patients, bacteremia due to organisms from the urine, necessitating antibiotic therapy, will occur in $<3 \%$. $^{21}$

Results of this present study reveal that the main pathogen for infectious non-bacterial pneumonia was HSV-1. Although HSV is commonly detected in the lower respiratory tracts of ICU patients receiving mechanical ventilation, lung tissue invasion occurs in a particular subset. ${ }^{22}$ Linssen et al. confirmed the presence of HSV pneumonia in ICU patients. In this study, the presence of HSV-1 DNA in BAL-samples was established in $32 \%$ (99/308) of patients suspected for VAP. ${ }^{15}$ Our results are supported by Luyt et al. who diagnosed HSV bronchopneumonia in 42 of 201 patients receiving mechanical 
ventilation and a clinical suspicion of lung infection. ${ }^{23}$ HSV bronchopneumonia is associated with poor clinical outcome. ${ }^{15,23,24}$ However, the exact significance of HSV pneumonia remains to be established. ${ }^{24}$

CMV pneumonia was diagnosed in one of our patients. Osawa and Singh showed in a review that $\mathrm{CMV}$ infection occurs in $0-36 \%$ of critically ill patients, depending on the applied criteria. ${ }^{25} \mathrm{CMV}$ infection was related to prolonged mechanical ventilation and duration of ICU-stay and showed an association with organ system failure and higher mortality. ${ }^{25}$ The exact significance of cytomegalovirus recovery from respiratory samples from non-immunocompromised patients has not yet been defined. ${ }^{23,25}$

Fever and pulmonary densities may have a wide range of origins. When BAL fluid examination does not reveal a causative micro-organism, it is important to continue the search for an alternative diagnosis. A delay may lead to induction of further organ dysfunction and can be an explanation for the high hospital mortality of patients with a negative BAL result. ${ }^{26}$

Meduri et al. proposed a systemic diagnostic approach based on the diagnosis most frequently encountered in their ICU. ${ }^{26}$ Our results show that the diagnostic examination eventually leading to the alternative diagnosis varied widely. The additional tests being performed are individualized and focused on clinical signs, radiologic information and laboratory abnormalities. A standardized diagnostic strategy would have to incorporate so many diagnostic modalities that it might not be practicably and cost-effective. Nevertheless, a standard blood culture on the day of BAL may be sensible because it can first of all support the diagnosis of VAP if it proves a bacteremia with the same microorganism as found in the BAL fluid and secondly it can give guidance establishing an alternative diagnosis in case of a negative BAL.

Although the present study was performed in a large, well-defined group of mixed medical and surgical ICU patients some study limitations should be mentioned. The data collection and analysis in the present study was retrospective. Although all results were validated by two authors independently, they were liable to subjective interpretation.

About half the patients with a suspected VAP according to clinical and radiographic criteria have a negative BAL result requiring further diagnostic evaluation.

Our results show that a wide spectrum of alternative diagnoses should be considered. Early establishment of a correct diagnosis may be vital for initiating adequate treatment and thereby patient outcome. An individually tailored diagnostic strategy appears most effective with standard blood culture on the day of BAL as the most important measure. Otherwise most frequently found alternative diagnoses are viral pneumonia and non-infectious pneumonitis. 


\section{References}

1. Torres A, Carlet J. Ventilator-associated pneumonia. European Task Force on ventilator-associated pneumonia. The European respiratory journal 2001;17:1034-45.

2. Melsen WG, Rovers MM, Bonten MJ. Ventilator-associated pneumonia and mortality: a systematic review of observational studies. Crit Care Med 2009;37:2709-18.

3. Safdar N, Dezfulian C, Collard HR, Saint S. Clinical and economic consequences of ventilator-associated pneumonia: a systematic review. Critical care medicine 2005;33:2184-93.

4. Bonten MJ. Controversies on diagnosis and prevention of ventilator-associated pneumonia. Diagn Microbiol Infect Dis 1999;34:199-204.

5. Pingleton SK, Fagon JY, Leeper KV Jr. Patient selection for clinical investigation of ventilator-associated pneumonia. Criteria for evaluating diagnostic techniques. Chest 1992;102:553S-6S.

6. Baselski V. Microbiologic diagnosis of ventilator-associated pneumonia. Infectious disease clinics of North America 1993; 7: 331-57.

7. Rea-Neto A, et al. Diagnosis of ventilator-associated pneumonia: a systematic review of the literature. Critical care 2008;12:R56.

8. Combes A, Luyt CE, Trouillet JL, Chastre J. Controversies in ventilator-associated pneumonia. Semin Respir Crit Care Med 2010;31:47-54.

9. Chastre J, Fagon JY. Ventilator-associated pneumonia. American journal of respiratory and critical care medicine 2002;165:867-903.

10. Torres A, El-Ebiary M. Bronchoscopic BAL in the diagnosis of ventilator-associated pneumonia. Chest 2000;117:198S-202S.

11. Raoof S, Baumann MH. An official multi-society statement: ventilator-associated events--the new definition. Annals of the American Thoracic Society 2014;11:99-100.

12. Linssen $\mathrm{CF}$, et al. Influence of antibiotic therapy on the cytological diagnosis of ventilator-associated pneumonia. Intensive care medicine 2008;34:865-72.

13. Bonten MJ, et al. Implementation of bronchoscopic techniques in the diagnosis of ventilator-associated pneumonia to reduce antibiotic use. American journal of respiratory and critical care medicine 1997;156:1820-4.

14. Oudhuis GJ, et al. Soluble Triggering Receptor Expressed on Myeloid cells-1 in bronchoalveolar lavage fluid is not predictive for ventilator-associated pneumonia. Intensive care medicine 2009;35:1265-70.

15. Linssen CF, et al. Herpes simplex virus load in bronchoalveolar lavage fluid is related to poor outcome in critically ill patients. Intensive care medicine 2008;34:2202-9.

16. Meduri GU, et al. Causes of fever and pulmonary densities in patients with clinical manifestations of ventilator-associated pneumonia. Chest 1994;106:221-35.

17. Balthazar $\mathrm{AB}$, et al. Diagnostic investigation of ventilator-associated pneumonia using bronchoalveolar lavage: comparative study with a postmortem lung biopsy. Brazilian journal of medical and biological research 2001;34:993-1001.

18. Corley DE, et al. Reproducibility of the histologic diagnosis of pneumonia among a panel of four pathologists: analysis of a gold standard. Chest 1997;112:458-65.

19. Hilbert G, et al. Comparison of B-mode ultrasound and computed tomography in the diagnosis of maxillary sinusitis in mechanically ventilated patients. Critical care medicine 2001;29:1337-42.

20. Humphrey MA, Simpson GT, Grindlinger GA. Clinical characteristics of nosocomial sinusitis. Ann Otol Rhinol Laryngol 1987;96:687-90.

21. Marik PE. Fever in the ICU. Chest 2000;117:855-69.

22. Luyt CE, Combes A, Nieszkowska A, Trouillet JL, Chastre J. Viral infections in the ICU. Current opinion in critical care 2008;14:605-8.

23. Luyt $\mathrm{CE}$, et al. Herpes simplex virus lung infection in patients undergoing prolonged mechanical ventilation. American journal of respiratory and critical care medicine 2007;175:935-42.

24. Simoons-Smit AM, Kraan EM, Beishuizen A, Strack van Schijndel RJ, Vandenbroucke-Grauls CM. Herpes simplex virus type 1 and respiratory disease in critically-ill patients: Real pathogen or innocent bystander? Clinical microbiology and infection 2006;12:1050-9. 
25. Osawa R, Singh N. Cytomegalovirus infection in critically ill patients: a systematic review. Crit Care 2009;13:R68.

26. Meduri GU. Diagnosis and differential diagnosis of ventilator-associated pneumonia. Clinics in chest medicine 1995;16:61-93. 



\section{Chapter}

Candida pneumonia in ICU?

R Schnabel, C Linssen, N Guion, W van Mook, D Bergmans

Open Forum Infect Dis. 2014;1:ofu026. 


\begin{abstract}
Background

Candida pneumonia has been questioned if it exists as a clinical entity. Only histopathology can establish the definite diagnosis. Less invasive diagnostic strategies lack specificity and have been insufficiently validated. Scarcity of this pathomechanism and non-specific clinical presentation makes validation and the development of a clinical algorithm difficult. In the present study we analyse if Candida pneumonia exists in our critical care population.
\end{abstract}

\title{
Method
}

We used a bronchoalveolar lavage specimen database that we have built in a structural diagnostic approach to ventilator-associated pneumonia for more than a decade consisting of 832 samples. Microbiological data were linked to clinical information and available autopsy data. We searched for critically ill patients with respiratory failure with no other microbiological or clinical explanation than exclusive presence of Candida species in bronchoalveolar lavage fluid.

\section{Result}

Five cases could be identified with Candida as the likely cause of pneumonia. 


\section{Introduction}

Pneumonia is a frequent diagnosis in patients admitted to the intensive care unit (ICU). In the majority of cases the pathogenic organism is of bacterial origin. There are known differences in the spectrum of these pathogens depending on the circumstances at the time the patient acquired pneumonia. Pneumonia patients develop at home is called community acquired pneumonia (CAP). CAP is distinguished from hospital acquired pneumonia (HAP), since the latter develops when the patient is already admitted to hospital. If the patient lives in a nursing home or comparable institution before admittance the causative pathogen is more likely within the spectrum of HAP. If pneumonia affects a patient on the respirator it is called ventilator associated pneumonia (VAP). ${ }^{1}$ The bronchoalveolar lavage (BAL) is a widely accepted diagnostic tool to confirm the diagnosis of pneumonia and to identify the nature of the associated pathogen. It is indicated if there is clinical suspicion of pneumonia i.e. a newly developed infiltrate on the chest X-ray, fever and an increased leukocyte count in the blood. BAL examination showing more than the cut-off value of $2 \%$ intracellular organisms (ICO) and BAL culture yielding more than $10^{4} \mathrm{CFU} / \mathrm{ml}$ is recognized as proof of a bacterial infection. ${ }^{2-4}$ There is still debate whether fungal infections play a role in the development of pneumonia. Especially the role of Candida species remains a diagnostic dilemma. It has been questioned whether Candida pneumonia exists at all. In contrast to the defined culture threshold for bacterial colony forming units there is no such standard to distinguish fungal colonization from fungal infections. The question raised in this study is if we can identify critical ill patients with respiratory failure with Candida growth in BAL specimens as single possible explanation of pneumonia? To answer that, we reviewed our database of bronchoalveolar lavage specimens build in more than 10 years containing 832 BAL samples.

\section{Materials and methods}

The study was conducted at the intensive care unit of the University Hospital Maastricht. The intensive care unit is an 18-bed mixed medical and surgical unit. Patients suspected of pneumonia were included. Clinical criteria were rectal temperature $>38^{\circ} \mathrm{C}$ or $<35.5^{\circ} \mathrm{C}$, blood leukocytosis $\left(>10 \times 10^{3} / \mathrm{mm}^{3}\right)$ and/or left shift or blood leukopenia $\left(<3 \times 10^{3} / \mathrm{mm}^{3}\right)$, more than 10 leukocytes in Gram stain of tracheal aspirate (in high-power field), positive culture of tracheal aspirate and a new, persistent or progressive infiltrate on chest radiograph. Patients underwent bronchoscopy with BAL conducted by senior fellows or consultant pneumologists. A fibreoptic bronchoscope (Pentax FB-15H/FB-15X, Pentax Medicals, Tokyo, Japan) was introduced and 'wedged' into the affected segmental or subsegmental bronchus. Sterile saline $(0.9 \% \mathrm{NaCl}$, room temperature) was instilled in four aliquots of $50 \mathrm{ml}$, immediately 
aspirated and recovered. BAL samples were transported to the laboratory within 15 min after collection and processed immediately upon arrival. BAL workup included: a total cell count, a differential cell count, microscopic investigation of a Gram-stained preparation, quantitative bacterial and fungal culture. Depending on clinical suspicion PCR for viruses and atypical bacteria were included. Bronchoalveolar lavage fluid samples were excluded if a) the recovered volume was less than $20 \mathrm{ml}$; b) the total cell count was less than $60.000 \mathrm{cells} / \mathrm{ml}$; c) presence of more than $1 \%$ squamous epithelial cells, d) presence of more than $5 \%$ bronchial epithelial cells. ${ }^{2}$ Between January 2000 and December 2010, 832 BAL fluid samples were retrieved from ICU patients and therefore eligible for inclusion. A total of 131 BAL fluid samples were excluded because they fitted one or more of the exclusion criteria. Therefore, a total of 701 BAL fluid samples were finally included in the present study. Solely clinical data collected during the treatment of patients were used in the analysis. No further experimental data were collected. Patients consented to the use of clinical data for scientific analysis according to the admission regulations if they did not opt out. This was approved by our local ethics commission.

\section{Results}

Case 1 patient was an elderly woman who was admitted to hospital in a state of malnourishment. She suffered from loss of appetite, with significant weight loss, diarrhea, vomiting and dehydration. At presentation she had shortness of breath and decreased consciousness. X-ray examination showed bilateral micronodular infiltrations. [Figure 3.1] Community acquired pneumonia was suspected. After resuscitation, intubation and ventilation BAL was carried out. BAL analysis revealed 360.000 cells $/ \mathrm{ml}$, no squamous epithelium, many leucocytes but no bacteria on Gramstaining. Further analysis showed $6.2 \%$ intracellular yeasts and no intracellular bacteria. [Figure 3.2] Differentiation showed $97.4 \%$ polymorphonuclear cells, $2.2 \%$ lymphocytes and $0.2 \%$ macrophages. Thoracic CT scanning revealed bullae, interstitial abnormalities with fibrosis and nodules as well as a cystic mediastinal abnormality. [Figure 3.3] Further diagnostic evaluation by gastroscopy elucidated the presence of a Zenker's diverticulum in the upper respiratory tract. Sputum cultures, BAL and cultures from the Zenker's diverticulum revealed colonization with a high load of Candida glabrata. We suspect that recurrent silent aspiration of food remnants colonized with Candida glabrata out of the Zenker's diverticulum finally caused pneumonia. The development of pneumonia was promoted by a reduced immunological defence due to serious malnourishment and cachexia. After surgical treatment of the Zenker's diverticulum and administration of antifungal medication she recovered from respiratory insufficiency and was eventually discharged from hospital. 


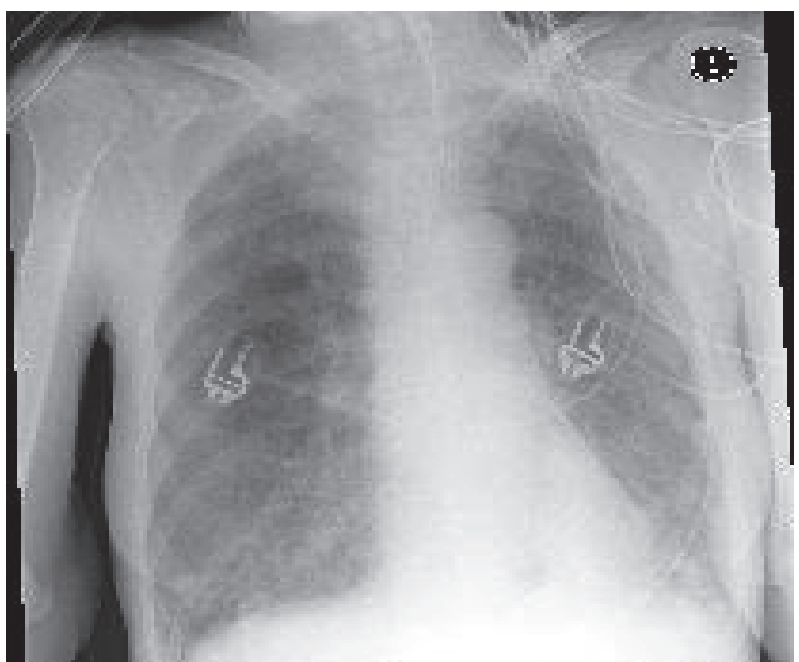

Figure 3.1 Chest X-ray of case 1 patient showing bilateral micronodular infiltrations

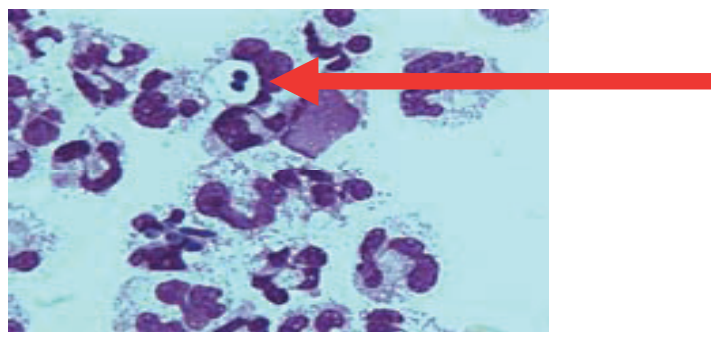

Figure 3.2 May-Grünwald-Giemsa stain (1000fold) of case 1 patient BALF showing intracellular microorganisms (arrow)

Case 2 concerns a 55 year old male patient who was immunocompromised by prednisolon and ciclosporin medication after stem cell transplantation due to myelodysplastic syndrome. The treatment was complicated by graft versus host disease. The patient was admitted to ICU in state of general malaise with serious respiratory failure. Chest $\mathrm{X}$-ray revealed infiltrative consolidations in the right lung and pleural effusions. Under suspicion of hospital acquired pneumonia a BAL targeting the affected site was done and yielded $55 \%$ intracellular yeasts and more than $10^{5} \mathrm{CFU} / \mathrm{ml}$ Candida albicans. Despite maximal treatment efforts the condition of the patient deteriorated and he subsequently died from respiratory failure. We obtained permission for an autopsy. Lung tissue culture yielded Candida species. Therefore we consider this a proven Candida pneumonia. 


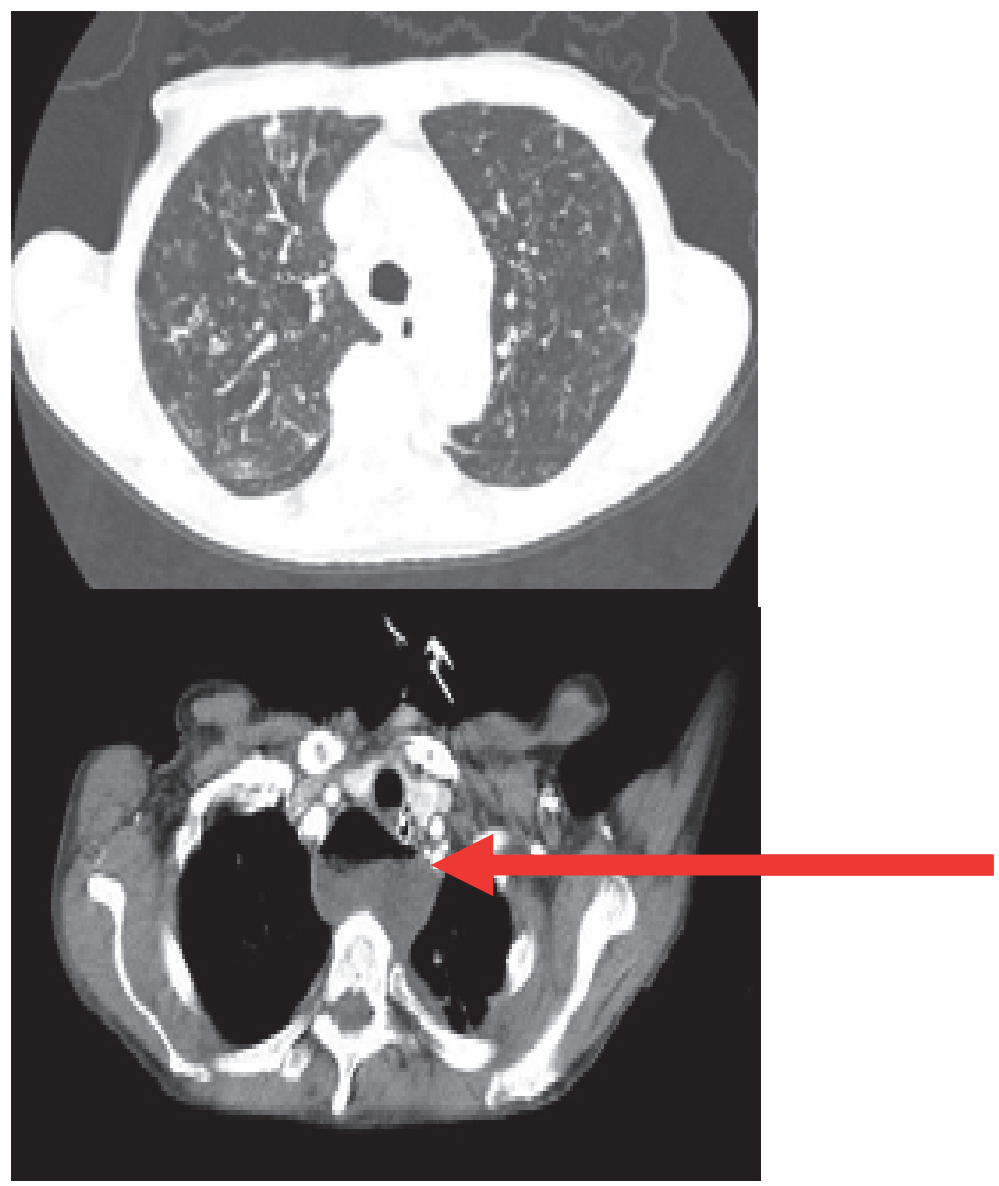

Figure 3.3 ThoracicCT-scan of case 1 patient showing bullae, interstitial abnormalities, fibrosis and a cystic mediastinal abnormality (arrow)

Case 3 describes a 64 year old male patient admitted to hospital with bacterial meningitis. He was treated with ceftriaxon and high dose dexamethason. In hospital he developed peritonitis due to perforated diverticulitis. After laparotomy he was admitted to ICU with septicaemia and respiratory failure. Chest X-ray revealed bilateral both upper quadrant infiltrative consolidations. Hospital acquired pneumonia was suspected. BAL fluid contained a low percentage of intracellular yeast $(0.4 \%)$ but yielded $4 \times 10^{3} \mathrm{CFU} / \mathrm{ml}$ Candida albicans and $5 \times 10^{2} \mathrm{CFU} / \mathrm{ml}$ Candida glabrata. Peritoneal fluid and sputum specimen cultures also revealed Candida species. The patient received fluconazol treatment and finally recovered. Specific risk factors that colonization with Candida results in infection were the immunosuppression with dexamethason and 
gastrointestinal perforation. We think that the pneumonia in this case was likely caused by Candida species in absence of other microorganisms.

Case 4 refers to a 55 year old male patient known with alcohol abuse. He was treated in the department of neurosurgery for brain metastasis due to adenocarcinoma of unknown origin. The histology was most compatible with lung carcinoma. To reduce oedema he was treated with dexamethason after surgery. Later he developed acute pancreatitis and was admitted to ICU in septic shock with respiratory failure. He was intubated and ventilated. Thorax CT revealed infiltrative consolidations in all quadrants. We performed BAL and demonstrated the presence of $7.4 \%$ intracellular yeasts and yielded $5.6 \times 10^{5} \mathrm{CFU} / \mathrm{ml}$ Candida albicans. Sputum culture from a tracheal aspirate also contained Candida albicans. The origin of a Streptococcus mitis found in a blood culture was not evident. Streptococcus mitis are commensal bacteria that colonize hard surfaces in the oral cavity as well as mucous membranes. These Gram-positive bacteria are not usually pathogenic but can cause bacterial endocarditis. There were no signs of endocarditis or central venous line infections in this patient. Despite antimycotic and antibacterial treatment and maximal efforts the patient subsequently died from respiratory failure. Permission for autopsy could not be obtained. We recognize a number of risk factors in this patient that could explain that Candida colonization probably resulted in pulmonary infection. The patient was immunocompromised due to steroid treatment after neurosurgery. He had an active malignant process, a history of alcohol abuse and developed an acute pancreatitis with septic shock.

Case 5 concerns a 70 year old male patient with coronary artery disease who was admitted to hospital with acute myocardial infarction. Before successful intubation and ventilation he aspirated a significant amount of gastric contents. Subsequently he developed ventilator associated pneumonia with bilateral infiltrations on chest X-ray. We performed a BAL and started with broad spectrum antibiotics. BAL revealed a small amount of intracellular yeasts and yielded Candida glabrata in culture. The patient finally died from circulatory failure. There was no permission for an autopsy to further confirm pulmonary infection. In absence of other causative microorganisms Candida species most likely played a role in the development of pneumonia. Although Candida species may have been innocent bystander in an otherwise chemical damage of the lungs by acidic gastric fluid aspiration, we would support the choice for antifungal treatment in such a clinical situation.

Table 3.1 gives an overview of all five cases of presumed Candida pneumonia. 


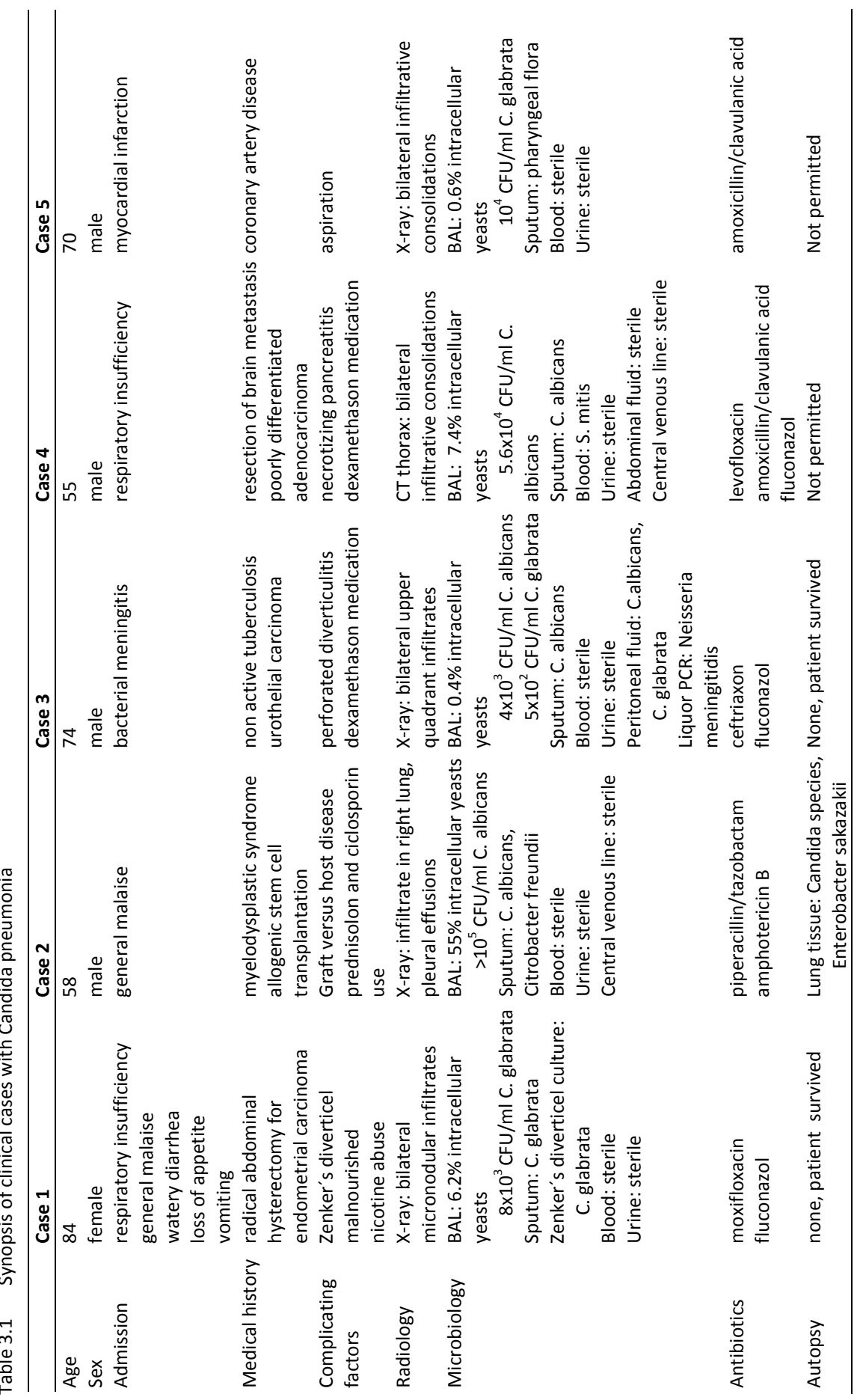




\section{Discussion}

After reviewing all 701 included BAL specimens and corresponding clinical cases we were able to identify only five cases $(0.7 \%)$ of presumed Candida pneumonia.

In case 1 Zenker's diverticulum represented a source of substantial fungal growth and presumably microaspirations. In state of chronic malnourishment the elderly patient developed pneumonia. Diagnostic specimens all yielded fungi and the patient responded well to surgical removal of the source of infection and additional antimycotic therapy. Case 2 patient's specific risk factor was serious immunosuppression by haematological malignancy and subsequent treatment. Diagnostic specimens resulted in a high number of ICO and significant fungal growth. After death the diagnosis of Candida pneumonia could be established by autopsy. In case 3 the patient was also immunocompromised by steroid treatment. There was a substantial growth of fungi in BAL fluid and peritoneal fluid. In absence of other pathogens pneumonia was presumably caused by fungi. Case 4 patient was also immunocompromised by steroid treatment and malignancy. BAL fluid analysis revealed a substantial number of ICO and fungal growth. Case 5 patient had a witnessed aspiration. Later there was substantial growth of fungi in BAL fluid. Although the signs of pneumonia could be caused by chemical damage after aspiration the treatment with antimycotics can probably be justified in a clinically life threatening situation.

Candida species are frequently found in tracheal aspirate specimens even in healthy patients. After 48 hours of intubation and ventilation up to $20 \%$ of patients are colonized with Candida species at the tracheobronchial site. This proportion increases with the duration of ventilation. ${ }^{5}$ Wood et al. analysed bronchoalveolar lavage cultures from critically ill patients over three years. They found $8 \%$ positivity for Candida. $97 \%$ of positive findings were thought to be colonization or inconclusive and only $3 \%$ classified as VAP by the treating physician. Even though anti-fungal treatment was not initiated, no patient developed systemic candidiasis. ${ }^{6}$ Candida risk score was conceptualised and validated to identify patients with a high risk to develop invasive candidiasis. In a multicentre approach enough patients with invasive candidiasis could be included to develop a clinical score that consists of the components severe sepsis, septic shock, total parenteral nutrition, surgery, multifocal Candida colonisation. In patients with a score $>3$ the risk of developing invasive candidiasis was significantly increased. Those patients would benefit from antifungal therapy. ${ }^{7,8}$ Candida pneumonia is an even scarcer pathomechanism. That makes the development of a comparable diagnostic algorithm difficult. Treatment of all patients with BAL fluid analysis positive for Candida would result in excessive use of antifungal agents with risk of rapid development of drug resistance. Sheer presence of Candida in the BAL obviously does not prove a pathogenetic role of this microorganism in the development of pneumonia. Kontoyiannis et al. found in their study of cancer patients a poor association between tracheal aspiration specimens, bronchoalveolar lavage specimens and autopsy studies 
for fungal infections. ${ }^{9}$ The radiological morphology of Candida lesions is diverse. Bronchopneumonia, abscesses, granulomas, intracavitary membranous exudates have all been described as X-ray findings. ${ }^{10}$ Moreover, there is no specific appearance on high resolution chest tomography. Random nodules are commonly seen in patients with candidiasis. The real incidence of Candida pneumonia is thus notoriously difficult to determine. The most reliable method would be lung histology and proof of an association between Candida lung invasion and local inflammation. Needle biopsy of a suspected lesion is a diagnostic option only if the infiltrate is safely accessible. The patients clinical condition, high oxygen dependency and thrombocytopenia, which are commonly present, all exclude the possibility of pulmonary biopsies. For this reason there have been no studies so far to validate biopsy strategies to prove Candida pulmonary infections. Therefore, most reports on Candida pneumonia are based on isolation of Candida from sputum aspirates or BAL in the absence of other causative pathogens. A few autopsy studies in cancer patients claim to have identified Candida species as causing pathogens in pneumonia. Wakayama et al. found nine cases of Candida pneumonia in a series of 149 autopsies in patients who had undergone haematopoetic stem cell transplantation. ${ }^{11}$ Haron et al. reviewed fatal cancer patients from a period of 20 years and could only find 55 cases with unequivocal evidence of primary candidiasis. ${ }^{12}$ El-Ebiary et al. undertook a small prospective study to assess the incidence and significance of isolation of Candida species from various diagnostic sites in critically-ill, ventilated and non-neutropenic patients. Quantitative cultures from tracheal aspirate and BAL could not discriminate presence from absence of Candida pneumonia established by autopsy findings. The general incidence of Candida in biopsy findings was found to be as high as $40 \%$ but the definite incidence of Candida associated pneumonia was found to be only $8 \% .{ }^{13}$ However, an elaborately designed study by Meersseman et al. provided no evidence for the existence for such clinical entity at all. The group was able to perform autopsies in a large number of patients who died in ICU. The routine tracheal surveillance cultures were used to classify the patients into one group having Candida species in their respiratory tract and one group who had not. In the post-mortal examination the presence of Candida pneumonia was established using histological criteria that included pseudohyphae and budding yeasts in an area with various signs of acute inflammation. Cases of Candida pneumonia could neither be found in 232 autopsied patients nor in 77 patients with pre-mortem positive tracheal aspirates. Taking into account the high number of patients colonized with Candida species in the tracheal tract it seems a convincing conclusion that colonization alone does not lead to pulmonary infection. ${ }^{14}$ We concede, by the present data, that it is convincingly proven, that Candida species are at most a very rare cause of pneumonia. But do these findings rule out the existence of Candida pneumonia as a clinical entity at all? The next question would be whether these Candida species colonizing the tracheobronchial tree are merely innocent bystander? Recently it has been shown that mechanically ventilated patients colonized with Candida species were 
more at risk to develop Pseudomonas aeruginosa VAP. Those patients who received antifungal treatment had a reduction in Pseudomonas aeruginosa VAP. Furthermore, it could be demonstrated that colonization with Candida species is an independent risk factor for an increased morbidity and mortality in ICU patients. But it could not be established convincingly whether colonization with Candida had a causative role or was merely a marker for poor outcome. ${ }^{15-17}$

We hypothesize that under certain clinical circumstances Candida pneumonia can affect patients indeed. However, the clinical presentation is neither specific nor characterized by the presence of sepsis and marked respiratory insufficiency. The presumed route of infection could be either a primary infection that occurs after oropharyngeal aspiration or a secondary haemotogenous spread to the lungs in candidiasis. In a primary Candida pneumonia concomitant Candida esophagitis and colonization of the upper respiratory tract can be frequently found. The presumed mechanism of pulmonary infection is aspiration of oesophagopharyngeal contents. It is supposed that under certain circumstances Candida organisms reach and invade distal air spaces. In this way there is spread in the airspaces but no vascular invasion. In secondary pulmonary Candida infection the inoculation with the microorganisms takes place by spread in the bloodstream from any distant site. This can be dissemination from the skin, translocation from the gastrointestinal tract or spread from extensive mucositis. In this case vascular invasion including small arteriols and capillaries around the pulmonary tissue can be found. Taking into account the scarcity of Candida pneumonia a certain special clinical condition is needed to develop it. Diabetes mellitus has been associated with $20 \%$ increase in colonization by Candida species. Nicotine and alcohol abuse as well as use of steroids and prior antibiotic use have been linked to increased colonization with Candida species at various anatomical sites. ${ }^{18,19}$ An increasing number of immunocompromised patients due to immunosuppressive therapy (transplant recipients, immunomodulation in rheumatoid arthritis), malignancies and infections (HIV, granulomatous diseases) are treated in ICU. Klapholz et al. described a patient with AIDS who developed Candida pneumonia secondary to a tracheobronchial fistula. ${ }^{20}$

\section{Conclusion}

In our institution BAL has been used as a routine diagnostic tool for more than ten years. Reviewing all 701 included BAL specimens and subsequently linking it to the clinical cases we could identify five patients $(0.7 \%)$ with Candida pneumonia. We concede that Candida pneumonia is a rare entity. But we have gathered evidence that the condition can occur under certain clinical circumstances: 1 . immunosuppression by cancer, sepsis, drugs, malnutrition, 2. risk factors for increased Candida load as diabetes mellitus, nicotine and alcohol abuse, aspiration of gastric fluids, diverticulum of the 
oesophagus, 3. broad spectrum antibiotic treatment. Specific cut-off values for fungi in BALF are lacking. We emphasize that we do not want to promote overuse of antimycotic agents. We strongly believe in a meticulous diagnostic approach in pneumonia and tailored use of antimicrobial drugs. On the other hand we should not withhold an effective treatment if the evidence is strong by declaring a clinical entity as non-existent. In cases of serious respiratory failure, radiographic and laboratory evidence for pneumonia and no other growth than a Candida in the BAL fluid Candida pneumonia should be considered and subsequently treated. 


\section{References}

1. Torres A, Ewig S, Lode H, Carlet J, European HAP working group. Defining, treating and preventing hospital acquired pneumonia: European perspective. Intensive care medicine 2009;35:9-29.

2. Linssen CF, Bekers O, Drent M, Jacobs JA. C-reactive protein and procalcitonin concentrations in bronchoalveolar lavage fluid as a predictor of ventilator-associated pneumonia. Annals of clinical biochemistry 2008;45:293-8.

3. Baselski V. Microbiologic diagnosis of ventilator-associated pneumonia. Infectious disease clinics of North America 1993;7:331-57.

4. Allaouchiche B, Jaumain H, Dumontet C, Motin J. Early diagnosis of ventilator-associated pneumonia. Is it possible to define a cutoff value of infected cells in BAL fluid? Chest 1996;110:1558-65.

5. Azoulay $\mathrm{E}$, et al. Candida colonization of the respiratory tract and subsequent pseudomonas ventilatorassociated pneumonia. Chest 2006;129:110-7.

6. Wood GC, Mueller EW, Croce MA, Boucher BA, Fabian TC. Candida sp. isolated from bronchoalveolar lavage: clinical significance in critically ill trauma patients. Intensive care medicine 2006;32:599-603.

7. Leon $\mathrm{C}$, et al. Usefulness of the "Candida score" for discriminating between Candida colonization and invasive candidiasis in non-neutropenic critically ill patients: a prospective multicenter study. Critical care medicine 2009;37:1624-33.

8. Leroy G, et al. Evaluation of "Candida score" in critically ill patients: a prospective, multicenter, observational, cohort study. Annals of intensive care 2011;1:50.

9. Kontoyiannis DP, et al. Pulmonary candidiasis in patients with cancer: an autopsy study. Clinical infectious diseases : an official publication of the Infectious Diseases Society of America 2002;34:400-3.

10. Masur H, Rosen PP, Armstrong D. Pulmonary disease caused by Candida species. The American journal of medicine 1977;63:914-25.

11. Wakayama $\mathrm{M}$, et al. Deep-seated mycosis as a complication in bone marrow transplantation patients. Mycoses 2002; 45:146-51.

12. Haron E, Vartivarian S, Anaissie E, Dekmezian R, Bodey GP. Primary Candida pneumonia. Experience at a large cancer center and review of the literature. Medicine 1993;72:137-42.

13. el-Ebiary $M$, et al. Significance of the isolation of Candida species from respiratory samples in critically ill, non-neutropenic patients. An immediate postmortem histologic study. American journal of respiratory and critical care medicine 1997;156:583-90.

14. Meersseman W, et al. Significance of the isolation of Candida species from airway samples in critically ill patients: a prospective, autopsy study. Intensive care medicine 2009;35:1526-31.

15. Nseir S, et al. Impact of antifungal treatment on Candida-Pseudomonas interaction: a preliminary retrospective case-control study. Intensive care medicine 2007;33:137-42.

16. Nseir S, Ader F. Pseudomonas aeruginosa and Candida albicans: do they really need to stick together? Critical care medicine 2009;37:1164-6.

17. Delisle MS, et al. The clinical significance of Candida colonization of respiratory tract secretions in critically ill patients. Journal of critical care 2008;23:11-7.

18. Tapper-Jones LM, Aldred MJ, Walker DM, Hayes TM. Candidal infections and populations of Candida albicans in mouths of diabetics. Journal of clinical pathology 1981;34:706-11.

19. Pasqualotto AC. Candida and the paediatric lung. Paediatric respiratory reviews 2009;10:186-91.

20. Klapholz A, Wasser L, Stein S, Talavera W. Candida pneumonia secondary to an acquired tracheoesophageal fistula in a patient with AIDS. New York state journal of medicine 1988;88:279-80. 



\section{Chapter 4}

Mimivirus is not a frequent cause of ventilatorassociated pneumonia in critically ill patients

M Vanspauwen, R Schnabel, C Bruggeman, M Drent, W van Mook, D Bergmans,

C Linssen

Med Virol. 2013;85:1836-41 


\begin{abstract}
Introduction

Acanthamoeba polyphaga mimivirus (APMV) belongs to the amoebae-associated micro-organisms. Antibodies to APMV have been found in patients with pneumonia suggesting a potential role as a respiratory pathogen. In addition, positive serology for APMV was associated with an increased duration of mechanical ventilation and intensive care unit (ICU) stay in patients with ventilator-associated pneumonia (VAP). The aim of the present study was to assess the presence of APMV in bronchoalveolar lavage (BAL) fluid samples of critically ill patients suspected of VAP.
\end{abstract}

\title{
Methods
}

The study was conducted in the ICU of the Maastricht University Medical Centre. All consecutive BAL fluid samples obtained between January 2005 and October 2009 from patients suspected of VAP were eligible for inclusion. All samples were analyzed by realtime PCR targeting the APMV.

\section{Results}

A total of 260 BAL fluid samples from 214 patients (139 male, 75 female) were included. Bacterial VAP was confirmed microbiologically in 105 out of 260 (40\%) suspected episodes of VAP (86 patients). The presence of APMV DNA could not be demonstrated in the bacterial VAP positive or in the bacterial VAP negative BAL fluid samples.

\section{Conclusions}

Although suspected, APMV appeared not to be present in critically ill patients suspected of VAP, and APMV does not seem to be a frequent cause of VAP. 


\section{Introduction}

Ventilator-associated pneumonia (VAP) is defined as a pneumonia in patients on mechanical ventilation, occurring 48 hours after intubation. VAP is the most common hospital acquired infection in intensive care patients, occurring in 9-27\% of intubated patients. ${ }^{1,2}$ VAP is associated with a high mortality, ranging from 20 to $70 \%$, depending on the micro-organism involved ${ }^{1}$. Apart from the high mortality associated with VAP, it has been demonstrated that VAP prolongs both the duration of mechanical ventilation and intensive care unit (ICU) stay. ${ }^{1,2}$ VAP is can be caused by bacteria such as Pseudomonas aeruginosa and Staphylococcus aureus. ${ }^{1}$ However, using criteria described previously ${ }^{3,4}$, approximately $30-40 \%$ of patients suspected of VAP have a bacterial VAP which is confirmed microbiologically. Often, the cause of infection is not found in the remaining $60-70 \%$ of patients suspected of VAP. In recent years, viruses have been suggested as the cause of respiratory infections in non-immunocompromised critically ill patients.

Acanthamoeba polyphaga mimivirus (APMV) is a giant virus, discovered in 2003, which belongs to the amoebe-associated micro-organisms. ${ }^{5}$ Other amoebe-associated microorganisms, such as Legionella pneumophila, are known to cause pneumonia in different patient groups. Various studies have suggested the possible pathogenicity of APMV. Seroconversion to APMV was shown in patients with community-acquired pneumonia $(\mathrm{CAP})^{6}$ or nosocomial pneumonia. ${ }^{7}$ In these studies, antibodies against APMV were found in respectively $9.7 \%$ and $7.1 \%$ of the patients included. In addition, in patients with VAP, positive serology for APMV was associated with an increased duration of mechanical ventilation and ICU stay. ${ }^{8}$ However, the virus itself was found only in one patient in one particular study. ${ }^{6}$ Because of the potential role of APMV as a respiratory pathogen and the significant proportion of patients suspected of VAP without a causative micro-organism found, the aim of the present study was to assess the presence of APMV in bronchoalveolar lavage (BAL) fluid samples of critically ill patients suspected of VAP by real-time PCR (RT-PCR).

\section{Materials and methods}

\section{Patients included}

This retrospective study was conducted in the ICU of the Maastricht University Medical Centre, Maastricht, the Netherlands, a 750-bed hospital. All consecutive BAL fluid samples obtained between January 2005 and October 2009 from patients suspected of VAP were eligible for inclusion. 


\section{Clinical variables}

Clinical suspicion of VAP was defined as described by Bonten et al.. ${ }^{9}$ Microbiologically confirmed VAP was defined as admission to the ICU at least 48 hours prior to BAL collection, a total quantitative culture result of $\geq 10^{4} \mathrm{cfu} / \mathrm{ml}$ and/or $\geq 2 \%$ cells with intracellular organisms. ${ }^{3,4}$ Collected data included patients' demographic characteristics such as, age and gender, as well as clinical data such as, APACHE II score, reason for performing BAL, diagnosis upon admittance, admittance to ICU ward, smoking, length of ICU stay before the performance of BAL, total length of stay at ICU, total length of hospital stay, mortality, diagnosis at post-mortem examination, diagnosis of pulmonary disease after BAL and laboratory data concerning BAL fluid such as, total cell count, differential cell count, presence of ciliated epithelial cells, squamous epithelial cells, reactive pneumocytes type $\mathrm{II}^{10}$ and quantitative culture results.

\section{Rejection criteria}

BAL fluid samples were rejected if the recovered volume was less than $20 \mathrm{ml}$, if the total cell count was less than 60.000 cells $/ \mathrm{ml}$, if preparations showed excessive amounts of intercellular debris or damaged nucleated cells or more than $1 \%$ squamous epithelial cells.

\section{Sampling technique}

Bronchoscopy with subsequent lavage was performed as described previously. ${ }^{11} \mathrm{BAL}$ fluid samples were transported to the laboratory within 15 minutes after collection and processed immediately upon arrival at the microbiology laboratory.

\section{Laboratory processing}

The first fraction of BAL fluid, representing the bronchial fraction, was used only for Mycobacterium spp culture and/or PCR. The remaining three fractions (alveolar fractions) were pooled. A total cell count was performed using a Fuchs Rosenthal haemocytometer chamber. Quantitative bacterial culture was performed as described previously. ${ }^{12}$ Cytocentrifuged preparations ${ }^{13}$ were stained with May-Grünwald Giemsa stain and Gram stain. A differential cell count ${ }^{14}$ was performed including the number of cells, intracellular organisms and Reactive type II pneumocytes. ${ }^{10}$ From each sample $6 \mathrm{ml}$ was centrifuged $(250 \mathrm{~g}, 10$ minutes), dividing the sample into cells and supernatant. The supernatant was stored in tubes of $1 \mathrm{ml}$ at $-80^{\circ} \mathrm{C}$. The cells were resuspended in $6 \mathrm{ml}$ of a mixture of Eagle's Minimal Essential Medium with 2\% Dimethyl Sulfoxide and stored in tubes of $1 \mathrm{ml}$ at $-80^{\circ} \mathrm{C}$ for future use. 


\section{Additional samples}

To identify possible infectious sources of APMV in the hospital, a total of 20 water samples (1 litre each) were collected. These samples included 10 water samples obtained from taps located at the ICU and 10 samples from cooling towers supplying the water to the hospital. Samples were filtered through $0.2 \mu \mathrm{m}$ polycarbonate filters (Sartorius Stedim biotech, Goettingen, Germany). Afterwards the filters were placed in $5 \mathrm{ml}$ sterile water and sonicated for 5 minutes in a sonication bath (Bandelin electronic GmbH \& Co. KG, Berlin, Germany) at $40 \mathrm{kHz}$.

\section{APMV real-time PCR}

A total of $500 \mu \mathrm{l}$ of the stored BAL cell fractions and $5 \mathrm{ml}$ of the filtered water samples were used for DNA isolation using the Wizard ${ }^{\circledR}$ Genomic DNA Purification Kit (Promega, Madison, USA). Purified DNA was resuspended in a final volume of $120 \mu$ l. Each sample was spiked with a control plasmid (murine cytomegalovirus glycoprotein $B$ gene $(\mathrm{mCMV}-\mathrm{gb}))^{15}$ before DNA isolation as an isolation and amplification control. An inhouse PCR was performed using primers and probes, designed with the Primer3 software, which target the Mimi L396 VV A18 helicase gene [Table 4.1]. Assays were performed in a 96-well Optical Reaction plate (Applied Biosystems, Foster City, California) in a total volume of $50 \mu \mathrm{l}$ which contained $0.3 \mu \mathrm{M}$ forward primer, $0.3 \mu \mathrm{M}$ reverse primer, $0.1 \mu \mathrm{M}$ probe, $25 \mu \mathrm{l}$ ABsolute QPCR Mastermix (ABgene, Epsom, UK) and $10 \mu \mathrm{l}$ DNA. The PCR reactions for the isolation and amplification control (mCMV-gb) were carried out using primers and a probe described previously. ${ }^{15}$ The PCR thermal profile for both APMV and $\mathrm{mCMV}$-ie consisted of an initial incubation of 15 minutes at $95^{\circ} \mathrm{C}$ followed by a total of 43 cycles of amplification ( 15 seconds at $95^{\circ} \mathrm{C}$ and 1 minute at $60^{\circ} \mathrm{C}$ ). Amplification was performed using the $A B I$ Prism ${ }^{\circledR} 7000$ Sequence Detection System and data were interpreted using the ABI Prism ${ }^{\circledR}$ SDS software. A positive control containing APMV was supplied by professor D. Raoult. ${ }^{5}$ This positive control was included during each PCR run.

Table 4.1 Primers and probe targeting the Mimi L396 VV A18 helicase gene, designed with the Primer3 software.

\begin{tabular}{ll}
\hline Forward primer & TTTCTAGCACCCATGTGATGA \\
Reverse primer & TCCTTTTGTAGTTTCAATGGTTCA \\
Probe & ATCTCGTCGTTG TAATTTATCTTTGCT \\
Amplicon length & $114 \mathrm{bp}$ \\
\hline
\end{tabular}

\section{APMV real-time PCR validation}

DNA was isolated from cultured APMV and evaluated using a spectrophotometer (Nanodrop Spectrophotometer ND-1000, Isogen Life Science, De Meern, 
The Netherlands) to determine concentration and purity of the sample. Standard curves were generated using 10 -fold serial dilutions $\left(10^{5}, 10^{4}, 10^{3}, 10^{2}, 10\right.$

and 1 copies $/ \mathrm{ml}$ ). Tests were performed on cultured APMV resuspended in $\mathrm{NaCl} 0.9 \%$, on both BAL fluid and tap water spiked with APMV. Amplification efficiency was calculated using ABI Prism SDS software showing an efficiency of $98 \%$. To

determine the detection limit, serial dilutions were tested, the lower limit of detection was established at 300 copies/ml (12 copies/PCR). Specificity of our assay was tested using the most common respiratory viruses (both RNA and DNA viruses). These viruses included: influenza $A$ and $B$, para-influenza 1-4, RSV, hMPV, coronavirus, rhinovirus, HSV-1, and CMV. All tested negative in the PCR. To determine repeatability serial dilutions in BAL fluid $\left(10^{5}, 10^{4}, 10^{3}, 10^{2}, 10\right.$ and 1 copies/ml) were tested by the same technician in 10 independent experiments. APMV dilutions were detected with a variation of 1-2 Ct values. A further five serial dilutions in BAL fluid were tested four times by two different technicians showing the in-house repeatability to be high.

\section{Results}

\section{Patient population}

Between January 2005 and October 2009, 363 BAL fluid samples were eligible for inclusion. Unfortunately insufficient material was available for 75 (20.6\%) of these samples. A total of 28 samples met the exclusion criteria and were excluded from the study. Finally a total of 260 samples from 214 patients were included. Table 4.2 shows the demographic data of the included patients.

\section{Causative micro-organisms of VAP}

Out of the 260 included samples with clinically suspected episodes of VAP, 106 episodes in 101 patients were microbiologically confirmed. Table 4.3 shows the causative micro-organisms in these episodes. When multiple micro-organisms were found in the BAL fluid, only the micro-organisms present in quantities $10^{4} \mathrm{cfu} / \mathrm{ml}^{3,4}$ were considered as causative micro-organisms. The micro-organisms isolated most frequently were enterobactericeae and non-fermenters [Table 4.3].

All included samples were tested retrospectively for the presence of cytomegalovirus, which yielded 12 positive samples.

\section{APMV RT-PCR}

APMV DNA was not detected in any of the 260 BAL fluid samples tested. APMV DNA was not detected in any of the water samples collected from the hospitals cooling towers and the water tabs of the ICU. 
Table 4.2 demographic data included patients $(n=214)$

\begin{tabular}{|c|c|}
\hline Median age, years (range) & $64(19-84)$ \\
\hline Male:female ratio & $2: 1$ \\
\hline \multicolumn{2}{|l|}{ Reason for intensive care unit admission (\%) } \\
\hline \multicolumn{2}{|l|}{ Pulmonary } \\
\hline Community acquired pneumonia & $3(1)$ \\
\hline Pneumocystis pneumonia & $7(3)$ \\
\hline Respiratory insufficiency due to underlying disease & $58(27)$ \\
\hline Tuberculosis & $1(0.5)$ \\
\hline Trauma & $32(15)$ \\
\hline \multicolumn{2}{|l|}{ Surgery } \\
\hline Abdominal & $19(9)$ \\
\hline Heart-valve replacement & $15(7)$ \\
\hline Aneurysm of aorta & $8(4)$ \\
\hline Coronary bypass surgery & $11(5.5)$ \\
\hline Other & $1(0.5)$ \\
\hline \multicolumn{2}{|l|}{ Neurological/neurosurgical } \\
\hline Sub-arachnoidal bleeding & $7(3)$ \\
\hline Intracerebral bleeding & $5(2)$ \\
\hline Epileptic insult & $1(0.5)$ \\
\hline Surgery for intracranial process & $7(3)$ \\
\hline Meningitis & $1(0.5)$ \\
\hline \multicolumn{2}{|l|}{ Other } \\
\hline Sepsis & $10(5)$ \\
\hline Gastro-intestinal bleeding & $4(2)$ \\
\hline Kidney failure & $1(0.5)$ \\
\hline Resuscitation & $7(3)$ \\
\hline Other & $17(8)$ \\
\hline \multicolumn{2}{|l|}{ Smoking (\%) } \\
\hline Yes & $41(19)$ \\
\hline No & $51(24)$ \\
\hline Quit & $29(14)$ \\
\hline Unknown & $93(43)$ \\
\hline Days of intensive care unit admittance before lavage: mean (range) & $10(2-249)$ \\
\hline Length of hospital stay: mean $\mathrm{nr}$ of days (range) & $48(3-540)$ \\
\hline Length of intensive care unit stay: mean nr of days (range) & $42(2-261)$ \\
\hline APACHE II score; mean (range) & $23(9-44)$ \\
\hline \multicolumn{2}{|l|}{ Outcome $<30$ days after lavage (\%) } \\
\hline Survived & $158(74)$ \\
\hline Died & $56(26)$ \\
\hline \multicolumn{2}{|l|}{ Outcome $<30$ days after intensive care unit admittance (\%) } \\
\hline Survived & $172(80)$ \\
\hline Died & $42(20)$ \\
\hline
\end{tabular}


Table 4.3 Causative micro-organisms in the microbiologically confirmed episodes of ventilator-associated pneumonia

\begin{tabular}{lc}
\hline Causative micro-organisms & Number (\%) \\
\hline Growth of one micro-organism: $^{\text {Enterobacteriaceae }}{ }^{\text {a }}$ & $30(28)$ \\
Non-fermenters $^{\text {b }}$ & $21(20)$ \\
Staphylococcus aureus $^{c}$ & $8(8)$ \\
Haemophilus spp. $_{\text {Coagulase-negative staphylococci }}$ & $5(4)$ \\
Streptococcus pneumoniae & $2(2)$ \\
Other & $2(2)$ \\
Growth of multiple micro-organisms: & $4(4)$ \\
Multiple types of Enterobacteriaceae & \\
S. aureus and Enterobacteriaceae & $4(4)$ \\
S. aureus and non-fermenter & $3(3)$ \\
Enterobacteriaceae and non-fermenter & $2(2)$ \\
Multiple types of non-fermenters & $3(3)$ \\
S. pneumoniae and Haemophilus spp. & $1(1)$ \\
S. pneumoniae and non-fermenter & $1(1)$ \\
S. aureus and Haemophilus spp. & $1(1)$ \\
Other & $1(1)$ \\
Commensal flora of oropharynx & $3(3)$ \\
Candida albicans & $11(10)$ \\
No growth & $2(2)$ \\
\hline
\end{tabular}

a including: Escherichia coli, Proteus spp, Klebsiella spp, Enterobacter spp. and Citrobacter spp. ${ }^{b}$ including: Pseudomonas aeruginosa, Acinetobacter spp and Stenotrophomonas maltophilia. ${ }^{\mathrm{c}}$ including 1 methicillinresistant Staphylococcus aureus. ${ }^{\mathrm{d}}$ Microscopic evaluation did show $\geq 2 \%$ intracellular micro-organisms thereby confirming the diagnosis ventilator-associated pneumonia; both patients had already received adequate antibiotic therapy before lavage

\section{Discussion}

In the present study no APMV DNA was detected in BAL fluid samples of critically ill patients with suspected VAP.

An animal study performed by Khan et al. ${ }^{16}$ has shown that APMV was able to induce histological evidence of pneumonia with the formation of diffuse alveolar damage in mice. Since the virus is able to induce pneumonia in mice, it was hypothesized that it would also be able to induce pneumonia in humans. Several studies have been conducted to detect APMV DNA in different patient populations. ${ }^{17,18}$ Until now, evidence of APMV as a respiratory pathogen has been based mainly on serologic studies. La Scola et al. ${ }^{6}$ performed a study in Canada showing the presence of antibodies to APMV in $9.7 \%$ of patients with CAP. Berger et al. ${ }^{7}$ collected blood samples from all patients admitted to the ICU with a clinical suspicion of pneumonia. A total of 210 episodes of pneumonia were included. Antibodies against APMV were detected in 7.1\% of these patients. Another study performed on an $\mathrm{ICU}^{8}$ determined the APMV 
sero-status of the admitted patients. All patients with a suspicion of VAP were sampled. Acute and covalescent-phase serum samples were tested for the presence of antibodies against APMV by an immunofluorescence assay. A total of $19.7 \%$ of the ICU patients with a suspicion of VAP were sero-positive for APMV. Furthermore, seropositivity for APMV was associated with an increased duration of both mechanical ventilation and ICU stay. All these studies show a possible role for APMV in respiratory infections. However, the presence of antibodies against APMV does not necessarily proof an active infection caused by the virus. In order to establish a causal link between APMV and pulmonary infections the criteria described in an article by Robinson et al. could be used. These specific criteria are based on Koch's postulates but adapted to fit (the majority of) viruses. ${ }^{19}$ These criteria state that the virus should be present in respiratory specimens of a significant percentage of patients with a suspicion of the infection and should be absent in the majority of healthy people. The mere presence of antibodies shows that the individual has been into contact with the virus, but does not always imply disease. The results of the present study are in line with two previous studies. APMV DNA could not be detected in neither patients with CAP nor in patients with hospital-acquired pneumonia $(\mathrm{HAP})^{17}$ in nasal and nasopharyngeal aspirates of nine different patient-groups consisting of 496 patients. The patients included in the present study were all critically ill patients suspected of VAP opposed to the study performed by Dare et al., consequently, the patient-groups may not be fully comparable. The patient material on which the PCR was performed also differed; the present study only used BAL fluid samples, whilst the PCR in the study performed by Dare et al. was conducted on nasal and nasopharyngeal aspirates. In a study conducted by Larcher et al. ${ }^{18}$ a total of 214 nasopharyngeal aspirates from children, hospitalized for respiratory tract infections, were tested for the presence of different respiratory viruses, including APMV. APMV could not be detected in any of the respiratory samples tested by APMV-specific PCR. Only one study currently describes a patient in whom APMV DNA was detected in a BAL specimen ${ }^{6}$. La Scola et al. performed a study in a Canadian population consisting of 376 patients diagnosed with CAP and 511 healthy controls. The patient in whom APMV was detected was a 60-year-old critically ill patient who had two episodes of HAP during hospitalization. APMV DNA was only detected in the sample from the second episode; unfortunately no serum was tested for the presence of antibodies against APMV in this patient. Since APMV was only detected during the second episode of suspected HAP it suggests it was acquired during hospitalization, probably through water present on the ICU.

Since APMV has only been isolated once in a single patients with a clinical respiratory infection ${ }^{6}$, APMV might not be a major cause of respiratory infections in intensive care patients.

However, a remark has to be made concerning the negative PCR results of the present study. Since the discovery and description of the first APMV strain, many other APMV related viruses have been detected. The probe used in the present study matches with 
both APMV and mamavirus, but not with other closely related viruses of the APMV family. Therefore, the patients in the present study could be positive for other viruses of the APMV family. Since the viruses of the APMV family are prone to polymorphisms at the nucleotide level, designing a universal PCR model, with a high sensitivity, for the complete APMV family is difficult. One of the limitations of the present study was the lacking of serology results of the patients. Therefore, the extent of exposure of the studied patients to APMV is yet to be unraveled. Likewise, to the authors best knowledge the seroprevalence of antibodies against APMV in the general Dutch population is also not known, making it impossible to predict the population at risk for a possible APMV infection. Another limitation might be the retrospective nature of the study. Due to the duration of the study, all BAL fluid samples were stored and frozen, some of them for a long time. This might have altered the composition of the BAL fluid samples. A third limitation of the study is the amount of excluded BAL fluid samples. Due to the amount of other test already performed on the BAL fluid samples for diagnostic and research purposes, a proportion of samples did not contain enough material to perform the DNA extraction for APMV correctly.

\section{Conclusion}

Although suspected, APMV appeared not to be present in the studied critically ill patients suspected of VAP. Therefore, APMV does not seem to be a frequent cause of VAP. 


\section{References}

1. Chastre J, Fagon JY. Ventilator-associated pneumonia. American journal of respiratory and critical care medicine 2002;165, 867-903.

2. Rello J, et al. Epidemiology and outcomes of ventilator-associated pneumonia in a large US database. Chest 2002;122:2115-21.

3. Baselski V. Microbiologic diagnosis of ventilator-associated pneumonia. Infectious disease clinics of North America 1993;7:331-57.

4. Allaouchiche B, Jaumain H, Dumontet C, Motin J. Early diagnosis of ventilator-associated pneumonia. Is it possible to define a cutoff value of infected cells in BAL fluid? Chest 1996;110:1558-65.

5. Raoult D, La Scola B, Birtles R. The discovery and characterization of mimivirus, the largest known virus and putative pneumonia agent. Clinical infectious diseases : an official publication of the Infectious Diseases Society of America 2007;45:95-102.

6. La Scola B, Marrie TJ, Auffray JP, Raoult D. Mimivirus in pneumonia patients. Emerging infectious diseases 2005;11:449-52.

7. Berger $\mathrm{P}$, et al. Ameba-associated microorganisms and diagnosis of nosocomial pneumonia. Emerging infectious diseases 2006;12:248-55.

8. Vincent $A$, et al. Clinical significance of a positive serology for mimivirus in patients presenting a suspicion of ventilator-associated pneumonia. Critical care medicine 2009;37:111-8.

9. Bonten MJ, et al. Implementation of bronchoscopic techniques in the diagnosis of ventilator-associated pneumonia to reduce antibiotic use. American journal of respiratory and critical care medicine 1997;156:1820-4.

10. Linssen KC, et al. Reactive type II pneumocytes in bronchoalveolar lavage fluid. Acta cytologica 2004;48: 497-504.

11. Linssen CF, et al. Influence of antibiotic therapy on the cytological diagnosis of ventilator-associated pneumonia. Intensive Care Med 2008;34:865-72.

12. Jacobs JA, De Brauwer EI, Cornelissen EI, Drent M. Accuracy and precision of quantitative calibrated loops in transfer of bronchoalveolar lavage fluid. Journal of clinical microbiology 2000;38:2117-21.

13. De Brauwer El, et al. Cytocentrifugation conditions affecting the differential cell count in bronchoalveolar lavage fluid. Analytical and quantitative cytology and histology / the International Academy of Cytology [and] American Society of Cytology 2000;22:416-22.

14. De Brauwer El, Jacobs JA, Nieman F, Bruggeman CA, Drent M. Bronchoalveolar lavage fluid differential cell count. How many cells should be counted? Analytical and quantitative cytology and histology / the International Academy of Cytology [and] American Society of Cytology 2002;24:337-41.

15. Vliegen I, Duijvestijn A, Stassen F, Bruggeman C. Murine cytomegalovirus infection directs macrophage differentiation into a pro-inflammatory immune phenotype: implications for atherogenesis. Microbes and infection / Institut Pasteur 2004;6:1056-62.

16. Khan M, La Scola B, Lepidi H, Raoult D. Pneumonia in mice inoculated experimentally with Acanthamoeba polyphaga mimivirus. Microbial pathogenesis 2007;42:56-61.

17. Dare RK, Chittaganpitch M, Erdman DD. Screening pneumonia patients for mimivirus. Emerging infectious diseases 2008;14:465-7.

18. Larcher C, Jeller V, Fischer H, Huemer HP. Prevalence of respiratory viruses, including newly identified viruses, in hospitalised children in Austria. European journal of clinical microbiology \& infectious diseases 2006;25:681-6.

19. Robinson CR. Koch's postulates and the modern era in virus research. Canadian Medical Association journal 1958;79:387-9. 



\section{Chapter}

Clinical course and complications following diagnostic bronchoalveolar lavage in critically ill mechanically ventilated patients

R Schnabel, K van der Velden, A Osinski, G Rohde, P Roekaerts, D Bergmans BMC Pulm Med 2015;15:107 


\begin{abstract}

\section{Introduction}

Flexible, fibreoptic bronchoscopy (FFB) and bronchoalveolar lavage (BAL) have been used for diagnostic purposes in critically ill ventilated patients. The additional diagnostic value compared to tracheal aspirations in ventilator-associated pneumonia (VAP) has been questioned. Nevertheless, BAL can provide extra information for the differential diagnosis of respiratory disease and good antibiotic stewardship. These benefits should outweigh potential hazards caused by the invasiveness of this diagnostic technique. The focus of the present study was on the clinical course and complications of patients following BAL procedures up to 24 hours.
\end{abstract}

\title{
Methods
}

Hundred sixty-four FFB guided BAL procedures for suspected pneumonia were analysed in an observational study. The clinical course of patients was monitored by respiratory and haemodynamic data before BAL, one hour and 24 hours after BAL. Complications were defined and registered. Factors associated with complications were analysed by logistic regression.

\section{Results}

Clinical course: a decrease in average $\mathrm{pO}_{2} / \mathrm{FiO}_{2}$ ratio 1 hour after $\mathrm{BAL}$ from $29 \mathrm{kPa}$ $(218 \mathrm{mmHg}$ ) to $25 \mathrm{kPa}(189 \mathrm{mmHg})(\mathrm{p}<0.05)$ was observed which fully recovered within 24 hours. Respiratory complications: the incidence of procedure related hypooxygenation $\left(\mathrm{SaO}_{2} \leq 88 \%\right)$ and/or bronchospasm was $9 \%$; a decrease of $>25 \% \mathrm{PaO}_{2} / \mathrm{FiO}_{2}$ ratio one hour after BAL was found in $29 \%$ of patients; no bleeding or pneumothorax were registered. Haemodynamic complications: there were no cases of hypertension and cardiac rhythm disturbances; haemodynamic instability within the first 24 hours after BAL was recorded in $22 \%$; this was correlated with a cardiovascular diagnosis at admission (OR 2.9; 95\% Cl 1.2-6.7) and the presence of cardiovascular co-morbidity (OR 3.5; 95\% Cl 1.5-8.3). The incidence of bacteraemia was $7 \%$. There was no case of procedure related death.

\section{Conclusions}

Frequently occurring haemodynamic and respiratory instability but no cases of cardiac rhythm disturbances, bleeding, pneumothorax or procedure related death were attributable to diagnostic FFB and BAL. The procedures should be conducted under careful supervision by experienced physicians. Only a randomized controlled trial that compares diagnostic FFB and BAL with a non-invasive strategy could ultimately establish the safety profile and clinical utility of these procedures in critically ill ventilated patients. 


\section{Background}

Flexible, fibreoptic bronchoscopy (FFB) and bronchoalveolar lavage (BAL) have been established for diagnostic purposes in critically ill ventilated patients in intensive care units (ICUs). The technique is applicable at the bedside and therefore makes potentially hazardous patient transfers outside the ICU unnecessary. With regard to the diagnosis of ventilator-associated pneumonia (VAP) there is no consensus in the literature and between clinicians. Bronchoscopic BAL from the presumed site of infection with cytological analysis and quantitative microbiological culture of the lavage fluid is thought by many to be a specific diagnostic approach to identify patients with a true infection of the lungs and to enable tailored antibiotic therapy. The most cited benefit of BAL is the prevention of incorrect use of antibiotics. The administration of unnecessary antibiotics is associated with risks of toxicity and development of multiresistance. ${ }^{1-3}$ Others question the use of BAL because several investigations have shown similar outcome and overall use of antibiotics when clinical diagnostic criteria added by non-quantitative culture results from tracheal aspirations were used in the diagnosis of VAP. ${ }^{4,5}$ However, there are other benefits associated with the performance of BALs. Direct visualisation of the airway by FFB delivers additional clinical information and guides the selection of lung areas where specimens are taken. ${ }^{6,7}$ Moreover, the information provided by BAL analysis is more comprehensive than from tracheal aspirates as it not only can benefit the diagnosis of bacterial VAP ${ }^{8}$ but can also support the diagnosis of alternative infectious causes ${ }^{9}$ or other respiratory diseases. ${ }^{10}$

In order to evaluate FFB and BAL as a diagnostic tool in ICU patients, it is necessary to balance benefits with potential hazards caused by the invasiveness of the technique. The focus of the present study is on the clinical tolerance of FFB and BAL. The clinical course and complications of critically ill mechanically ventilated patients after a diagnostic FFB and BAL were investigated. Clinical data were collected before BAL, one hour and 24 hours after BAL. The frequency of haemodynamic, respiratory and procedure related complications were registered. This information can contribute to the discussion whether or not utility and benefits of the more invasive diagnostic approach outweigh its potential risks.

\section{Methods}

The study was conducted in the Maastricht University Medical Centre+, a tertiary-care, university hospital in the Netherlands with 1,700 ICU admissions per year. Adult critically ill, mechanically ventilated patients with a clinical suspicion of infectious pneumonia who underwent a diagnostic FFB and BAL were included in the analysis. Exclusion criteria for the procedure were thrombocytopenia $(<40,000 / \mu l)$ and other coagulation abnormalities. Only clinical data were used in the study. The data were 
collected retrospectively in 43 cases and prospectively in 121 cases in the period from 2011 to 2014. Patients consented to the use of clinical data for scientific analysis according to the admission regulations of the hospital if they did not opt out. This is approved by the local ethics commission (Medisch Ethische Toetsingscommissie azM).

Senior registrars or consultant pulmonologists conducted all BAL procedures. The fraction of inspired oxygen $\left(\mathrm{FiO}_{2}\right)$ was increased to 1.0 for 5 to 15 minutes prior to and during FFB and BAL procedures. Patients were anaesthetised by an experienced intensive care physician, present during the whole procedure, with either propofol or midazolam and fentanyl continuous infusion and as required rocuronium for muscle relaxation. Patients had tracheal tubes with an inner diameter varying from 7.5 to $8.5 \mathrm{~mm}$ or a Portex ${ }^{\circledR}$ tracheal cannula with an inner diameter of $8 \mathrm{~mm}$ in place. A flexible, fibreoptic bronchoscope (Pentax ${ }^{\circledR}$ FB-15H/FB-15X, Pentax Medicals, Tokyo, Japan) with a calibre of $4.9 \mathrm{~mm}$ was introduced and 'wedged' into the affected segmental or subsegmental bronchus. Before performing BAL, a quick inspection of all the major airways in both lungs was carried out. Sterile saline $(0.9 \%$ sodium chloride at room temperature) was instilled. An initial aliquot of $20 \mathrm{ml}$ and subsequent four aliquots of $50 \mathrm{ml}$ were immediately aspirated and recovered. After completing the BAL, the bronchoscope was removed, and the patient was monitored closely by continuous pulse oximetry and arterial blood gases while the $\mathrm{FiO}_{2}$ was then gradually decreased. BAL samples were transported to the laboratory within 15 minutes after collection and processed immediately upon arrival. Information about the quality of BAL sampling was collected. The BAL fluid was regarded non-representative if the volume of recovery was $<20 \mathrm{ml}$, the total cell count was $<60.000 / \mathrm{ml}$, the presence of squamous epithelial cells was $>1 \%$, the presence of bronchial epithelial cells was $>5 \%$ or in the presence of extensive amounts of debris and damaged cells. Further BAL workup in the laboratory included: a differential cell count, microscopic investigation of a Gram-stained preparation, quantitative bacterial and fungal culture. BAL fluid analysis was considered to support the diagnosis of VAP when Memphis Consensus Conference criteria were met. These criteria include: $\geq 2 \%$ BAL fluid cells containing intracellular organisms, and/or identification of a bacterial micro-organism in the BAL fluid in a concentration of $\geq 10^{4}$ colony forming units/millilitre $(\mathrm{cfu} / \mathrm{ml}) .{ }^{11,12}$ Demographic characteristics and Acute Physiology and Chronic Health Evaluation (APACHE-II) scores were recorded on admission. All diagnoses apart from the principal reason for admission to the ICU were regarded as co-morbidities: 1 . cardiovascular: severe ischemic heart disease, NYHA IV heart failure, disabling peripheral vascular disease; 2. respiratory: disabling chronic pulmonary disease, COPD Gold III and IV, continuous additional oxygen therapy; 3. chronic renal failure: chronic dialysis, serum creatinine level chronically $>177 \mu \mathrm{mol} / \mathrm{l} ; 4$. immunocompromised: disease and drug effects, prednisone equivalent $>7.5 \mathrm{mg} / \mathrm{d} ; 5$. active malignancy; 6. neurologic impairment: cerebral haemorrhage, meningitis, encephalitis, severe paresis; 7. chronic coagulation disorder; 8. chronic hepatic failure: hepatic encephalopathy, Child C cirrhosis, portal hypertension. Patients were classified 
as "severe sepsis" following the Surviving Sepsis Campaign criteria. ${ }^{13}$ Clinical parameters were collected at baseline, at $1 \mathrm{~h}$ and $24 \mathrm{~h}$ after the BAL procedure. Blood cultures were obtained before and $24 \mathrm{~h}$ after the procedure, chest X-rays were performed within $24 \mathrm{~h}$ after BAL and sputum cultures were taken prior to the procedure. In general, the results of Gram staining, differential cell count and percentage of intracellular organisms of samples obtained by BAL were available within $2 \mathrm{~h}$ after bronchoscopy, preliminary culture results after 1 day, and definite culture results after 4 days. When BAL fluid analysis rejected the diagnosis of bacterial pneumonia, additional steps followed to determine an alternative diagnosis. Empirical antibiotic therapy was directed towards pathogens isolated from clinical and surveillance cultures of sputum cultures, and patients with VAP were treated with antibiotics for 8 to 14 days according to causative microorganisms. In case of clinical suspicion of pneumonia, antibiotic therapy was initiated after BAL had been performed. When a patient was receiving antibiotics for more than $48 \mathrm{~h}$ for another unrelated infection or for prophylaxis on the day that the criteria for a clinical suspicion of pneumonia were met, antibiotics were not changed until the BAL procedure.

The clinical course of the patients was monitored for 24 hours after diagnostic FFB and BAL. $\mathrm{PaO}_{2} / \mathrm{FiO}_{2}$ ratios, positive end-expiratory pressure (PEEP) levels, fractions of oxygen $\left(\mathrm{FiO}_{2}\right)$, ph, $\mathrm{PaCO}_{2}$, mean arterial pressure (MAP), heart rate and dosages of norepinephrine and dobutamine were assessed. Clinical complications of BAL were defined as complications occurring during the BAL procedure and up to 24 hours after BAL. 1. Respiratory complications: hypo-oxygenation $\left(\mathrm{SaO}_{2} \leq 88 \%\right)$ during $\mathrm{BAL}$ and/or bronchospasm; a decrease in $\mathrm{PaO}_{2} / \mathrm{FiO}_{2}$ ratio $>25 \%$ compared to baseline; bleeding defined as haemoptysis requiring medical intervention and/or interruption of the procedure; pneumothorax. 2. Haemodynamic complications: hypertension defined as an increase of MAP $>25 \%$ baseline; cardiac rhythm disturbances defined as newly developed pathologic rhythm (atrial fibrillation, ventricular tachycardia, ventricular fibrillation, asystole) or bradycardia or rapid atrial fibrillation with decrease in MAP; haemodynamic instability defined as a decrease of MAP $<55 \mathrm{mmHg}$ at any time and/or necessity to initiate norepinephrine $>0.15 \mu \mathrm{g} / \mathrm{kg} / \mathrm{min}$ or dubutamine $>5 \mu \mathrm{g} / \mathrm{kg} / \mathrm{min}$ and/or the necessity to more than double the dose of norepinephrine or dobutamine. 3. Bacteraemia: positive blood cultures following BAL. 4. Death: procedure related death within 24 hours. Possible correlations of demographic and clinical items (age, gender, APACHE II, SOFA, diagnosis at admission, severe sepsis, co-morbidities) with a respiratory and hemodynamic complication following BAL were analysed by multiple logistic regression. Odds ratios with 95\% confidence interval were calculated.

Data were analysed using the SPSS version 20 statistical package for MS

Windows. Quantitative variables were expressed as means with standard deviations (SD). Qualitative variables were reported with the percentage distribution of each of the categories. Fisher's Exact Test and Chi Square Test were used for the analyses of categorical variables and ANOVA analysis and Kruskal-Wallis test for numerical 
variables. Linear mixed models analysis was performed in all patients, excluding consecutive BALs in the same patients who underwent more than one BAL

\section{Results}

A total of 164 datasets of FFB and BAL procedures were recorded during the study period.

Patient demographics are shown in Table 5.1. In 68 patients (41\%) analysis of BAL fluid supported the diagnosis bacterial pneumonia. The most frequently acquired microorganisms were Pseudomonas aeruginosa (12), Staphylococcus aureus (5) and Escherichia coli (5). In retrospection $92 \%$ of all BAL positive patients received adequate empiric antibiotic treatment. Ninety-six BAL fluid analyses were classified as negative. However, in $68 \%$ of these an alternative diagnosis could be established in the following diagnostic process. [Table 5.2] In 26 patients there was a significant presence of viruses in the BAL fluid. In 7 patients Pneumocystis jiroveci could be detected. Further diagnostic workup including computed tomography, lung biopsy, ultrasound examinations and advanced laboratory tests revealed a broad spectrum of alternative diagnoses in the putative ventilator-associated pneumonia patient not meeting lavagebased diagnostic criteria.

The clinical course of patients following diagnostic FFB and BAL is illustrated in Table 5.3. Baseline data before BAL were compared with data after 1 hour and 24 hours. The average $\mathrm{PaO}_{2} / \mathrm{FiO}_{2}$ ratio declined from $29 \mathrm{kPa}(218 \mathrm{mmHg})$ to $25 \mathrm{kPa}(189 \mathrm{mmHg}$ ) $(\mathrm{p}<0.05)$ after 1 hour but had reached baseline again after 24 hours. The average PEEP level of $9.4 \mathrm{cmH}_{2} \mathrm{O}$ was not significantly increased after 1 hour and kept constant after 24 hours. After 1 hour, PEEP level was increased in 7\% of patients and in 15\% after 24 hours. The average $\mathrm{FiO}_{2}$ level of $52 \%$ was not significantly altered after 1 hour and had decreased to $43 \%(p<0.0001) 24$ hours after BAL. One hour after BAL, $27 \%$ of patients had an increased $\mathrm{FiO}_{2}$ of $\geq 10 \%$ compared to baseline; after 24 hours $8 \%$ of patients had an increased $\mathrm{FiO}_{2}$ of $\geq 10 \%$ compared to baseline. The $\mathrm{pH}$ and $\mathrm{paCO}_{2}$ were unchanged after one hour and 24 hours compared to baseline. The averages of haemodynamic parameters (MAP, heart rate, number of patients receiving norepinephrine and/or dobutamine and dose) were not significantly different after one hour and 24 hours from baseline. 
Table 5.1 Patient demographics

\begin{tabular}{|c|c|c|c|}
\hline \multicolumn{2}{|l|}{ Age (years) } & \multicolumn{2}{|c|}{$61 \pm 14$} \\
\hline \multirow[t]{2}{*}{ Gender } & male & 116 & $71 \%$ \\
\hline & female & 48 & $29 \%$ \\
\hline APACHE II & & 21 & \pm 9 \\
\hline SOFA (at time of BAL) & & 7 & \pm 4 \\
\hline \multirow[t]{4}{*}{ Parameters (at time of $\mathrm{BAL}$ ) } & $\mathrm{pH}<7.25$ & 10 & $6 \%$ \\
\hline & $\mathrm{PaCO}_{2} \geq 7.5 \mathrm{kPa}(56 \mathrm{mmHg})$ & 9 & $5 \%$ \\
\hline & $\mathrm{PaO}_{2} \leq 8 \mathrm{kPa}(60 \mathrm{mmHg})$ & 10 & $6 \%$ \\
\hline & $\mathrm{PaO} 2 / \mathrm{FiO} 2$ ratio $\leq 13 \mathrm{kPa}(100 \mathrm{mmHg})$ & 12 & $7 \%$ \\
\hline \multirow[t]{8}{*}{ Diagnosis upon admission } & respiratory & 64 & $38 \%$ \\
\hline & cardiovascular & 37 & $22 \%$ \\
\hline & haematological & 19 & $11 \%$ \\
\hline & gastrointestinal & 16 & $10 \%$ \\
\hline & trauma/orthopaedic & 10 & $6 \%$ \\
\hline & neurological & 12 & $7 \%$ \\
\hline & urogenital & 3 & $2 \%$ \\
\hline & other & 7 & $4 \%$ \\
\hline Severe Sepsis at admission & & 52 & $32 \%$ \\
\hline \multirow[t]{4}{*}{ Co-morbidity } & none & 53 & $33 \%$ \\
\hline & one item & 72 & $44 \%$ \\
\hline & two items & 35 & $21 \%$ \\
\hline & $\geq$ three items & 4 & $2 \%$ \\
\hline \multirow[t]{8}{*}{ Co-morbidity } & cardiovascular & 34 & $21 \%$ \\
\hline & respiratory & 12 & $7 \%$ \\
\hline & chronic renal failure & 8 & $5 \%$ \\
\hline & immunocompromised & 47 & $29 \%$ \\
\hline & active malignancy & 32 & $20 \%$ \\
\hline & neurologic impairment & 17 & $10 \%$ \\
\hline & coagulation disorder & 3 & $2 \%$ \\
\hline & chronic hepatic failure & 2 & $1 \%$ \\
\hline BAL positive & & 68 & $41 \%$ \\
\hline ICU mortality & & 80 & $49 \%$ \\
\hline In-hospital mortality & & 90 & $55 \%$ \\
\hline \multirow[t]{7}{*}{ Cause of death } & cardiovascular & 13 & $15 \%$ \\
\hline & persistent respiratory failure & 24 & $27 \%$ \\
\hline & neurological impairment & 9 & $10 \%$ \\
\hline & multi organ failure & 10 & $11 \%$ \\
\hline & active malignancy & 28 & $31 \%$ \\
\hline & other & 4 & $4 \%$ \\
\hline & unknown & 2 & $2 \%$ \\
\hline
\end{tabular}

Results are given either as number, percentages or mean \pm standard deviation. 
Table 5.2 Alternative diagnosis in patients with negative bacterial growth BAL result

\begin{tabular}{lc}
\hline BAL negative & $(\mathrm{n}=96)$ \\
\hline Viral & 26 \\
Pneumocystis jirovecii & 7 \\
Fungal & 6 \\
Heart failure & 4 \\
Bronchiolitis obliterans organizing pneumonia & 3 \\
Usual interstitial pneumonia & 1 \\
All trans retinoic acid (ATRA) syndrome & 1 \\
Pulmonary embolism; obstructive shock & 2 \\
Endocarditis & 1 \\
Abdominal sepsis with ARDS & 4 \\
Necrotizing pancreatitis & 2 \\
Abdominal ischaemia & 1 \\
Urinary tract sepsis with ARDS & 2 \\
Ovarian cancer with pulmonary metastases & 1 \\
Systemic lupus erythematosus & 1 \\
Toxic epidermal necrolysis & 1 \\
Postanoxic encephalopathy with multiple infarction & 1 \\
Myasthenia gravis & 1 \\
None established & 31 \\
\hline
\end{tabular}

Table 5.3 Results - clinical course 1 hour and 24 hours after BAL procedure

\begin{tabular}{|c|c|c|c|}
\hline & Before BAL & 1h after BAL & 24h after BAL \\
\hline $\mathrm{PaO}_{2} / \mathrm{FiO}_{2}[\mathrm{kPa}]$ & $29(\mathrm{Cl} 25-32)$ & $25(\mathrm{Cl} 23-29) p<0.05$ & $31(\mathrm{Cl} 27-33)$ \\
\hline $\mathrm{PaO}_{2} / \mathrm{FiO}_{2}[\mathrm{mmHg}]$ & $218(\mathrm{Cl} 188-240)$ & 189 (Cl 173-218) & $233(\mathrm{Cl} 203-248)$ \\
\hline $\begin{array}{l}\mathrm{PaO}_{2} / \mathrm{FiO}_{2} \text { decreased }>25 \% \text { baseline }[\% \text { of } \\
\text { patients] }\end{array}$ & & $29 \%$ & $14 \%$ \\
\hline PEEP mean $\left[\mathrm{cmH}_{2} \mathrm{O}\right]$ & $9.4(\mathrm{Cl} 9.1-9.8)$ & $9.6(\mathrm{Cl} 9.2-9.9)$ & $9.6(\mathrm{Cl} 9.2-10)$ \\
\hline PEEP increased & & $7 \%$ & $15 \%$ \\
\hline $\mathrm{FiO}_{2}$ mean [\%] & $52(\mathrm{Cl} 49-55)$ & $54(\mathrm{Cl} 51-57)$ & $43(\mathrm{Cl} 41-46) \mathrm{p}<0.0001$ \\
\hline $\begin{array}{l}\mathrm{FiO}_{2} \text { increased } \geq 10 \% \text { baseline }[\% \text { of } \\
\text { patients] }\end{array}$ & & $27 \%$ & $8 \%$ \\
\hline $\mathrm{pH}$ mean & 7.41 (CI 7.40-7.42) & 7.40 (CI 7.39-7.41) & 7.41 (Cl 7.40-7.42) \\
\hline $\mathrm{pCO}_{2}$ mean $[\mathrm{kPa}]$ & $5.2(\mathrm{Cl} 5.0-5.4)$ & $5.4(\mathrm{Cl} 5.2-5.6)$ & $5.2(\mathrm{Cl} 5.0-5.4)$ \\
\hline $\mathrm{pCO}_{2}$ mean $[\mathrm{mmHg}]$ & $39(\mathrm{Cl} 38-41)$ & 41 (Cl 39-42) & $39(\mathrm{Cl} 38-41)$ \\
\hline MAP mean $[\mathrm{mmHg}]$ & $84(\mathrm{Cl} 81-86)$ & $79(\mathrm{Cl} 76-81)$ & $83(\mathrm{Cl} 81-86)$ \\
\hline Heart rate mean [beats/min] & 96 (Cl 93-100) & 94 (Cl 93-99) & $91(\mathrm{Cl} 88-94)$ \\
\hline Norepinephrine [\% of patients] & $58 \%$ & $57 \%$ & $62 \%$ \\
\hline Norepinephrine median & 0.125 & 0.109 & 0.125 \\
\hline 1. quartile / 3. quartile $[\mu \mathrm{g} / \mathrm{kg} / \mathrm{min}]$ & $0.050 / 0.201$ & $0.075 / 0.202$ & $0.068 / 0.219$ \\
\hline Dobutamine [\% of patients] & $3 \%$ & $3 \%$ & $3 \%$ \\
\hline Dobutamine median & 5 & 5 & 3 \\
\hline 1. quartile / 3. quartile $[\mu \mathrm{g} / \mathrm{kg} / \mathrm{min}]$ & $3 / 5$ & $2 / 5$ & $3 / 5$ \\
\hline Hemodynamic instability ${ }^{1} \%$ of patients] & & $5 \%$ & $7 \%$ \\
\hline $\begin{array}{l}\text { Hemodynamic instability }{ }^{1} \text { at any time } \\
\text { within } 24 \mathrm{~h} \text { [\% of patients] }\end{array}$ & & & $22 \%$ \\
\hline
\end{tabular}

$\mathrm{Cl}$ : 95\% confidence interval, MAP: mean arterial pressure, PEEP: positive end-expiratory pressure, $\mathrm{FiO}_{2}$ : fraction of inspired oxygen, $\mathrm{PaO}_{2}$ : arterial partial oxygen pressure, SOFA: sequential organ failure assessment ${ }^{1}$ decrease of mean arterial pressure (MAP) $55 \mathrm{mmHg}$ and/or necessity to initiate norepinephrine $>0.15 \mu \mathrm{g} / \mathrm{kg} / \mathrm{min} /$ dubutamine $>5 \mu \mathrm{g} / \mathrm{kg} / \mathrm{min}$ and/or the necessity to more than double the dose of norepinephrine or dobutamine 
The following complications of diagnostic FFB and BAL were registered. 1. Respiratory complications: hypo-oxygenation $\left(\mathrm{SaO}_{2} \leq 88 \%\right)$ during $\mathrm{BAL}$ and/or bronchospasm was documented in $9 \%$ of patients; a decrease of $>25 \% \mathrm{PaO}_{2} / \mathrm{FiO}_{2}$ ratio compared to baseline was registered in $29 \%$ of patients one hour after $\mathrm{BAL}$; in half of these patients a persisting decrease of $>25 \% \mathrm{PaO}_{2} / \mathrm{FiO}_{2}$ ratio was found 24 hours after $\mathrm{BAL}$; no cases of clinically significant bleeding requiring interruption of the procedure or treatment were reported. Further analysis could not establish a significant correlation of respiratory complications with demographic or clinic items [Figure 5.1]. 2. Haemodynamic complications: no patients had hypertension or cardiac rhythm disturbances during the FFB and BAL procedure; hemodynamic instability (as defined in the methods section) was found in $5 \%$ of patients one hour after BAL and $7 \%$ of patients 24 hours after BAL. However, $22 \%$ of patients had hemodynamic instability at any time during the first 24 hours after BAL. This was correlated with a cardiovascular diagnosis at admission (OR 2.9; 95\% Cl 1.2-6.7) and the presence of cardiovascular co-morbidity (OR 3.5; 95\% $\mathrm{Cl}$ 1.5-8.3) [Figure 5.2]. Multiple logistic regression revealed that the correlation was independent from age and gender (OR 2.3; 95\% Cl 1-5.6 / OR 2.8; 95\% Cl 1.1-6.7) and the APACHE II score at admission (OR 3.5; 95\% Cl 1.5-8.5 / OR 3.5; 95\% Cl 1.4-8.6) 3. Bacteraemia: newly positive blood cultures were observed in $7 \%$ of patients. 4 . Death: no case of procedure related death was reported.

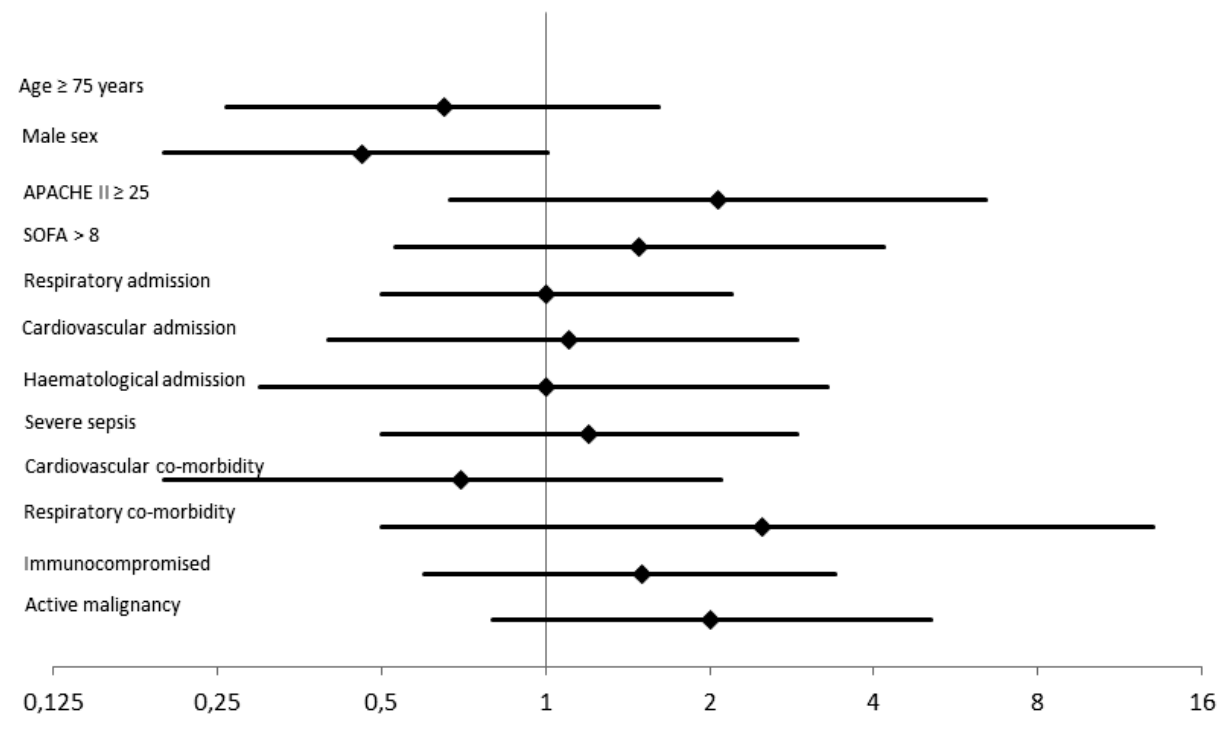

Figure 5.1 Results - Odds ratios and 95\% confidence interval for respiratory complications ${ }^{1}$ of BAL.

${ }^{1}$ Decrease of the $\mathrm{PaO}_{2} / \mathrm{FiO}_{2}>25 \%$ compared to baseline within one hour after $\mathrm{BAL}$ 


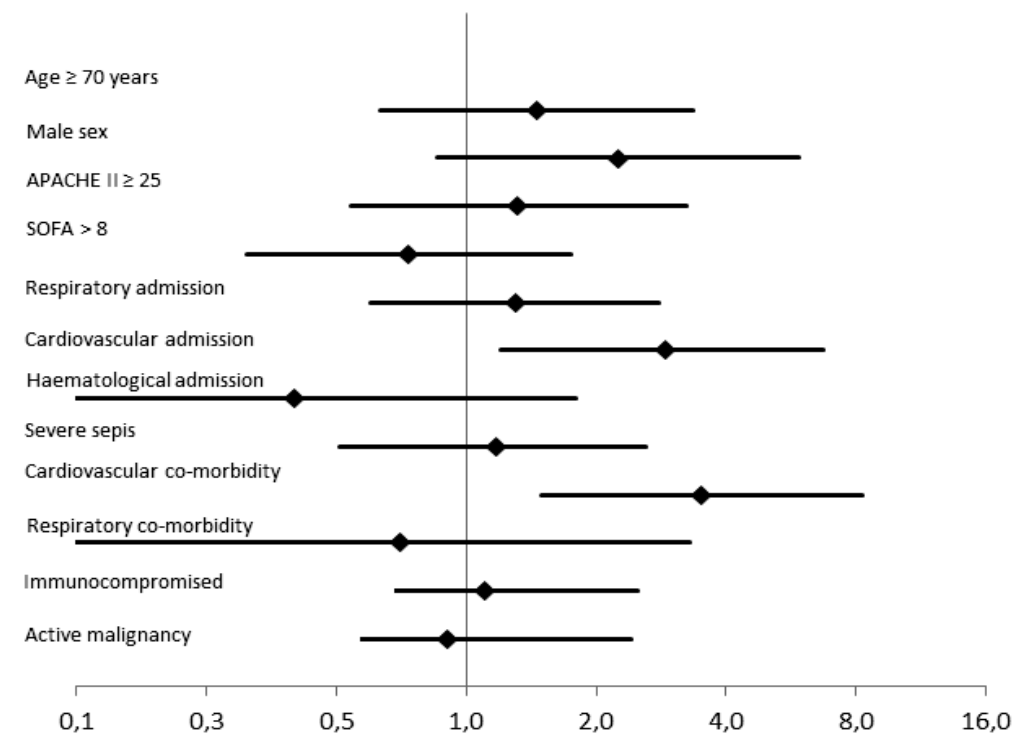

Figure 5.2 Results - Odds ratios with $95 \%$ confidence interval for hemodynamic complications ${ }^{1}$ of BAL. A cardiovascular diagnosis upon admission and cardiovascular co-morbidity are associated with significantly more hemodynamic complications.

${ }^{1}$ decrease of mean arterial pressure (MAP) $<55 \mathrm{mmHg}$ at any time and/or necessity to initiate norepinephrine $>0.15 \mu \mathrm{g} / \mathrm{kg} / \mathrm{min}$ / dubutamine $>5 \mu \mathrm{g} / \mathrm{kg} / \mathrm{min}$ and $/$ or the necessity to more than double the dose of norepinephrine or dobutamine

\section{Discussion}

The present observational study monitored the 24 hour clinical course and complications following diagnostic FFB and BAL in critically ill ventilated patients. Patients' characteristics illustrate the severity of illness before BAL procedures. The high percentage of patients with active malignancy, immunosuppression and neurologic impairment can be explained by the function of the hospital as referral centre for haematology, oncology, immunologic diseases and neurosurgery.

Following diagnostic FFB and BAL there were no cases of cardiac rhythm disturbances, bleeding, pneumothorax or procedure related death during this study. Nevertheless, haemodynamic (22\%) and respiratory (29\%) instability according to the applied definitions were frequently recorded. Due to the complexity of human nature, physiology and pathophysiologic mechanisms of diseases, there might be no simple and consistent definition of respiratory and haemodynamic instability. It has been notoriously difficult to define cut-off variables with regard to vital parameters in clinical trials and practice. ${ }^{14-16}$ A single vital parameter or even a set of absolute values of vital 
parameters will rarely suffice. For example in patients with preserved or abolished autoregulation the same absolute value of MAP can have different effects on the blood flow and vital functions. Hemodynamic and respiratory variables in critical care and ventilated patients markedly interact. MAP and heart rate should be related to dosages of inotropic and vasoactive medication; partial pressure of oxygen should always be correlated with the applied fraction of oxygen and PEEP level. Relative changes of vital parameters with regard to baseline might provide a better assessment of the impact of invasive diagnostic techniques. The definitions for respiratory and hemodynamic complications in the present study were eventually based on pathophysiologic reasoning, earlier publications of bronchoscopy associated complications ${ }^{17,18}$ and literature. ${ }^{19}$ Haemodynamic instability in the study population was associated with a cardiovascular diagnosis at admission or presence of cardiovascular co-morbidity reflecting an expected causal relationship. Interestingly these two risk factors were independent from age, gender and APACHE II score. Haemodynamic changes could have been influenced by cardiovascular effects of the applied anaesthetic drugs to facilitate the procedure, as judged by the supervising physician. Hypo-oxygenation $\left(\mathrm{SaO}_{2} \leq 88 \%\right)$ during $\mathrm{BAL}$ and/or bronchospasm occurred in $9 \%$ of patients and was always manageable and did not necessitate terminating the procedure. Nevertheless, one hour after $\mathrm{BAL}$ there was a significant decrease in the average $\mathrm{PaO}_{2} / \mathrm{FiO}_{2}$ ratio which fully recovered to baseline after 24 hours. Average PEEP and $\mathrm{FiO}_{2}$ levels remained constant. After 24 hours more patients had PEEP adjustment than one hour after BAL explaining the decrease of the average $\mathrm{FiO}_{2}$ from $52 \%$ to $43 \%$.

Altogether, haemodynamic and respiratory instability could be attributed to FFB and BAL in a substantial number of patients. This is in line with previous studies concerning the safety of bronchoscopic diagnostic techniques in critical care patients. Table 5.4 provides an overview of the literature..$^{17,18,20-25}$ The studies differ in patient population, setting, applied diagnostic technique and length of observation. All authors described a certain impact of diagnostic FFB on respiratory mechanics, respiratory and hemodynamic parameters.

To warrant a high procedural safety level of FFB and BAL in ICU patients, a structured approach is mandatory. ${ }^{6}$ An experienced bronchoscopist should concentrate on the procedure while another physician surveys the patient, regulates analgosedation and adjusts the support of vital functions as necessary. The benefits of a BAL should be weighed against the potential additional harm for the patient secondary to the invasiveness of the procedure and the additional costs as compared to less invasive diagnostic measures. There is ongoing discussion on the pros and cons of BAL in the diagnosis of VAP. In this study, the majority of patients had a substantial benefit from the BAL. In $41 \%$ of patients the diagnosis of bacterial pneumonia was confirmed by BAL fluid analysis. In a further $24 \%$ of patients a viral or fungal infection or Pneumocystis jiroveci pneumonia could be diagnosed. When no infectious cause in the BAL fluid analysis was detected, the medical team was urged to look for non-infectious diagnoses 
without any delay and to adjust the therapy. This practice could beneficially affect the patients' outcome and at the same time reduce unnecessary antibiotic use. The latter becomes increasingly important with the rapid emergence and dissemination of multidrug resistant microorganisms particularly in the ICU environment worldwide. ${ }^{26}$ Antibiotic stewardship programs (ASPs) were developed to address the problem and ensure a responsible use of antimicrobial drugs. ${ }^{27,28}$ The diagnostic BAL can be implemented in an ASP and deliver important information to confirm an infectious disease, to optimize antimicrobial treatment (e.g. in the presence of Pneumocystis jiroveci), to de-escalate and narrow antibiotic therapy once the responsible pathogen is known and to stop antibiotic therapy in patients unlikely to have infections. ${ }^{27,29}$

Table 5.4 Results of studies with regard to bronchoscopically guided diagnostic techniques in ICU patients

\begin{tabular}{|c|c|c|c|c|}
\hline Reference & Year & Patients & Setting & Results \\
\hline Montravers et al. ${ }^{21}$ & 1990 & $\mathrm{~N}=107$ & $\begin{array}{l}\text { acutely ill } \\
\text { ventilated } \\
\text { patients; } \\
\text { bronchial brush } \\
\text { mechanically } \\
\text { ventilated } \\
\text { patients; BAL }\end{array}$ & $\begin{array}{l}26 \% \text { of patients }(\mathrm{p}<0.01) \text { with a drop in } \mathrm{PaO}_{2} ; \\
\text { modest alterations in mean systolic blood } \\
\text { pressure related to sedation; six patients } \\
\text { developed arrhythmias during the procedure } \\
\text { mild haemodynamic variations but a marked } \\
\text { decrease in } \mathrm{PaO}_{2} \text { during bronchoscopy with a } \\
\text { maximum at the end of the procedure that not } \\
\text { fully recovered up to two hours thereafter }\end{array}$ \\
\hline Steinberg et al. ${ }^{17}$ & 1993 & $N=110$ & $\begin{array}{l}\text { ARDS patients; } \\
\text { BAL }\end{array}$ & $\begin{array}{l}21 \text { patients with a moderate to severe drop in } \\
\mathrm{PaO}_{2} / \mathrm{FiO}_{2} ; 4 \text { patients with a decrease of mean } \\
\text { arterial pressure }<60 \mathrm{mmHg} ; 6 \text { patients } \\
\text { developed arrhythmias during the procedure; } \\
1 \text { pneumothorax; } 2 \text { cases of bacteraemia within } \\
24 \text { hours }\end{array}$ \\
\hline Turner et al. ${ }^{25}$ & 1994 & $N=107$ & $\begin{array}{l}\text { intensive care } \\
\text { patients; } \\
\text { bronchial brush }\end{array}$ & $\begin{array}{l}\text { study describes therapeutic and diagnostic } \\
\text { fiberoptic bronchoscopies; } 23 \text { bronchial brush } \\
\text { procedures included; low rate of complications } \\
(4.1 \%) ; \text { none with long-term sequelae }\end{array}$ \\
\hline Bauer et al. ${ }^{22}$ & 2001 & $N=37$ & $\begin{array}{l}\text { mechanically } \\
\text { ventilated } \\
\text { patients; BAL }\end{array}$ & $\begin{array}{l}\text { patients showed a lower } \mathrm{PaO}_{2} / \mathrm{FiO}_{2} \text { ratio and } \\
\text { higher MAP after BAL up to } 24 \text { hours }\end{array}$ \\
\hline Chou et al. ${ }^{23}$ & 2009 & $N=56$ & $\begin{array}{l}\text { mechanically } \\
\text { ventilated } \\
\text { patients; BAL }\end{array}$ & $\begin{array}{l}\text { alterations in respiratory mechanics more } \\
\text { pronounced by BAL in patients with intrinsic } \\
\text { positive end-expiratory pressure before the } \\
\text { procedure was started }\end{array}$ \\
\hline Estella $^{24}$ & 2010 & $N=50$ & $\begin{array}{l}\text { Mechanically } \\
\text { ventilated } \\
\text { patients; BAL }\end{array}$ & $\begin{array}{l}\text { respiratory mechanics during BAL procedures } \\
\text { showed significant decrease in lung compliance } \\
\text { and increase in resistance that only reached } \\
\text { baseline after } 90 \text { minutes to } 3 \text { hours }\end{array}$ \\
\hline Estella $^{18}$ & 2012 & $N=148$ & ICU patients; BAL & $\begin{array}{l}\text { desaturations }<90 \%(7 \%) \text {, supraventricular } \\
\text { tachycardia ( } 4 \%) \text { and slight bronchial bleeding } \\
(2 \%)\end{array}$ \\
\hline
\end{tabular}


Limitations of the study are its observational design of FFB and BAL as standard of care in a single centre without a randomized control group. Part of the included cases were retrospectively collected. In the assessment of a long term clinical course it might be difficult to differentiate the natural course of the underlying disease from the impact of the bronchoscopic intervention. Evidently, FFB and BAL procedures should not be performed in patients in a deplorable clinical condition. Unfortunately, the present study does not allow to define clear-cut clinical criteria for withholding FFB and BAL because the limited number of patients with severe acidosis $(\mathrm{pH}<7.25 ; \mathrm{n}=10)$, hypercapnia ( $\mathrm{PaCo} 2 \geq 7.5 \mathrm{kPa} / 56 \mathrm{mmHg} ; \mathrm{n}=9$ ) and hypoxia ( $\mathrm{PaO} 2 \leq 8 \mathrm{kPa} / 60 \mathrm{mmHg} ; \mathrm{n}=10$ or $\mathrm{PaO} 2 / \mathrm{FiO} 2$ ratio $\leq 13 \mathrm{kPa} / 100 \mathrm{mmHg} ; \mathrm{n}=12$ ). Further limitation is the lack of the measurement of respiratory mechanics before, during and after FFB.

\section{Conclusion}

Frequently occurring haemodynamic and respiratory instability could be attributable to diagnostic FFB and BAL but no cases of cardiac rhythm disturbances, bleeding, pneumothorax or procedure related death were observed in the present study. The procedures should be conducted under careful supervision by experienced physicians. Only a randomized controlled trial that compares diagnostic FFB and BAL with a noninvasive strategy could ultimately establish the safety profile and clinical utility of these procedures in critically ill ventilated patients. 


\section{References}

1. Fagon $\mathrm{JY}$, et al. Invasive and noninvasive strategies for management of suspected ventilator-associated pneumonia. A randomized trial. Annals of internal medicine 2000;132;621-30.

2. Shorr AF, Sherner JH, Jackson $\mathrm{WL}$, Kollef $\mathrm{MH}$. Invasive approaches to the diagnosis of ventilatorassociated pneumonia: a meta-analysis. Critical care medicine 2005;33:46-53.

3. Fagon JY. Diagnosis and treatment of ventilator-associated pneumonia: fiberoptic bronchoscopy with bronchoalveolar lavage is essential. Seminars in respiratory and critical care medicine 2006;27:34-44.

4. Canadian Critical Care Trials, G. A randomized trial of diagnostic techniques for ventilator-associated pneumonia. The New England journal of medicine 2006;355:2619-30.

5. Berton DC, Kalil A C, Teixeira PJ. Quantitative versus qualitative cultures of respiratory secretions for clinical outcomes in patients with ventilator-associated pneumonia. The Cochrane database of systematic reviews 2014;10:CD006482.

6. Meduri GU, Chastre J. The standardization of bronchoscopic techniques for ventilator-associated pneumonia. Chest 1992;102:557S-64S.

7. Timsit JF, et al. Usefulness of airway visualization in the diagnosis of nosocomial pneumonia in ventilated patients. Chest 1996;110:172-9.

8. Kirtland $\mathrm{SH}$, et al. The diagnosis of ventilator-associated pneumonia: a comparison of histologic, microbiologic, and clinical criteria. Chest 1997;112:445-57.

9. Linssen CF, et al. Herpes simplex virus load in bronchoalveolar lavage fluid is related to poor outcome in critically ill patients. Intensive care medicine 2008;34:2202-09.

10. Linssen KC, et al. Reactive type II pneumocytes in bronchoalveolar lavage fluid. Acta cytologica 2004;48: 497-504.

11. Linssen CF, et al. Influence of antibiotic therapy on the cytological diagnosis of ventilator-associated pneumonia. Intensive care medicine 2008;34:865-72.

12. Bonten MJ, et al. Implementation of bronchoscopic techniques in the diagnosis of ventilator-associated pneumonia to reduce antibiotic use. American journal of respiratory and critical care medicine 1997;156:1820-4.

13. Dellinger RP, et al. Surviving Sepsis Campaign: international guidelines for management of severe sepsis and septic shock, 2012. Intensive care medicine 2013;39:165-228.

14. Bijker JB, et al. Incidence of intraoperative hypotension as a function of the chosen definition: literature definitions applied to a retrospective cohort using automated data collection. Anesthesiology 2007;107: 213-20.

15. Lonjaret L, Lairez O, Minville V, Geeraerts T. Optimal perioperative management of arterial blood pressure. Integrated blood pressure control 2014;7:49-59.

16. Sevransky JE, et al. Hemodynamic goals in randomized clinical trials in patients with sepsis: a systematic review of the literature. Critical care 2007;11:R67.

17. Steinberg KP, et al. Safety of bronchoalveolar lavage in patients with adult respiratory distress syndrome. The American review of respiratory disease 1993;148:556-61.

18. Estella, A. [Analysis of 208 flexible bronchoscopies performed in an intensive care unit]. Medicina intensiva / Sociedad Espanola de Medicina Intensiva y Unidades Coronarias 2012;36:396-401.

19. Walsh $\mathrm{M}$, et al. Relationship between intraoperative mean arterial pressure and clinical outcomes after noncardiac surgery: toward an empirical definition of hypotension. Anesthesiology 2013;119:507-15.

20. Trouillet $\mathrm{JL}$, et al. Fiberoptic bronchoscopy in ventilated patients. Evaluation of cardiopulmonary risk under midazolam sedation. Chest 1990;97:927-33.

21. Montravers P, Gauzit R, Dombret MC, Blanchet F, Desmonts JM. Cardiopulmonary effects of bronchoalveolar lavage in critically ill patients. Chest 1993;104:1541-7.

22. Bauer TT, et al. Effects of bronchoalveolar lavage volume on arterial oxygenation in mechanically ventilated patients with pneumonia. Intensive care medicine 2001;27:384-93.

23. Chou MY, Ou CY, Chen CW. Alterations in respiratory mechanics in mechanically ventilated patients following bronchoalveolar lavage. Journal of the Formosan Medical Association 2009;108:704-12.

24. Estella A. Effects on respiratory mechanics of bronchoalveolar lavage in mechanically ventilated patients. Journal of bronchology \& interventional pulmonology 2010;17:228-231. 
25. Turner JS, Willcox PA, Hayhurst MD, Potgieter PD. Fiberoptic bronchoscopy in the intensive care unit--a prospective study of 147 procedures in 107 patients. Critical care medicine 1994;22:259-64.

26. Laxminarayan $\mathrm{R}$, et al. Antibiotic resistance-the need for global solutions. The Lancet infectious diseases 2013;13:1057-98.

27. Arnold HM, Micek ST, Skrupky LP, Kollef MH. Antibiotic stewardship in the intensive care unit. Seminars in respiratory and critical care medicine 2011;32:215-27.

28. Goff DA. Antimicrobial stewardship: bridging the gap between quality care and cost. Current opinion in infectious diseases 2011;24 Suppl 1:S11-20.

29. Luyt CE, Brechot N, Trouillet JL, Chastre J. Antibiotic stewardship in the intensive care unit. Critical care 2014;18:480. 



\section{Chapter}

\section{Analysis of volatile organic compounds in exhaled breath to diagnose ventilator-associated pneumonia}

R Schnabel, R Fijten, A Smolinska, J Dallinga, M-L Boumans, E Stobberingh, A Boots, P Roekaerts, D Bergmans, F van Schooten 


\begin{abstract}
Ventilator-associated pneumonia (VAP) is a nosocomial infection occurring in the intensive care unit (ICU). The diagnostic standard is based on clinical criteria and bronchoalveolar lavage (BAL). Exhaled breath analysis is a promising non-invasive method for rapid diagnosis of diseases and contains volatile organic compounds (VOCs) that can differentiate diseased from healthy individuals. The aim of this study was to determine whether analysis of VOCs in exhaled breath can be used as a non-invasive monitoring tool for VAP.

One hundred critically ill patients with clinical suspicion of VAP underwent BAL. Before BAL, exhaled breath samples were collected and analysed by gas chromatography timeof-flight mass spectrometry (GC-tof-MS). The clinical suspicion of VAP was confirmed by BAL diagnostic criteria in 32 patients $[\operatorname{VAP}(+)]$ and rejected in 68 patients [VAP(-)]. Multivariate statistical comparison of $\operatorname{VOC}$ profiles between $\operatorname{VAP}(+)$ and $\operatorname{VAP}(-)$ revealed a subset of 12 VOCs that correctly discriminated between those two patient groups with a sensitivity and specificity of $75.8 \% \pm 13.5 \%$ and $73.0 \% \pm 11.8 \%$, respectively.

These results suggest that detection of VAP in ICU patients is possible examining exhaled breath, enabling a simple, safe and non-invasive approach that could diminish diagnostic burden of VAP.
\end{abstract}




\section{Introduction}

Ventilator-associated pneumonia (VAP) is a common hospital-acquired infection occurring in the intensive care unit (ICU) with an incidence that varies from $4-42 \%$ depending on the applied diagnostic criteria. ${ }^{1}$ It is a severe complication of mechanical ventilation with an attributable mortality risk of approximately $13 \%{ }^{2}$ To date, the diagnosis is based on clinical criteria in combination with bacterial culture results. In patients clinically suspected of having VAP, bronchoalveolar lavage (BAL) from the site of the presumed infection and subsequently cytological and microbiological analysis of the lavage fluid is regarded a suitable diagnostic approach. ${ }^{3}$ However, this technique is invasive, involves risks and has its limitations in patients with severe pulmonary disease, high respiratory support settings and coagulation abnormalities. Additionally, analysis of BAL is laborious, time- consuming and takes up to 48 hours before definitive results are available. Only then can the diagnosis of VAP be confirmed or rejected. During this period patients empirically receive broad spectrum antibiotics. Facing a rapid emergence and dissemination of multi-drug resistant microorganisms particularly in the ICU environment, strategies to reduce such general and non-targeted antibiotic consumption have become very important. ${ }^{4}$

It is therefore of interest to find a new method that allows fast, reliable, non-invasive VAP diagnosis. Using exhaled breath for disease diagnosis is a promising technique that may be able to fulfil these criteria. Exhaled breath contains a multitude of volatile organic compounds (VOCs) originating from both exogenous and endogenous sources. Endogenous VOCs are produced by biological processes including oxidative stress and inflammation in the human body, ${ }^{5,6}$ as well as by invading microorganisms. ${ }^{7}$ Upon their production, VOCs are excreted into the blood after which they diffuse into the lungs where they are exhaled. Oxidative stress and inflammation induce alterations in the composition of VOCs excreted by the affected organ and thus the exhaled breath. Additionally, microorganisms themselves may produce specific compounds leading to different VOC profiles in exhaled breath. Taking into account the invasion of harmful microorganisms in the lungs and the defence mechanisms that are subsequently set in motion by the host, it can be expected that VOCs are present in different concentrations and compositions in patients with VAP compared to patients without VAP. These discriminating VOC profiles may be used to aid VAP diagnosis.

Thus far, discriminating VOC profiles have been found for various respiratory diseases such as chronic obstructive pulmonary disease (COPD), asthma, tuberculosis and cystic fibrosis. $^{8-13}$ It has already been demonstrated that Pseudomonas aeruginosa, Staphylococcus aureus, Escherichia coli and Klebsiella pneumoniae could be identified correctly based on the analysis of VOCs excreted into the headspace of cultured bacteria. ${ }^{14}$ Many of these strains frequently cause VAP. In another study, VOCs of Streptococcus pneumoniae and Haemophilus influenzae cultures were analysed at different time points during cultivation, leading to the identification of strain-specific 
VOCs for both bacterial species. ${ }^{15}$ A systematic review summarized both strain-specific and commonly occurring VOCs from 31 recent in vitro studies that investigated bacterial species. ${ }^{7}$ A recently published study by Fowler et al. found that, in a wellcharacterized group of patients with sterile brain injury, exhaled breath analysis can adequately detect the presence of airway pathogens in vivo that can induce VAP. ${ }^{16}$ The aim of the current study is to identify VAP-specific VOCs in vivo by analysis of the exhaled breath of critically ill mechanically ventilated patients independent of their underlying disease upon admission to the ICU.

\section{Materials and methods}

\section{Study design}

This study was conducted at Maastricht University Medical Centre+, a tertiary, university hospital in the Netherlands with 1,700 ICU admissions per year. The ICU consists of two 9- bed units for medical and surgical patients and one 9-bed unit for cardiothoracic surgery patients. Adult critically ill, mechanically ventilated patients with a clinical suspicion of VAP who underwent a diagnostic BAL were included. Exclusion criteria for the BAL procedure were thrombocytopenia $(<40,000 / \mu \mathrm{l})$ and other coagulation abnormalities. The exhaled breath study and its experimental protocols were evaluated by the joint medical ethics committee at Maastricht University and Maastricht University Medical Centre+ (METC azM/UM). After evaluation and approval of the experimental protocols, the METC azM/UM committee concluded that the study did not fall under the scope of the medical research involving human subjects act (WMO), and was therefore denoted as "non-WMO research" as no direct and invasive patient intervention was required and results of the analyses did not influence the patient's outcome. Experimental protocols were performed in accordance with the approved national Dutch guidelines for non-WMO research. ${ }^{17}$

A patient was clinically suspected of VAP after $\geq 48$ hours of mechanical ventilation, fulfilling the clinical criteria depicted in Table 6.1. BAL was performed on the day of clinical suspicion for VAP. A fibreoptic bronchoscope (Pentax FB-15H/FB-15X, Pentax Medicals, Tokyo, Japan) was introduced and 'wedged' into the affected segmental or subsegmental bronchus. Sterile saline ( $0.9 \%$ sodium chloride at room temperature) was instilled in four aliquots of $50 \mathrm{ml}$, immediately aspirated and recovered. Further analysis was highly standardized as described by de Brauwer et al.. ${ }^{18} \mathrm{~A}$ clinically suspected episode was considered microbiologically confirmed when the following criteria were met in BAL fluid (BALF): presence of $\geq 2 \%$ cells containing intracellular organisms (ICO) and/ or quantitative culture results of $\geq 10^{4} \mathrm{cfu} / \mathrm{ml}^{19,20}$ One hundred patients were included in the study. Upon BALF analysis they were divided into two groups: (1) BALF confirmed the clinical suspicion of $\operatorname{VAP}(\operatorname{VAP}(+), n=32) ;(2)$ the diagnosis of VAP was 
rejected by BALF analysis (VAP(-), n=68). The Sequential Organ Failure Assessment (SOFA) score was registered at the moment of BAL to compare the seriousness of illness. The diagnosis of the underlying disease on admission to the ICU of all patients were documented and allocated into seven diagnostic groups. Differences between $\operatorname{VAP}(+)$ and $\operatorname{VAP}(-)$ were tested for significance: two-sided paired t-test for age and SOFA scores; chi square for diagnosis upon admission. A p-value $<0.05$ was considered significant. (Table 6.2)

Table 6.1 Criteria of clinical suspicion of VAP.

\begin{aligned} & \hline I. Three or more positive out of the following \\ & \hline 1. Rectal temperature $>38^{\circ} \mathrm{C}$ or $<35.5^{\circ} \mathrm{C} \\ &$ 2. Blood leukocytosis $(>10.000 / \mu \mathrm{l})$ and/or left shift or blood leukopenia $(<3.000 / \mu \mathrm{l}) \\ &$ 3. More than ten leukocytes in Gram stain of tracheal aspirate (in high-flow field) \\ & 4. Positive culture of tracheal aspirate \\ & and \\ & \hline II. New, persistent, or progressive infiltrate on chest radiograph \end{aligned}

Table 6.2 Characteristics of the patient groups in the study. The age and SOFA scores were tested for significance with a two-sided paired t-test; significance was tested for the diagnostic groups using a Chi Square test. $\mathrm{P}<0.05$ was considered significant. Age and SOFA scores are represented as mean \pm standard deviation.

\begin{tabular}{|c|c|c|c|}
\hline & $\operatorname{VAP}(+)$ & VAP(-) & \\
\hline Sample size & 32 & 68 & \\
\hline Average age [years] & $64 \pm 12$ & $60 \pm 14.5$ & $p=.16$ \\
\hline Male/Female & $26 / 6$ & $44 / 24$ & $p=.07$ \\
\hline SOFA at time of BAL & $6.4 \pm 3.4$ & $6.9 \pm 2.9$ & $p=.41$ \\
\hline Diagnostic group at admission & & & $p=.24$ \\
\hline gastrointestinal & 4 & 9 & \\
\hline cardiovascular & 9 & 13 & \\
\hline hematologic & 3 & 15 & \\
\hline neurologic & 4 & 6 & \\
\hline orthopaedic / trauma & 4 & 2 & \\
\hline respiratory & 8 & 20 & \\
\hline other & 0 & 3 & \\
\hline No comorbidity & 17 (53\%) & $38(56 \%)$ & $\mathrm{p}=.80$ \\
\hline One comorbidity & $8(25 \%)$ & $15(22 \%)$ & \\
\hline Two comorbidities & $5(16 \%)$ & $12(18 \%)$ & \\
\hline$\geq$ three comorbidities & $2(6 \%)$ & $3(4 \%)$ & \\
\hline Distribution of comorbidities & & & $p=.23$ \\
\hline cardiovascular & 3 & 3 & \\
\hline respiratory & 3 & 5 & \\
\hline chronic renal failure & 4 & 7 & \\
\hline active malignancy & 2 & 9 & \\
\hline immunocompromised & 7 & 15 & \\
\hline neurologic impairment & 3 & 8 & \\
\hline chronic liver failure & 2 & 2 & \\
\hline Severe sepsis & $11(34 \%)$ & $24(35 \%)$ & $p=.93$ \\
\hline ICU mortality & $12(38 \%)$ & $31(45 \%)$ & $p=.45$ \\
\hline In hospital mortality & $14(43 \%)$ & 37 (54\%) & $p=.34$ \\
\hline
\end{tabular}




\section{Sampling and measurement of exhaled breath}

Directly before BAL was performed, exhaled breath samples from ventilated patients were collected into a sterile Tedlar bag $(5 \mathrm{l})$. The bag was tightly connected to the expiratory limb of the Draeger ${ }^{\circledR}$ Evita XL ventilator (Lübeck, Germany). Exhaled breath from the patient could then flow into the Tedlar bag without any pollution from the environment. When the bag was filled, its valve was closed and the connection with the ventilator subsequently removed. The content of the bag was transported by vacuum pump (VWR International, France) onto stainless steel two-bed desorption tubes, filled with carbograph 1TD/Carbopack X (Markes International, Llantrisant, Wales, UK) that trap VOCs. The VOCs captured in these desorption tubes were measured by gas chromatography-time of flight-mass spectrometry (GC-tof-MS) based on the procedure described by Van Berkel et al.. ${ }^{8}$ This was done in a non-targeted way, meaning that the highest amount and variety of VOCs were measured and used for multivariate statistical analysis later on.

\section{Data processing and statistical analysis}

Raw GC-tof-MS data were pre-processed to remove various sources of artefacts before the actual statistical analysis. Pre-processing of the data reduces the influence of these artefacts and allows for the biological variation to come through. This was done by sequential use of the following methods: denoising, baseline correction, alignment, normalization and scaling of the data. ${ }^{21}$ In order to compare different groups, the number of samples in the larger group has to be reduced to the size of the smaller group to make the statistical analyses work efficiently. This was done by randomly choosing a subset of 32 samples of the $68 \mathrm{VAP}(-)$ samples to match the size of the VAP(+) group and using this subset for further statistical analysis. This procedure was repeated 250 times to ensure that each sample in the larger group was used. For this study, the multivariate statistical analysis method Random Forest (RF) was used. ${ }^{22}$. This machine learning method constructs a multitude of de-correlated decision trees to classify samples into the appropriate disease state. Decision trees are predictive models that try to classify samples based on a specific subset of the measured VOCs. RF creates many decision trees (e.g. 1,000) comprising of a small and randomly selected subset of VOCs and tries to predict the class outcome. The most discriminatory subset of VOCs is then used to create the final classification model. Validation of the RF model was done by calculating the "out-of-bag error". In this procedure $66.7 \%$ of the samples are randomly selected with replacement for each decision tree. The remaining $33.3 \%$ are used to calculate the performance of the RF classification model. This produces class probability values, which are used to calculate sensitivity and specificity illustrated by Receiver Operating Characteristic (ROC) curves. For the sensitivity and specificity parameters, the $95 \%$ confidence interval was calculated and written in the following way: mean \pm confidence interval. A ROC curve is a graphical representation of the 
performance of the predictive model established by RF. The area under the curve (AUC) is most commonly used as an indicator of predictive performance: a value close to 1 indicates high predictive power of the model, whereas an AUC close to 0.5 means that the model has no predictive power. ${ }^{23}$

For visualization purposes, principal component analysis (PCA) score plots of the RF proximities were created. The proximities are distance parameters ranging from 0 to 1 that visualize similarities of the selected VOC profile between individual samples. A small proximity value indicates similarity, while a large proximity value indicates dissimilarity between individuals. A PCA plot of proximities can therefore demonstrate groupings of samples and trends in the data.

\section{Influence of confounders}

To rule out that the VOC profile found by RF is influenced by confounding factors, regularized MANOVA was used ${ }^{24}$ to test for the following possible confounders: age, gender, diagnostic group at admission, SOFA scores, ICU mortality, general hospital mortality, the presence of comorbidities in general, and the presence of specific comorbidities mentioned in Table 6.2.

\section{Compound identification}

The VOCs implemented into the classification model were identified with spectrum recognition using the National Institute of Standard and Technology (NIST) library in combination with spectrum interpretation by an experienced mass spectrometrist and identification based on retention times of components.

\section{Pathway identification}

For each of the chemically identified VOCs the ChEBI ${ }^{25}$, ChemSpider ${ }^{26}$ and PubChem $\mathrm{IDs}^{27}$ were found in their respective databases. BridgeDb ${ }^{28}$, which links identifiers from several databases, was used to find additional identifiers corresponding to each VOC. This was necessary due to annotation problems in pathways, where the same metabolite is mentioned with a different identifier or name in different pathways.

The RRDF package ${ }^{29}$ was then used to find pathways in Wikipathways ${ }^{30}$ that included that specific VOC. Additionally, because Wikipathways includes only a limited number of metabolite pathways, the KEGG database ${ }^{31}$ was analysed for pathways containing the identified VOCs. This was done using the KEGG REST api.

Because VAP is mainly caused by a well-defined array of bacteria, a selection of pathways was made that were present in the human host or in bacteria most likely to cause VAP ${ }^{32}$ including Staphylococcus aureus, Pseudomonas aeruginosa, Escherichia coli, Klebsiella pneumoniae, Hemophilus influenzae. 


\section{Results}

\section{Clinical outcome/data}

An overview of demographic and clinical data is presented in Table 6.2. Sample size varies between the groups as a result of confirmation of VAP in only 32 of 100 individuals included in the study. There were no significant differences in the seriousness of disease at the moment of BAL (SOFA) or in the distribution of the underlying diagnosis on admission to the ICU. However, patients in the VAP(-) group seemed to suffer more from a haematological diagnosis upon admission and active malignancies. (Table 6.2) During the study period we found an average of 2.5 episodes of VAP per 1,000 ventilator days. The diagnosis of VAP was based in 6 patients on a percentage of ICO $>2 \%$ alone and in 26 patients on a bacterial growth of more than $10^{4} \mathrm{cfu} / \mathrm{ml}$. Staphylococcus aureus $(\mathrm{n}=5)$, Pseudomonas aeruginosa $(\mathrm{n}=4)$, Escherichia coli $(n=4)$, Klebsiella pneumoniae $(n=4)$, Hemophilus influenzae $(n=3)$ and Acinetobacter baumannii $(n=3)$ were the most frequently found microorganisms.

\section{RF classification model}

GC-MS measurements produced 100 chromatograms: one for each patient. After processing, these chromatograms consisted of $>1000$ chemically different VOCs. RF was used to filter VOCs that were discriminatory between VAP(+) and VAP(-). The final RF classification model was based on 12 discriminatory VOCs and correctly classified $74.2 \%$ $\pm 13.8 \%$ of all individuals with a sensitivity and specificity of $75.8 \% \pm 13.5 \%$ and $73.0 \% \pm 11.8 \%$ respectively. The corresponding ROC curve depicted in Figure $6.1 \mathrm{~A}$ had an AUC of 0.87 . The PCA score plot of proximities between the individual samples based on the 12 most important VOCs [Figure 6.1B] showed that the $\operatorname{VAP}(+)$ and $\operatorname{VAP}(-)$ patients are separated with small overlap. This indicates that patients suffering from VAP can be identified based on this combination of 12 VOCs with high accuracy.

\section{Influence of confounders}

The influence of potential confounders was tested to ensure that the discriminating VOC profile was purely a result of the VAP diagnosis. The following confounding factors were tested: age, gender, diagnostic group at admission, SOFA scores, ICU mortality, general hospital mortality, the presence of comorbidities in general, and the presence of specific comorbidities mentioned in Table 6.2. None of these confounders significantly influenced the model [Supplementary Table S6.1]. 

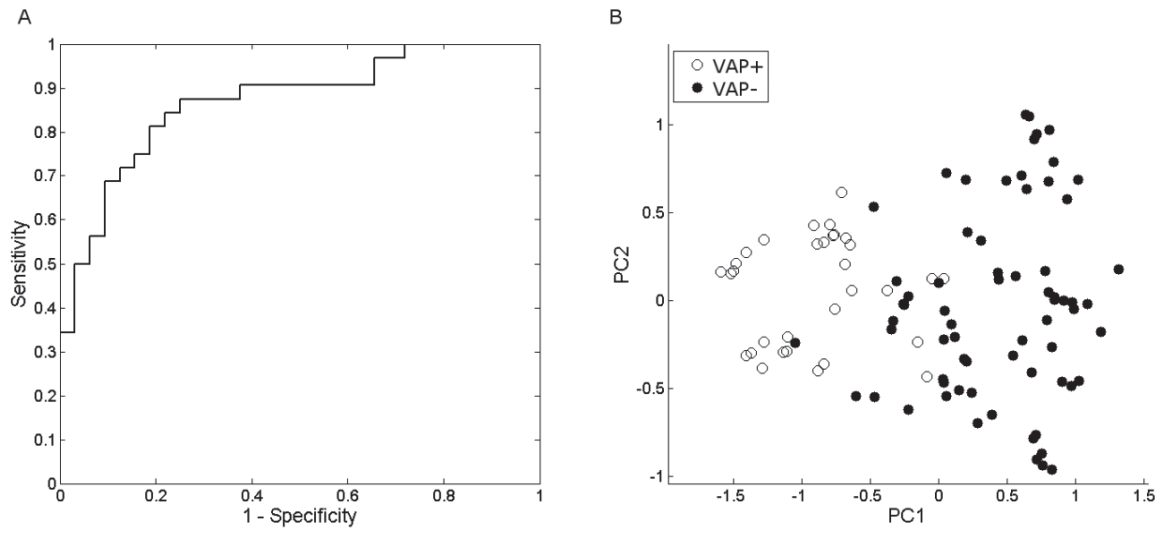

Figure 6.1 ROC and PCA plots visualizing the separation of the $\operatorname{VAP}(+)$ and $\operatorname{VAP}(-)$ groups. A: Receiver operating characteristic (ROC) curve of VAP(+) vs. VAP(-). It consists of 1-sensitivity on the x-axis and specificity on the $y$-axis. B: The PCA plot is based on the proximities between samples of $\operatorname{VAP}(+)$ (white) and VAP(-) (black).

\section{Compound identification}

The chemical identity of the 12 VOCs selected by RF is shown in Table 6.3. The identified VOCs include 2-methylbutane, heptane, dodecane and tetradecane (alkanes), carane (hydrocarbon ring structure), ethanol and isopropyl alcohol (alcohols), acrolein and tetradecanal (aldehydes). The remaining compounds were identified as acetone (ketone), ethylbenzene (aromatic hydrocarbon) and tetrahydrofuran (oxygencontaining heterocyclic compound).

Table 6.3 Identified VOCs for the comparison between $\operatorname{VAP}(+)$ and $\operatorname{VAP}(-)$. In addition to the compound name, CAS numbers were added for identification. Up/Down in VAP(+) vs. VAP(-) was based on mean peak height.

\begin{tabular}{|c|c|c|c|c|c|}
\hline Compound name & CAS nr & $\begin{array}{l}\text { Molecular } \\
\text { formula }\end{array}$ & $\begin{array}{c}\mathrm{M} / \mathrm{z} \text { of parent } \\
\text { molecule } \\
\text { (g mol-1) }\end{array}$ & $\begin{array}{c}\text { Average } \\
\text { retention time } \\
\text { (min) }\end{array}$ & $\begin{array}{c}\text { Up/Down in } \\
\text { VAP }(+) \text { vs } \\
\text { VAP(-) }\end{array}$ \\
\hline Butane , 2-methyl & $78-78-4$ & $\mathrm{C} 5 \mathrm{H} 12$ & 72.10 & 2.28 & $\uparrow$ \\
\hline Ethanol & $64-17-5$ & $\mathrm{C} 2 \mathrm{H} 6 \mathrm{O}$ & 46.04 & 2.26 & $\uparrow$ \\
\hline Acetone & $67-64-1$ & $\mathrm{C} 3 \mathrm{H} 6 \mathrm{O}$ & 58.04 & 2.59 & $\downarrow$ \\
\hline Isopropyl Alcohol & $67-64-1$ & $\mathrm{C} 3 \mathrm{H} 8 \mathrm{O}$ & 60.06 & 2.61 & $\downarrow$ \\
\hline Acrolein & $107-02-8$ & $\mathrm{C} 3 \mathrm{H} 4 \mathrm{O}$ & 56.03 & 2.55 & $\downarrow$ \\
\hline Furan, tetrahydro- & $109-99-9$ & $\mathrm{C} 4 \mathrm{H} 8 \mathrm{O}$ & 72.06 & 5.41 & $\downarrow$ \\
\hline Heptane & $142-82-5$ & $\mathrm{C} 7 \mathrm{H} 16$ & 100.13 & 7.25 & $\uparrow$ \\
\hline Ethylbenzene & $100-41-4$ & $\mathrm{C} 8 \mathrm{H} 10$ & 106.08 & 11.49 & $\uparrow$ \\
\hline Carane & $17530-24-4$ & $\mathrm{C} 10 \mathrm{H} 18$ & 138.14 & 14.30 & $\uparrow$ \\
\hline Dodecane & $112-40-3$ & $\mathrm{C} 12 \mathrm{H} 26$ & 170.20 & 17.47 & $\downarrow$ \\
\hline Tetradecane & $629-59-4$ & $\mathrm{C} 14 \mathrm{H} 30$ & 198.23 & 20.46 & $\uparrow$ \\
\hline Tetradecanal & $124-25-4$ & $\mathrm{C} 14 \mathrm{H} 28 \mathrm{O}$ & 212.37 & 23.18 & $\uparrow$ \\
\hline
\end{tabular}




\section{Pathway identification}

The Wikipathways and KEGG databases were searched for pathways containing one or more of the 12 discriminatory VOCs. Only pathways present in humans and VAPcausing bacteria were included in the analysis. Seven KEGG pathways remained containing two VOCs [Table 6.4]: one pathway that produced acrolein; five pathways with ethanol as an end-product and one which utilized ethanol. No human- or bacteriaspecific Wikipathways were found.

Table 6.4 KEGG pathways that contained one of the identified VOCs

\begin{tabular}{|c|c|c|c|c|}
\hline $\begin{array}{l}\text { Compound } \\
\text { name }\end{array}$ & $\begin{array}{c}\text { KEGG } \\
\text { pathway } \\
\text { ID } \\
\end{array}$ & Pathway name & $\begin{array}{l}\text { Microorganisms (M), } \\
\text { human(H), or both(B) }\end{array}$ & $\begin{array}{c}\text { Produced }(P) \text {, } \\
\text { used }(U) \text { or } \\
\text { intermediate }(I) \text { ? }\end{array}$ \\
\hline \multirow[t]{6}{*}{ Ethanol } & 00010 & Glycolysis / Gluconeogenesis & B & $P$ \\
\hline & 01100 & Metabolic pathways * & B & $\mathrm{P}$ \\
\hline & 01110 & $\begin{array}{l}\text { Biosynthesis of secondary } \\
\text { metabolites * }\end{array}$ & M & $\mathrm{P}$ \\
\hline & 01120 & $\begin{array}{l}\text { Microbial metabolism in diverse } \\
\text { environments * }\end{array}$ & M & $\mathrm{P}$ \\
\hline & 01130 & Biosynthesis of antibiotics * & B & $\mathrm{P}$ \\
\hline & 04750 & $\begin{array}{l}\text { Inflammatory mediator regulation } \\
\text { of TRP channels }\end{array}$ & $\mathrm{H}$ & $U$ \\
\hline Acrolein & 00982 & $\begin{array}{l}\text { drug metabolism - cytochrome } \\
\text { P450 }\end{array}$ & $\mathrm{H}$ & $P$ \\
\hline
\end{tabular}

For each pathway, the pathway ID and its pathway name as stated in the database are given, and additionally the species in which that pathway is present and whether the compound of interest is an end-product (produced), is being used (used), or is being produced as an intermediate for further utilization (intermediate). ${ }^{*}$ generic pathways, which contain other smaller pathways.

\section{Discussion}

In the present study, VOC profiles were determined in exhaled breath of patients clinically suspected of VAP to discriminate patients with VAP from other critically ill ventilated patients. Of 100 patients, 32 were diagnosed with VAP by quantitative BAL analysis. This ratio was in line with earlier publications. ${ }^{20,33}$ A discriminating profile of 12 exhaled VOCs was identified that could determine the presence of VAP with an accuracy of $74.2 \% \pm 13.8 \%$, accompanied by a sensitivity of $75.8 \% \pm 13.5 \%$, a specificity of $73.0 \% \pm 11.8 \%$ and an AUC of 0.87 . The 12 VOCs that were identified by the model were chemically diverse. There was no significant difference in the diagnosis at admission or in the frequency and distribution of comorbidities between the $\operatorname{VAP}(+)$ and VAP(-) group of patients. However, a haematological diagnosis at admission and active malignancy as comorbidity were more prevalent among VAP(-) patients. Several potential confounders, including haematological diagnosis and active malignancies, were tested and proven not to be significantly associated with the VOC profile. The 
predominance of male patients in the demographics of the present study reflects known gender differences in the incidence of sepsis and VAP. ${ }^{34,35}$

These results demonstrate the potential of exhaled breath as a diagnostic tool in the ICU, where less invasive and faster detection methods are of great importance. Although the results are encouraging, the external validation in a large, multicentre cohort is necessary for clinical application. The advantage of exhaled breath over BAL analysis - the current gold standard for diagnosis of VAP - is that it is easy to perform, non-invasive and can be analysed within a short time span. In contrast to BAL, where the time to diagnosis is at least $48 \mathrm{~h}$, exhaled breath sampling could take as little as one hour to get a diagnosis. To achieve this, exhaled breath, upon sampling after clinical suspicion of VAP, should be immediately transferred to a laboratory where it has to be processed by a mass spectrometer right away and subsequently checked for markers of VAP using a predesigned and validated algorithm. Eventually, such a fast diagnostic tool could support tailored antibiotic treatment, thereby aiding antibiotic resistance. ${ }^{4}$ Additionally, it could reduce hospital costs and medication use. ${ }^{36}$

Thus far, most of the research done on exhaled breath in diagnosis of VAP was done with the e-nose technology. One study tested the use of e-nose technology as a substitute for chest computed tomography scan as a diagnostic tool for diagnosing VAP. ${ }^{37}$ Although a prediction value of $80 \%$ was discovered, these results are difficult to interpret correctly due to the lack of independent validation. A more recent study by the same authors evaluated the use of the e-nose as a substitute for the Clinical Pulmonary Infection Score (CPIS). ${ }^{38}$ The CPIS is a measure of pulmonary infection that is used to diagnose VAP with an arbitrary cut-off of 6 for the diagnosis $[>6=\operatorname{VAP}(+),<6=$ $\operatorname{VAP}(-)$ ]. However, since the CPIS is considered to be not reliable enough to diagnose VAP in the clinical setting ${ }^{39}$, it is unclear whether the included patients were accurately diagnosed with VAP, which could consequently skew their findings. Bos et al. also performed a prospective cohort study on diagnosing VAP with the e-nose. ${ }^{40}$ They collected tracheal aspirates (TAs), and successively analysed the headspace of a bacterial culture medium of these TAs. They found an AUC of 0.85 in their crosssectional study, which is comparable to our observed AUC of 0.87. All of these studies utilize the e-nose technology which has some limitations including reproducibility, negative effects of temperature and humidity, and the inability to identify the chemical identity of VOCs underlying the disease. ${ }^{41}$ Knowing the identity of a VOC enables us to look at the underlying biological mechanisms of the disease.

Acute respiratory distress syndrome (ARDS) describes a condition of severe lung failure that can be caused by various non-infectious and infectious diseases including VAP. Additionally, mechanical ventilation in patients with ARDS can facilitate the development of VAP. Exhaled breath as a diagnostic marker of ARDS was recently tested and could correctly classify ARDS patients and controls with an AUC of $0.78 .^{42}$ In our study, an AUC of 0.87 was found for VAP, which suggests that VAP may produce more pronounced differences in the exhaled breath. The ARDS study was performed 
using GC-MS and identified three VOCs to be essential for the discriminating model, of which two alkanes and one aldehyde. Although none of the individual compounds corresponded to the VOCs identified in our study, we found alkanes and aldehydes as well. This could imply involvement of similar underlying biological mechanisms in VAP and ARDS as well as sufficient differences between the pathology of the conditions to make them distinguishable by exhaled breath.

Over the last few years, multiple studies were performed to identify VOCs specific to a certain strain of bacteria. A recent review summarized all VOCs found for the six most frequently found bacteria in the ICU: Staphylococcus aureus, Streptococcus pneumoniae, Enterococcus faecalis, Pseudomonas aeruginosa, Klebsiella pneuomoniae and Escherichia coli. ${ }^{7}$ These are all known to cause VAP in critically ill patients. ${ }^{43}$ Another recent study detected VOCs that could differentiate various species of bacteria in vitro. ${ }^{14}$ Although some of the bacteria included in this study were similar to those present in the current VAP patients, no overlap between the discriminating VOCs was observed. Aside from the small number of patients affected by each of these individual bacteria, this lack in overlap could also be explained by the fact that the in vitro study compared strains among one another whereas the present study compared diseased patients and controls. More generally, all of the studies described here were performed in vitro or ex vivo whereas our study has been carried out with in vivo samples from a very heterogeneous patient population. This may also explain the discrepancies with our findings, as there are well-known limitations to the translatability of in vitro and ex vivo experiments into an in vivo situation. ${ }^{44}$

Recently a study was published by Fowler et al. where 46 ICU patients with sterile brain injury were followed as some of them developed a significant presence of airway pathogens $\left(>10^{4} \mathrm{cfu} / \mathrm{ml}\right.$ ) that ultimately may have led to VAP in these patients. ${ }^{16}$ Their exhaled breath was sampled and analysed in a similar manner as in our study using thermal desorption coupled with gas chromatography - time of flight - mass spectrometry, followed by multivariate analysis of the data. Likewise, BAL results were used as a reference in the diagnosis of VAP. Remarkably, 33\% of the monitored patients demonstrated significant growth of pathogens in the lower respiratory tract. Hence, the incidence of VAP was much higher than in our ICU where we found an average of 2.5 episodes of VAP in 1,000 ventilator days. ${ }^{45}$ This discrepancy might be explained by a higher risk of aspirations in patients with brain injury requiring intubation. ${ }^{46}$ Although the patient population may not adequately reflect the overall ICU population, the results from Fowler et al. are very promising as a means to associate bacterial colonisation of the lower respiratory tract with exhaled VOCs. In contrast, our study reflects more the current clinical guidelines in the diagnosis of VAP, and the heterogeneity of an ICU population.

The list of VOCs found for $\operatorname{VAP}(+)$ vs. $\operatorname{VAP}(-)$ comparison consists of both endogenous and exogenous sources. Some endogenous compounds may be useful as they can indicate the cellular processes underlying VAP. 
Ethanol is a compound that is produced by both bacteria and the human host. It is produced as a metabolite end-product in all but one of these pathways, In all but one of these pathways it is produced as a metabolite end-product, which is reflected in the increased level of exhaled ethanol in $\operatorname{VAP}(+)$ patients.

Acetone is produced by spontaneous decarboxylation of acetoacetate, which is produced as a result of the build-up of ketone bodies. These ketones can be formed in the liver as a result of sepsis. ${ }^{47}$ As a consequence of acetone build-up, isopropyl alcohol is formed as break-down product of acetone during ketogenesis. The exhaled concentrations of both compounds were lower in VAP(+) compared to VAP(-) patients. This can be explained by the fact that ketogenesis is reduced during inflammatory or infectious states ${ }^{47}$, resulting in less production of acetone and isopropyl alcohol.

Acrolein is also very likely to originate from endogenous sources and can be produced by a number of cellular processes. Firstly, lipid peroxidation accounts for a small portion of the endogenously produced acrolein. Secondly, myeloperoxidase (MPO), plays a crucial role in oxidative stress and the immune response to bacteria and oxidizes threonine into acrolein. Lastly, polyamines can also be catabolized into acrolein ${ }^{48}$. These polyamines are essential to the cell as they influence a range of processes from RNA and DNA structure to enzyme activity. ${ }^{49}$ Additionally, one KEGG pathway was found where acrolein is formed as a breakdown product of anti-cancer drugs. A few patients in this study received cyclophosphamide, however the percentage of these patients did not differ between $\operatorname{VAP}(+)$ and $\operatorname{VAP}(-)$ group. It is therefore likely that the different abundance in acrolein originates from one of the described endogenous pathways.

Five of the 12 VOCs identified by the model can be classified as (branched) alkanes: heptane, 2-methylbutane, dodecane, tetradecane and tetradecanal. Two primary processes could account for the presence of alkanes in exhaled breath. First, lipid peroxidation as a result of oxidative stress is able to produce hydrocarbons. Heptane is thought to originate from oleic acid, and 2-methylbutane may originate from 2-methyl1,3-butadiene (also known as isoprene). Second, alkanes are also present in the environment and are inhaled on a daily basis. After ingestion, the compounds are broken down in the liver by cytochrome P450 enzymes (CYP). The activity of these enzymes decreases with aging, but also with disease, implicating reduced CYP activity in severely ill patients. ${ }^{50}$ Both mechanisms could explain the different abundances found between $\operatorname{VAP}(+)$ and $\operatorname{VAP}(-)$. Ethylbenzene is an benzene derivative and an indoor pollutant. ${ }^{51}$ Benzene and its derivatives are also broken down in the liver by CYP enzymes, which may not function properly in critically ill patients, resulting in different exhaled abundances of ethylbenzene in $\operatorname{VAP}(+)$ vs. VAP(-) patients. ${ }^{52}$ The two remaining compounds, tetrahydrofuran and carane, are also environmental pollutants and have no known endogenous source. Both compounds are likely metabolized by CYP enzymes in the liver, but no literature was found that supports this theory. 
A limitation of the present study is the relatively small number of subjects. We were unable to test for specific strains of bacteria. As VAP is generally caused by an array of bacteria, we only had a few patients per bacterial strain available at most, hindering the use of multivariate statistics to identify strain-specific VOCs in vivo.

Although the quantitative culture analysis of BAL is accepted as state-of-the art in the diagnosis of $\mathrm{VAP}^{53}$, the sensitivity and specificity were variable among earlier histopathology studies with percentages of $42-93 \%$ and $45-100 \%$, respectively. ${ }^{54-56}$ This could have led to misdiagnosing several patients which could have possibly influenced the findings of the current study. However, the use of RF as multivariate technique reduces the influence of mislabelled samples on the outcome.

\section{Conclusion}

The present study has demonstrated that it is possible to distinguish ICU patients with VAP from patients without VAP based on a profile of only 12 VOCs. Exhaled breath analysis is a promising, simple, safe and non-invasive technique for the rapid diagnosis of VAP. A larger study population is warranted to confirm our findings. Additionally, studies should be performed where strain-specific VOC profiles can be found. 


\section{Supplementary information}

Table S6.1 Statistical significance of confounding factors tested by rMANOVA. The presence of one or more comorbidities was tested as well as the presence of specific comorbidities. None of the potential confounding factors were significantly associated with the VOC profile.

\begin{tabular}{ll}
\hline Confounder & p-value \\
\hline Age & 0.5400 \\
Gender & 0.3750 \\
SOFA score & 0.1970 \\
ICU mortality & 0.2160 \\
In hospital mortality & 0.3030 \\
Diagnostic group upon admission & 0.2370 \\
Severe sepsis & 0.2070 \\
Comorbidities (present yes/no) & 0.1790 \\
$-\quad$ Respiratory & 0.4090 \\
$-\quad$ Chronic renal failure & 0.9460 \\
$-\quad$ Cardiovascular & 0.1590 \\
$-\quad$ Active malignancy & 0.4200 \\
$-\quad$ Immunocompromised & 0.7040 \\
$-\quad$ Chronic liver failure & 0.2320 \\
$-\quad$ Neurological impairment & 0.3020 \\
\hline
\end{tabular}




\section{References}

1. Ego A, Preiser JC, Vincent JL. Impact of diagnostic criteria on the incidence of ventilator-associated pneumonia. Chest 2015;147:347-55.

2. Melsen et al. Attributable mortality of ventilator-associated pneumonia: a meta-analysis of individual patient data from randomised prevention studies. Lancet Infect Dis 2013;13:665-71.

3. Fagon et al. Invasive and noninvasive strategies for management of suspected ventilator-associated pneumonia. A randomized trial. Ann Internal Med 2000;132:621-30.

4. Bush K, et al. Tackling antibiotic resistance. Nat Rev Microbiol 2011;9:894-96.

5. Miekisch W, Schubert JK, Noeldge-Schomburg GF. Diagnostic potential of breath analysis--focus on volatile organic compounds. Clin Chim Acta 2004;347:25-39.

6. Boots AW, et al. The versatile use of exhaled volatile organic compounds in human health and disease. J. Breath Res 2012;6:027108.

7. Bos LD, Sterk PJ, Schultz MJ. Volatile metabolites of pathogens: a systematic review. PLoS Pathog 2013;9:e1003311.

8. Van Berkel JJ, et al. A profile of volatile organic compounds in breath discriminates COPD patients from controls. Respir Med 2010;104:557-63.

9. Dallinga JW, et al. Volatile organic compounds in exhaled breath as a diagnostic tool for asthma in children. Clin Exp Allergy 2010;40:68-76.

10. Robroeks $\mathrm{CM}$, et al. Exhaled volatile organic compounds predict exacerbations of childhood asthma in a 1-year prospective study. Eur Respir J 2013;42:98-106.

11. Kolk AH, et al. Breath analysis as a potential diagnostic tool for tuberculosis. Int I Tuberc Lung Dis 2012;16:777-82.

12. Robroeks CM, et al. Metabolomics of volatile organic compounds in cystic fibrosis patients and controls. Pediatr Res 2010;68:75-80.

13. Smolinska A, et al. Profiling of volatile organic compounds in exhaled breath as a strategy to find early predictive signatures of asthma in children. PloS One 2014;9:e95668.

14. Boots AW, et al. Identification of microorganisms based on headspace analysis of volatile organic compounds by gas chromatography-mass spectrometry. J. Breath Res 2014;8: 027106.

15. Filipiak W, et al. Characterization of volatile metabolites taken up by or released from Streptococcus pneumoniae and Haemophilus influenzae by using GC-MS. Microbiology 2012;158:3044-53.

16. Fowler SJ, Basanta-Sanchez M, Xu Y, Goodacre R, Dark PM. Surveillance for lower airway pathogens in mechanically ventilated patients by metabolomic analysis of exhaled breath: a case-control study. Thorax 2015;70:320-5.

17. Central Committee on Research Involving Human Subjects (CCMO). Available at: http://www.ccmo.nl/en/help-me-on-my-way (Accessed: 4th September 2015)

18. De Brauwer, E.I., Jacobs, J.A., Nieman, F., Bruggeman, C.A. \& Drent, M. Bronchoalveolar lavage fluid differential cell count. How many cells should be counted? Anal Quant Cytol Histol 2002;24:337-41.

19. Linssen, C.F., Bekers, O., Drent, M. \& Jacobs, J.A. C-reactive protein and procalcitonin concentrations in bronchoalveolar lavage fluid as a predictor of ventilator-associated pneumonia. Ann Clin Biochem 2008;45:293-8.

20. Linssen, C.F. et al. Influence of antibiotic therapy on the cytological diagnosis of ventilator-associated pneumonia. Intensive Care Med 2008;34:865-72.

21. Smolinska A, et al. Current breathomics--a review on data pre-processing techniques and machine learning in metabolomics breath analysis. J. Breath Res 2014;8:027105.

22. Breiman L. Random Forest. Machine Learning 2001;45:5-32.

23. Hanley JA, McNeil BJ. The meaning and use of the area under a receiver operating characteristic (ROC) curve. Radiology 1982;143:29-36.

24. Engel J, et al. Regularized MANOVA (rMANOVA) in Untargeted Metabolomics. Anal Chim Acta 2015;899:1-12.

25. Hastings J, et al. The ChEBI reference database and ontology for biologically relevant chemistry: enhancements for 2013. Nucleic Acids Res 2013;41:D456-463. 
26. Pence HE, Williams A. ChemSpider: An Online Chemical Information Resource. J.Chem Educ 2010;87: 1123-4.

27. Bolton E, Wang Y, Thiessen PA, Bryant SH. Integrated Platform of Small Molecules and Biological Activities. Ann Rep Comput Chemistry 2008;4:217-41.

28. van lersel MP, et al. The BridgeDb framework: standardized access to gene, protein and metabolite identifier mapping services. BMC Bioinformatics 2010;11:5.

29. Willighagen EL. Accessing biological data in $\mathrm{R}$ with semantic web technologies. PeerJ PrePrints. doi:10.7287/peerj.preprints.185v3 (2014).

30. Kelder T, et al. WikiPathways: building research communities on biological pathways. Nucleic Acids Res 2012;40:D1301-1307.

31. Kanehisa $\mathrm{M}$, et al. Data, information, knowledge and principle: back to metabolism in KEGG. Nucleic Acids Res 2014;42:D199-205.

32. Scholte JB, et al. Endotracheal aspirate and bronchoalveolar lavage analysis: interchangeable diagnostic modalities in suspected ventilator-associated pneumonia? J. Clin Microbiol 2014;52:3597-604.

33. Meduri GU, et al. Causes of fever and pulmonary densities in patients with clinical manifestations of ventilator-associated pneumonia. Chest 1994;106:221-35.

34. Sakr Y, et al. The influence of gender on the epidemiology of and outcome from severe sepsis. Crit Care 2013;17:R50.

35. Sharpe JP, et al. Gender disparity in ventilator-associated pneumonia following trauma: identifying risk factors for mortality. J. Trauma Acute Care Surg 2014;77:161-5.

36. Safdar N, Dezfulian C, Collard HR, Saint S. Clinical and economic consequences of ventilator-associated pneumonia: a systematic review. Crit Care Med 2005;33:2184-93.

37. Hockstein NG, et al. Diagnosis of pneumonia with an electronic nose: correlation of vapor signature with chest computed tomography scan findings. Laryngoscope 2004;114:1701-5.

38. Hanson CW, Thaler ER. Electronic nose prediction of a clinical pneumonia score: biosensors and microbes. Anesthesiology 2005;102:63-8.

39. Zilberberg MD, Shorr AF. Ventilator-associated pneumonia: the clinical pulmonary infection score as a surrogate for diagnostics and outcome. Clin Infect Dis 2010;51:131-5.

40. Bos LD, et al. The volatile metabolic fingerprint of ventilator-associated pneumonia. Intensive Care Med 2014;40:761-2.

41. Wilson AD, Baietto M. Applications and advances in electronic-nose technologies. Sensors 2009;9: 5099-148.

42. Bos LD, et al. Exhaled breath metabolomics as a noninvasive diagnostic tool for acute respiratory distress syndrome. Eur Respir J 2014;44:188-97.

43. Park DR. The microbiology of ventilator-associated pneumonia. Respir Care 2005;50:742-63.

44. Zhu J, Bean HD, Wargo MJ, Leclair LW, Hill JE. Detecting bacterial lung infections: in vivo evaluation of in vitro volatile fingerprints. J. Breath Res 2013;7:016003.

45. Schnabel RM, Scholte JB, Van Der Velden KE, Roekaerts PM, Bergmans DC. Ventilator-associated pneumonia rates after introducing selective digestive tract decontamination. Infec Dis 2015;47:650-3.

46. Lee K, Rincon F. Pulmonary complications in patients with severe brain injury. Crit Care Res Pract. 2012;2012:207247.

47. Vary TC, Siegel JH, Nakatani T, Sato T, Aoyama H. A biochemical basis for depressed ketogenesis in sepsis. J. Trauma 1986;26:419-25.

48. Stevens JF, Maier CS. Acrolein: sources, metabolism, and biomolecular interactions relevant to human health and disease. Mol Nutr Food Res 2008;52;7-25.

49. Pegg AE. Mammalian polyamine metabolism and function. IUBMB Life 2009;61:880-94.

50. Kwak J, Preti G. Volatile disease biomarkers in breath: a critique. Curr Pharm Biotechnol 2011;12: 1067-74.

51. Midorikawa K, et al. Metabolic activation of carcinogenic ethylbenzene leads to oxidative DNA damage. Chemi Biol Interact 2004;150:271-81.

52. Sams C, Loizou GD, Cocker J, Lennard MS. Metabolism of ethylbenzene by human liver microsomes and recombinant human cytochrome P450s (CYP). Toxicol Lett 2004;147:253-60.

53. Fagon JY. Diagnosis and treatment of ventilator-associated pneumonia: fiberoptic bronchoscopy with bronchoalveolar lavage is essential. Semin Respir Crit Care Med 2006;27:34-44. 
54. Torres A, El-Ebiary M. Bronchoscopic BAL in the diagnosis of ventilator-associated pneumonia. Chest 2000;117:198S-202S.

55. Chastre J, et al. Evaluation of bronchoscopic techniques for the diagnosis of nosocomial pneumonia. Am J Respir Crit CareMed 1995;152:231-40.

56. Marquette $\mathrm{CH}$, et al. Diagnostic tests for pneumonia in ventilated patients: prospective evaluation of diagnostic accuracy using histology as a diagnostic gold standard. Am J Respir Crit Care Med 1995;151:1878-88. 


\section{Chapter 7}

Electronic nose analysis of exhaled breath to diagnose ventilator-associated pneumonia

R Schnabel, M Boumans, A Smolinska, E Stobberingh, R Kaufmann, P Roekaerts,

D Bergmans

Respir Med 2015;109:1454-9. 


\begin{abstract}
Background

Exhaled breath analysis is an emerging technology in respiratory disease and infection. Electronic nose devices (e-nose) are small and portable with a potential for point of care application. Ventilator-associated pneumonia (VAP) is a common nosocomial infection occurring in the intensive care unit (ICU). The current best diagnostic approach is based on clinical criteria combined with bronchoalveolar lavage (BAL) and subsequent bacterial culture analysis. BAL is invasive, laborious and time consuming. Exhaled breath analysis by e-nose is non-invasive, easy to perform and could reduce diagnostic time. Aim of this study was to explore whether an e-nose can be used as a non-invasive in vivo diagnostic tool for VAP.
\end{abstract}

\title{
Methods
}

Seventy-two patients met the clinical diagnostic criteria of VAP and underwent BAL. In thirty-three patients BAL analysis confirmed the diagnosis of VAP $[B A L+(V A P+)]$, in thirty-nine patients the diagnosis was rejected [BAL-]. Before BAL was performed, exhaled breath was sampled from the expiratory limb of the ventilator into sterile Tedlar bags and subsequently analysed by an e-nose with metal oxide sensors (DiagNose, C-it, Zutphen, The Netherlands). From further fifty-three patients without clinical suspicion of VAP or signs of respiratory disease exhaled breath was collected to serve as a control group [control(VAP-]). The e-nose data from exhaled breath were analysed using logistic regression.

\section{Results}

The ROC curve comparing [BAL+(VAP+)] and [control(VAP-)] patients had an area under the curve (AUC) of 0.82 ( $95 \% \mathrm{Cl} 0.73-0.9)$. The sensitivity was $88 \%$ with a specificity of $66 \%$. The comparison of [BAL+(VAP+)] and [BAL-] patients revealed an AUC of $0.69 ; 95 \%$ Cl $0.57-0.81$ ) with a sensitivity of $76 \%$ with a specificity of $56 \%$.

\section{Conclusion}

E-nose lacked sensitivity and specificity in the diagnosis of VAP in the present study for current clinical application. Further investigation into this field is warranted to explore the diagnostic possibilities of this promising new technique. 


\section{Introduction}

Ventilator-associated pneumonia (VAP) is a common nosocomial infection occurring in ventilator-assisted patients in the intensive care unit (ICU). To date, the diagnosis is based on clinical criteria combined with bacterial culture results. Bronchoalveolar lavage (BAL) from the site of the presumed infection and subsequent cytological and microbiological analysis of the lavage fluid is regarded the state of the art diagnostic approach. However, this technique is invasive and the potential for desaturations during the procedure limits its use in patients with severe pulmonary disease and high respiratory support settings. Analysis of BAL is laborious and time-consuming. It takes up to 48 hours before final results are available. Only then the diagnosis of VAP can be confirmed or rejected. Therefore, there is need for an equally reliable and accurate diagnostic tool as BAL, that is less invasive and delivers results without delay.

Electronic nose technology (e-nose) is an established method that detects patterns of volatile organic compounds (VOCs) in breath. It has been applied for various industrial purposes like environmental monitoring, pesticide detection and aroma detection. ${ }^{1}$ In the field of medicine, studies have demonstrated that e-nose technology can be used to identify patients with colorectal cancer $^{2}$, head and neck cancer ${ }^{3}$, tuberculosis ${ }^{4}$, cystic fibrosis $^{5}$, chronic obstructive lung disease and asthma. ${ }^{6}$ It has been suggested that enose could be used to diagnose patients suffering from pneumonia. ${ }^{7}$ In vitro studies have demonstrated that e-nose sensors are able to discriminate between potential pathogens by analyzing the air above bacterial culture medium. ${ }^{8}$ Comparison of the predictive value of e-nose to the clinical pulmonary infection score (CPIS) found e-nose capable of distinguishing between infected and uninfected state. ${ }^{9}$ Furthermore, the prognostic value of e-nose in the prediction of VAP was compared with chest computer tomography (CT) with $80 \%$ accuracy predicting the results of chest CT scans. ${ }^{10}$ To the best of our knowledge it has never been investigated, whether e-nose technology is able to identify patients with VAP when measuring directly in exhaled breath samples. But only if this would be possible, eliminating preliminary invasive sampling and the need for culturing sample material, e-nose could be a truly non-invasive, easily operated, fast diagnostic tool at bedside. Aim of this investigation is therefore to study whether e-nose can be used for non-invasive in vivo diagnosis of VAP. It was hypothesised that with a sample size of 100 patients under the assumption that the sensitivity is $95 \%$, this enables us to ensure that the lower limit of the $95 \%$ confidence interval exceeded $85 \%$ for the detection of VAP. A rapid, non-invasive detection of patients who develop pneumonia by e-nose could then potentially speed up adequate and timely antibiotic treatment. 


\section{Materials and methods}

The prospective study was conducted at the Maastricht University Medical Centre+, a tertiary-care, university hospital in the Netherlands with 1700 ICU admissions per year. The inclusion period was between 2009 and 2011. Adult patients ( $\geq 18$ years) admitted to the ICU were included. The exhaled breath study was evaluated by the institutional medical ethics commission. Informed consent was waived, as no direct patient intervention was required and results of the analyses did not influence therapy.

A patient was clinically suspected of VAP after $\geq 48$ hours of mechanical ventilation according to the criteria depicted in [Table 7.1]. Patients were screened daily for VAP using these clinical criteria. BAL was performed on the day of clinical suspicion for VAP.

Table 7.1 Diagnostic clinical criteria of VAP

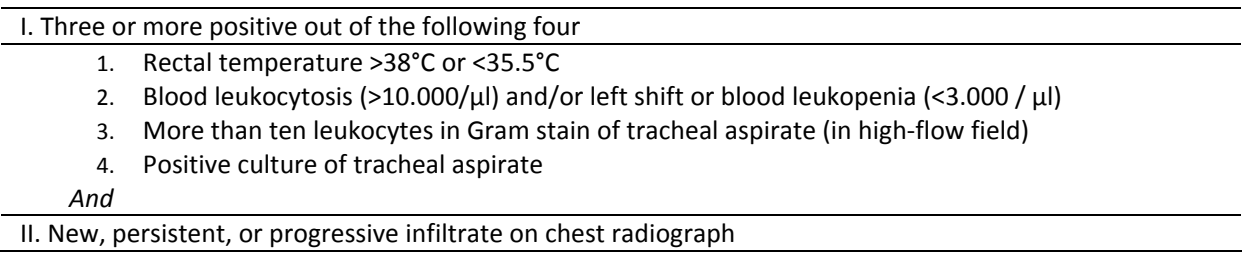

A fibreoptic bronchoscope (Pentax FB-15H/FB-15X, Pentax Medicals, Tokyo, Japan) was introduced and 'wedged' into the affected segmental or subsegmental bronchus. Sterile saline $(0.9 \%$ sodium chloride at room temperature) was instilled in four aliquots of $50 \mathrm{ml}$, immediately aspirated and recovered. Samples were directly transported towards the microbiological laboratory and were further processed. Information about the quality of BAL sampling was collected. The BAL fluid was regarded nonrepresentative if the volume of recovery was $<20 \mathrm{ml}$, the total cell count was $<60.000 / \mathrm{ml}$, the presence of squamous epithelial cells was $>1 \%$, the presence of bronchial epithelial cells was $>5 \%$ or in the presence of extensive amounts of debris and damaged cells. A clinically suspected VAP episode was considered microbiologically confirmed when the following criteria were met in BAL fluid: presence of $\geq 2 \%$ cells containing intracellular organisms (ICO) and/ or quantitative culture results of $\geq 10^{4}$ colony forming units (cfu) per millilitre of BAL fluid. ${ }^{11,12}$ Before BAL was conducted, exhaled breath samples were collected into a sterile Tedlar bag from the expiratory limb of the Draeger ${ }^{\circledR}$ Evita XL ventilator for subsequent e-nose analysis. The study patients were distributed into three groups. The first group comprises patients with clinical suspicion of VAP confirmed by BAL results [BAL+(VAP+)]. The second group were patients with clinical suspicion of VAP rejected by BAL results [BAL-]. Only patients without any bacterial growth in BAL fluid were selected. Four individuals were represented twice. A third group was formed by mechanically ventilated patients 
without clinical suspicion of VAP or signs of respiratory disease [control (VAP-)]. The inclusion of patients for the study is outlined in Figure 7.1.

135 eligible patients clinical suspicious for VAP and BAL achieved

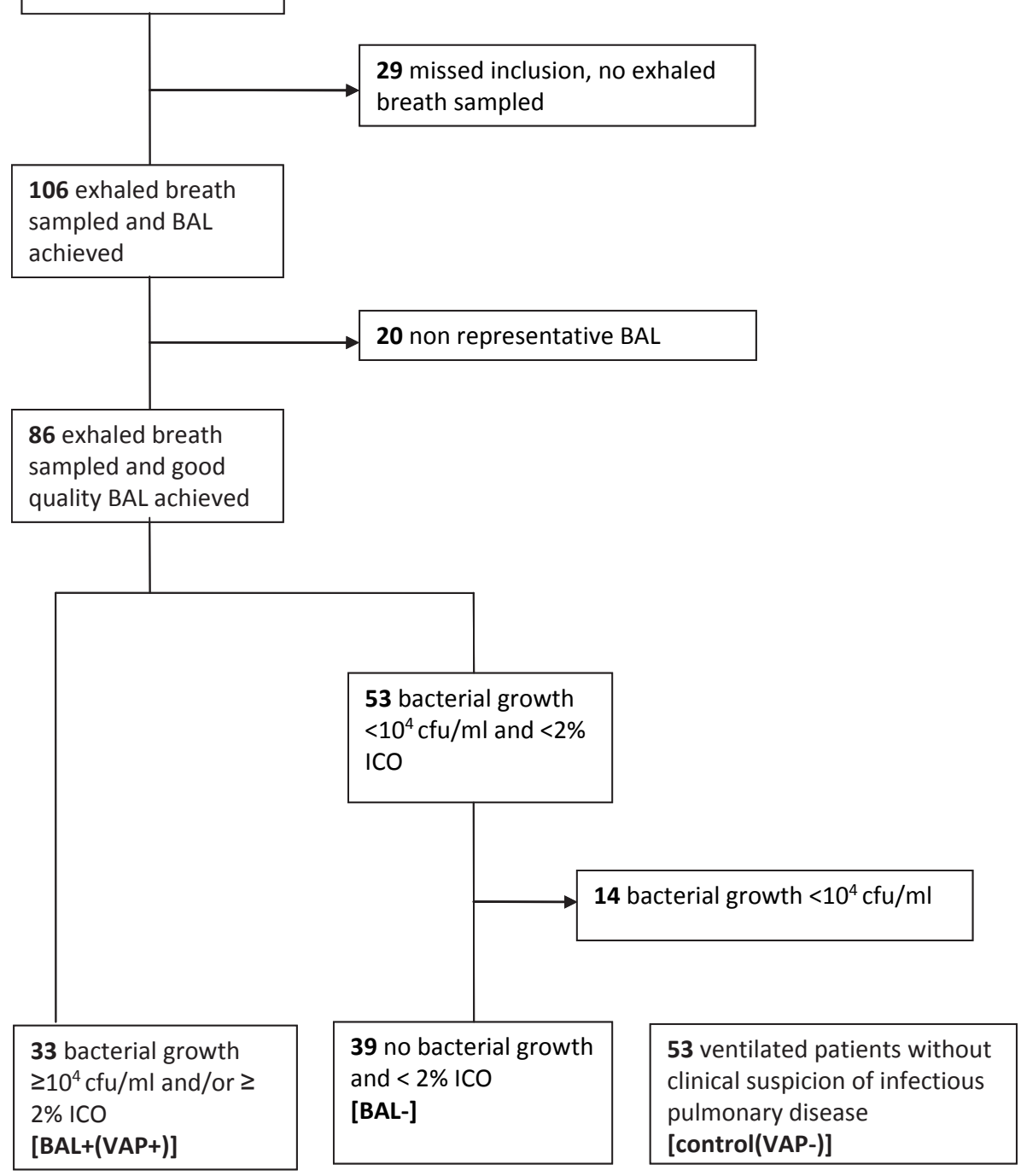

Figure 7.1 Patient inclusion 
Demographic data, clinical data and the sequential organ failure assessment score (SOFA) as a measurement of the seriousness of illness at the moment of exhaled breath collection were all registered in a data base. Breath samples were analysed using an enose (DiagNose ${ }^{\circledR}, \mathrm{C}$-it, Zutphen, The Netherlands). [Figure 7.2]
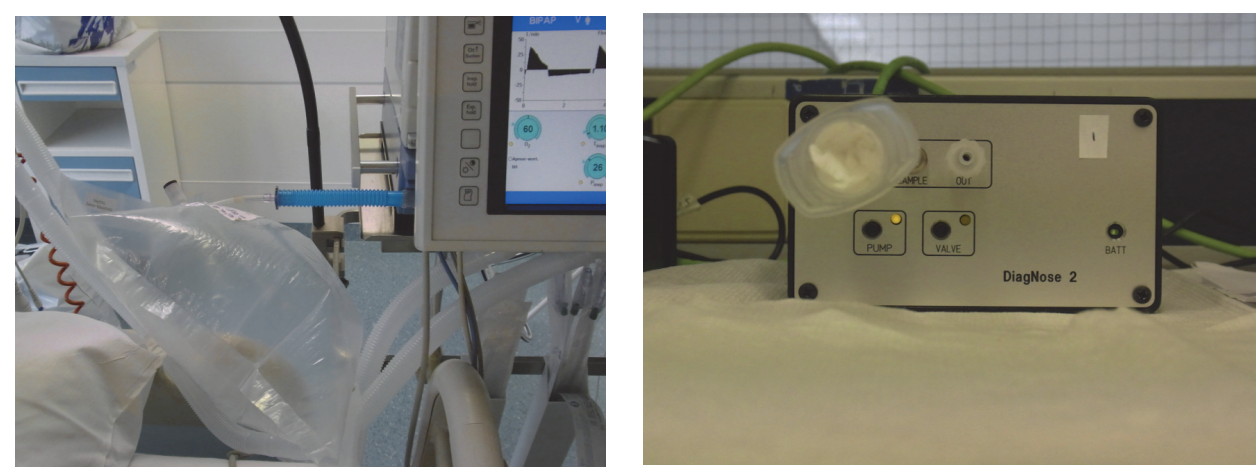

Figure 7.2 Collecting exhaled breath at the Draeger ${ }^{\circledR}$ Evita XL ventilator in a Tedlar bag (left part). The DiagNose ${ }^{\circledR}$ electronic nose (right part).

This device consists of three different hybrid metal oxide semiconductor sensor types: AS-MLN (NOx detection), AS-MLK (methane (alkane) detection) and AS-MLV (VOC detection). The DiagNose ${ }^{\circledR}$ is equipped with a pump, where the inlet is controlled by a solenoid switching between 2 different inlets, to create an active airflow across the sensors. One inlet is connected to a syringe filled with active carbon to provide a baseline almost free from environmental influence while the second inlet is attached to the sample bag. [Figure 7.2] The DiagNose ${ }^{\circledR}$ analyses the breath composition every 20 seconds using a 32-step sinusoidal modulation of the sensor surface temperature between $200^{\circ} \mathrm{C}$ and $320^{\circ} \mathrm{C}$, resulting in a vector of 32 values each 20 seconds for each sensor. In this range, the metal-oxide sensors behave as semiconductors. The redox reaction, taking place at the sensor surface, results in a measurable change of conductivity. These types of redox reactions are dependent on the nature of the metaloxide catalyst, the reacting gases, and the temperature. ${ }^{4} \mathrm{~A}$ single measurement lasts approximately 20 minutes composed of 5 minutes exposure and 15 minutes recovery, resulting in 3 matrices of $32 \times 23$ (temperature $x$ time). Due to the fact that the syringe containing charcoal was not able to filter all the environmental influences, an unexpected variance could have occurred in every measurement. To guarantee that only VOCs from the exhaled breath samples were used for further analysis only data from the plateau of the absorption time curve between 2.5 and 4.5 minutes from the start were included. [Figure 7.3a] Data processing: 1. data were min-max normalized within the vector of 32 values of the heat modulation. 2 . the mean value of the plateau 
of the time curve was computed and 3. the mean of the sensors of one sensor type was taken, resulting in $3 \times 32$ parameters for one sample. For statistical analysis the program IBM SPSS statistic 22 was used. Factor analysis grouped correlated parameters resulting in 5 uncorrelated factors to avoid the influence of multicollinearity in the analysis. The applied method was principal components with extraction criteria eigenvalues $>1$, rotation varimax, suppress small coefficients below 0.4 , save AndersonRubin factor scores. Two different analysis groups were used to create a prediction model, $[\mathrm{BAL}+(\mathrm{VAP}+)]$ versus [control(VAP-)] and [BAL+(VAP+)] versus [BAL-]. Factor scores saved for each different analysis group were used to predict a model by logistic regression analysis (method: forward Likelihood Ratio). The outcome of the logistic regression was used to construct a ROC-curve. The model was made with [BAL+(VAP+)] versus [control(VAP-)] and prediction values of [BAL-] were computed with this model. $A$ boxplot is made of these prediction values and significant difference between the groups were calculated with t-test for equality of means, equal variances not assumed. The multivariate statistical analysis method Random Forest (RF) was used to search for linear as well as non-linear patterns in the data. ${ }^{13}$ This machine learning method constructs a multitude of de-correlated decision trees to classify samples into the appropriate disease state. Decision trees are predictive models that try to classify samples based on a specific subset of e-nose data. RF creates many decision trees (e.g. $1,000)$ comprising of a small and randomly selected subset of e-nose data and tries to predict the class outcome. The most discriminatory subset of e-nose data is then used to create the final classification model. Validation of the RF model was done by calculating the "out-of-bag error". In this procedure $66.7 \%$ of the samples are randomly selected with replacement for each decision tree. The remaining $33.3 \%$ are used to calculate the performance of the RF classification model. This produces class probability values, which are used to calculate sensitivity and specificity illustrated by Receiver Operating Characteristic (ROC) curves. For the ROC analysis the $95 \%$ confidence interval was calculated. The ROC curve is a graphical representation of the performance of the predictive model established by RF. The area under the curve (AUC) is most commonly used as an indicator of predictive performance: a value close to 1 indicates high predictive power of the model, whereas an AUC close to 0.5 means that the model has no predictive power ${ }^{14}$. For visualization purposes, principal component analysis (PCA) score plots of the RF proximities were created. The proximities are distance parameters ranging from 0 to 1 that visualize similarities of the selected e-nose data profile between individual samples. A small proximity value indicates similarity, while a large proximity value indicates dissimilarity between individuals. A PCA plot of proximities can therefore demonstrate groupings of samples and trends in the data. 

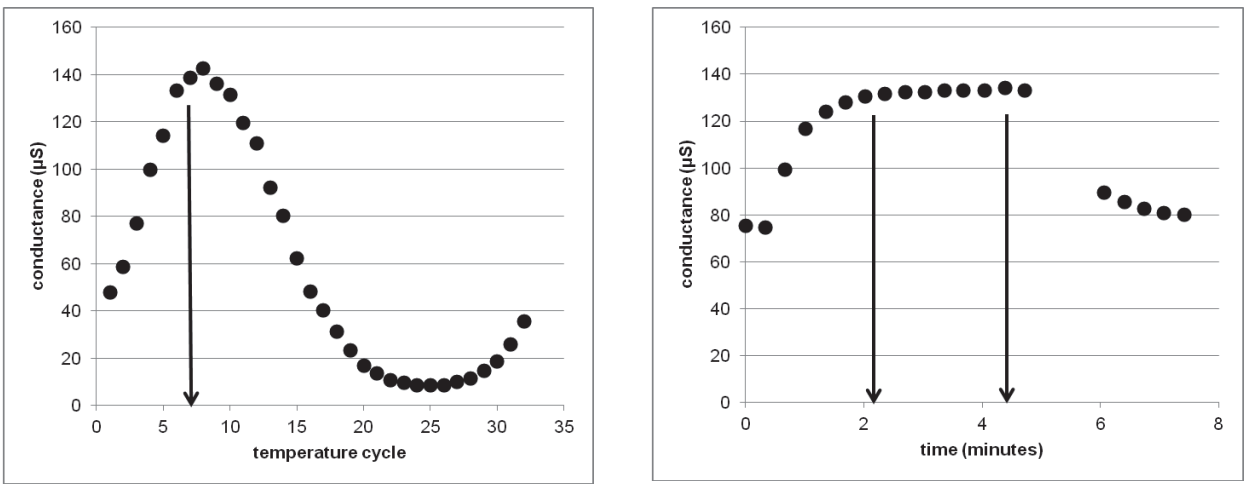

Figure 7.3 Exhaled breath analysis by e-nose: conductance response as function of the temperature of the sensor (above): Sensors are periodically heated between $200^{\circ} \mathrm{C}$ and $320^{\circ} \mathrm{C}$ in cycles of 20 seconds divided over 32 steps. Conductance-time response curve belonging to temperature value hatched by the arrow is shown below. Only data from the plateau of the absorption time curve between 2.5 and 4.5 minutes from the start are included in the analysis.

\section{Results}

Seventy-two patients who met the diagnostic clinical criteria for VAP [Table 7.1] subsequently underwent a BAL. In 33 patients the diagnosis of VAP could be confirmed based on the diagnostic criteria as described in the materials and methods section $[\mathrm{BAL}+(\mathrm{VAP}+)]$. Following bacteria were found causing VAP in the sequence of frequency: Pseudomonas aeruginosa (6), Staphylococcus aureus (5), Klebsiella spp. (5), Escherichia coli (3), Haemophilus influenzae (2), Acinetobacter baumannii (2), Stenothrophomonas maltophilia (2), Enterococcus faecium (1), Moraxella catarrhalis (1), Serratia marcescens (1), Proteus mirabilis (1), Streptococcus pneumoniae (1). Three patients had no significant bacterial growth in the BAL but a percentage above $2 \%$ ICOs in the differential cell count. In 39 patients the diagnosis of VAP was rejected by the results of BAL [BAL-]. Fifty-three patients without clinical suspicion for VAP or respiratory disease served as a control group [control(VAP-)]. The demographic data are reported in Table 7.2. More male patients suspicious for VAP finally had a positive BAL result. The diagnoses at admission covered a broad spectrum in all patient groups with differences in the numeric distribution. The SOFA score before BAL reflects a comparably seriousness of illness in all patient groups. The [control(VAP-)] group included significantly less patients with immunosuppression.

The comparison between [BAL+(VAP+)] versus [control(VAP-)] revealed an $A U C=0.82$; $95 \% \mathrm{Cl}=0.73-0.91$ and a sensitivity of $88 \%$ and specificity of $66 \%$. Analysis of $[\mathrm{BAL}+(\mathrm{VAP}+)]$ versus [BAL-] delivered an $\mathrm{AUC}=0.69 ; 95 \% \mathrm{Cl} 0.57-0.81)$ and a sensitivity 
of $76 \%$ and specificity of $56 \%$. [Figure 7.4] Random Forrest analysis confirmed these results. [online supplements] A box-plot provides an overview of the predicted probability, performed with analysis group 1, for having VAP ranging from $0=$ unlikely to 1=certainly for all examined patients. [Figure 7.5] A trend is seen of increasing probabilities from [control(VAP-)] to [BAL+(VAP+)]. However, the null hypothesis for the present study had to be rejected. In case of a clinically relevant sensitivity of $95 \%$ in the detection of VAP the corresponding specificity was only $38 \%$.

Table 7.2 Demographic data

\begin{tabular}{|c|c|c|c|c|c|}
\hline & $\begin{array}{c}\mathrm{BAL}+ \\
(\mathrm{VAP}+)\end{array}$ & BAL- & & $\begin{array}{c}\text { control (VAP- } \\
\text { ) }\end{array}$ & \\
\hline Number of samples & 33 & 39 & & 53 & \\
\hline Male / female & $26 / 7$ & $18 / 21$ & $p=0.004$ & $32 / 21$ & $p=0.7$ \\
\hline Average age & $62(20-82)$ & $57(23-82)$ & $p=0.21$ & $60(34-85)$ & $p=0.66$ \\
\hline Diagnostic group at admission & & & $\mathrm{p}=0.02$ & & $p=0.49$ \\
\hline 1. gastrointestinal & $3(10 \%)$ & $3(8 \%)$ & & $11(21 \%)$ & \\
\hline 2. cardiologic & $7(21 \%)$ & $5(13 \%)$ & & $11(21 \%)$ & \\
\hline 3. hematologic & $5(15 \%)$ & $10(26 \%)$ & & $5(9 \%)$ & \\
\hline 4. neurologic & $5(15 \%)$ & $2(5 \%)$ & & $8(15 \%)$ & \\
\hline 5. orthopaedic / trauma & $6(18 \%)$ & $0 \quad(0 \%)$ & & $9(17 \%)$ & \\
\hline 6. respiratory & $7(21 \%)$ & $17(43 \%)$ & & $6(11 \%)$ & \\
\hline 7. other & $0(0 \%)$ & $2(5 \%)$ & & $3(6 \%)$ & \\
\hline SOFA average (median) & $6.7(6)$ & $7.2(7)$ & $p=0.5$ & $5.2(5)$ & $p=0.03$ \\
\hline Active malignancy & $5(15 \%)$ & $11(28 \%)$ & $p=0.18$ & $11(21 \%)$ & $p=0.51$ \\
\hline Immunosuppression & $10(30 \%)$ & $10(26 \%)$ & $p=0.5$ & 5 (9\%) & $p=0.03$ \\
\hline
\end{tabular}

A

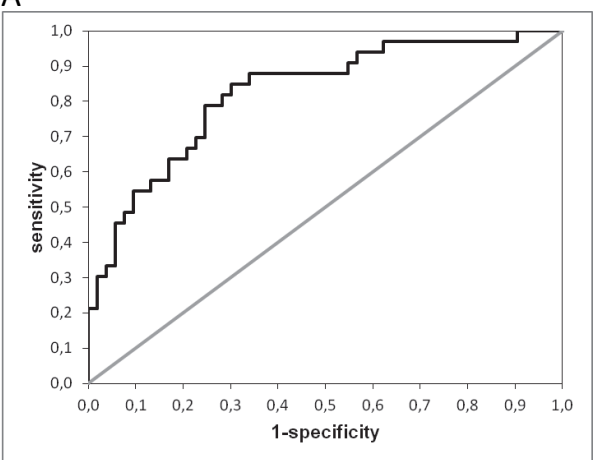

B

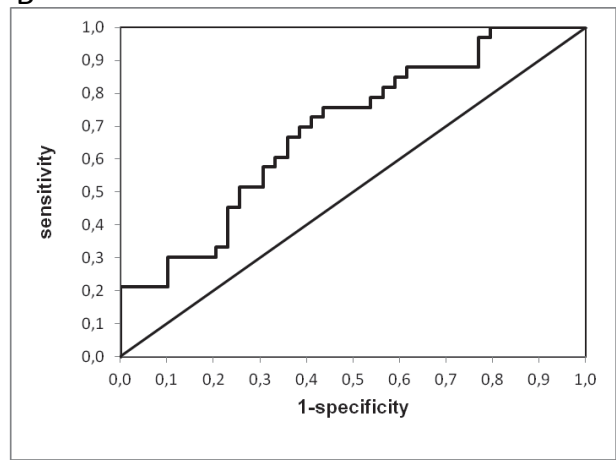

Figure 7.4 a: ROC curve of $B A L+(V A P+)$ versus Control (VAP-) (ROC-AUC=0.82; 95\% Cl=0.73-0.91). b: $R O C$ curve of $B A L+(V A P+)$ versus $B A L-(R O C-A U C=0.69 ; 95 \% C l=0.57-0.81)$ 


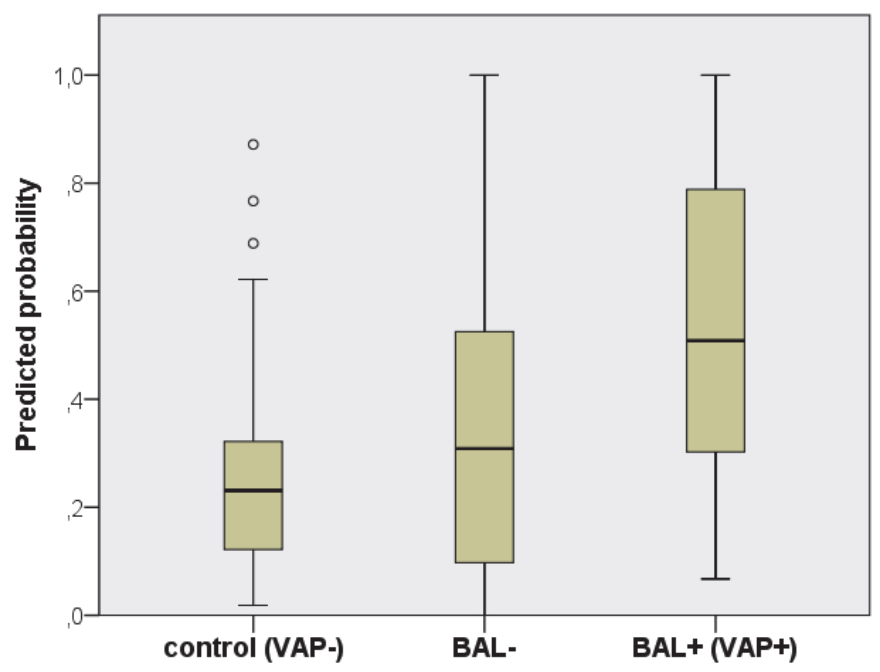

Figure 7.5 Predicted probability that a patient has VAP ranging from $0=$ unlikely to $1=$ certainly. E-nose cannot reliably predict patients with VAP. [Control (VAP-)]: patients without clinical suspicion of VAP. [BAL-]: patients with clinical suspicion of VAP, diagnosis rejected by BAL analysis. [BAL+(VAP+)]: patients with clinical suspicion of VAP confirmed by BAL analysis. [Control (VAP)$]$ versus $[B A L+(V A P+)] p<0.001 ;[B A L-]$ versus $[B A L+(V A P+)] p=0.001$; [Control (VAP-)] versus [BAL-] $p=0.23$. In an ideal model all predictions for [control(VAP-)] and [BAL-] patients should be close to 0 whereas all predictions in the $[\mathrm{BAL}+(\mathrm{VAP}+)]$ group should be close to 1 .

\section{Discussion}

In the present study, the applied e-nose sensors lacked the clinically required diagnostic specificity in the direct exhaled breath detection of patients with VAP. The capacity of e-nose in the prediction of VAP was tested compared to BAL as a reference and accepted clinical standard. ${ }^{15}$ Nevertheless, the sensitivity and specificity of BAL itself was variable among earlier histopathology studies with percentages of $42-93 \%$ and 45-100\%, respectively. ${ }^{16-18}$ This could have led to mislabelling of a few patients between the $[B A L+(V A P+)]$ and [BAL-] group of patients and possibly influence the findings of the study. However, e-nose was also unable to discriminate [BAL+(VAP+)] patients from a group of ventilated patients without any pulmonary infectious symptoms [control(VAP-)]. The demographics of the study population revealed a predominance of male patients who were BAL positive and therefore diagnosed with VAP. This might reflect known gender differences in the incidence of VAP ${ }^{19}$ but is not expected to be relevant for the outcome of the study.

It has been shown earlier that e-nose can discriminate certain bacteria when analysing the air above an in vitro bacterial culture medium. ${ }^{8}$ Two earlier studies suggested an applicability of e-nose in the diagnosis of VAP. ${ }^{9,10}$ However, these studies used as 
reference tool for the diagnosis of VAP the CPIS score and the chest CT, which are less well defined diagnostic tools as compared to BAL. Although there have been several reports on the sensing ability of e-nose for in vitro cultured bacteria, there are no studies concerning the applicability of detecting VAP directly in exhaled breath.

Why did the e-nose technology fail in the present study to identify directly from exhaled breath patients with VAP with a sufficient specificity? In mechanically ventilated patients on high ventilator settings, the collection of exhaled breath into the Tedlar bags results in admixture of death space ventilation. This results in a lower concentration of collected VOCs causing a weak signal. E-nose comprises different panels of hybrid metal-oxide semiconductor sensors. They analyze applied exhaled breath by creating a specific temperature-time-conductivity spectrum. Changes in this relation were expected due to a presumed change in the composition of VOCs caused by VAP in exhaled breath. Thereby changes in VOCs could be either caused by the presence of bacteria and their metabolites or by the hosts inflammatory response towards infection. The expected signal of a change in VOCs in the presence of VAP in vivo is very likely much less pronounced than in case of in vitro measurement of air above a bacterial culture medium.

E-nose does not detect the pathogenic agent directly because the technique is based on pattern recognition and depends on the composition of VOCs in exhaled breath. Therefore an adequate selection of the control group might be essential to avoid false positive interpretations of e-nose data in general. In the present study the control group patients without VAP were otherwise comparably ill with similar distribution of admission diagnoses to the ICU. In earlier e-nose studies a discriminating ability was found, but this could have been due to relevant differences between the diseased patients and the control groups. VOCs derived from the environment, diet or medication can interfere with exhaled breath tests. ${ }^{20}$ Thus, differences in social background and socioeconomic status could have influenced the results between patients diagnosed with tuberculosis by e-nose and healthy controls. ${ }^{4}$ In the study detecting colorectal carcinoma by e-nose, a 31-year difference in age between the patient and the control group could have been of influence. ${ }^{2}$ Age related differences or associated divergent common diets could cause differences in the VOC composition of faecal gas. The importance of a smoking history might explain why in an earlier study by Fens and colleagues, e-nose could discriminate between patients with asthma and patients with COPD but not between COPD (among them 90\% smokers) and healthy smokers. ${ }^{6}$

Limitations of the present study are the number of patients distributed over multiple diagnostic groups at admission. Although this reflected a typical heterogeneous ICU population it could have created a background noise of various factors associated with critical illness itself that made it difficult for e-nose to differentiate between possible minor differences due to the presence of VAP. Subgroup analysis in one single 
diagnostic group was not feasible due to the small sample size. For the same reason there was no bacterial strain specific analysis possible.

In the present study, direct e-nose analysis of exhaled breath was unable to identify patients with VAP with a sufficient specificity. There is no current clinical application, as a diagnostic test for VAP requires a high sensitivity to identify all patients with VAP and a high specificity to guarantee that only patients with a true bacterial infection are treated with antibiotics. This kind of tailored antibiotic treatment becomes increasingly important with the rapid emergence and dissemination of multi-drug resistant microorganisms particularly in the ICU environment worldwide. ${ }^{21}$ However, as the e-nose technique in itself has many practical and clinical advantages, further meticulous and repeated validation for all its potential diagnostic purposes is definitely warranted. After all, single diagnostic tests often lack sensitivity and specificity. Combining different tests and probability scores could thereby provide an improvement in the diagnostic accuracy. In the present study the number of patients and the effect size were too small for further analysis in this direction. The development of e-nose for non-invasive diagnostics in respiratory medicine could benefit from gas chromatography - mass spectrometry studies in exhaled breath. When sets of VOCs serving as biomarkers of certain diseases or of the presence of microorganisms can be identified, this knowledge could be applied to specify e-nose sensors and increase their sensitivity and specificity. This requires further study. ${ }^{20}$ 


\section{Supplemental information}

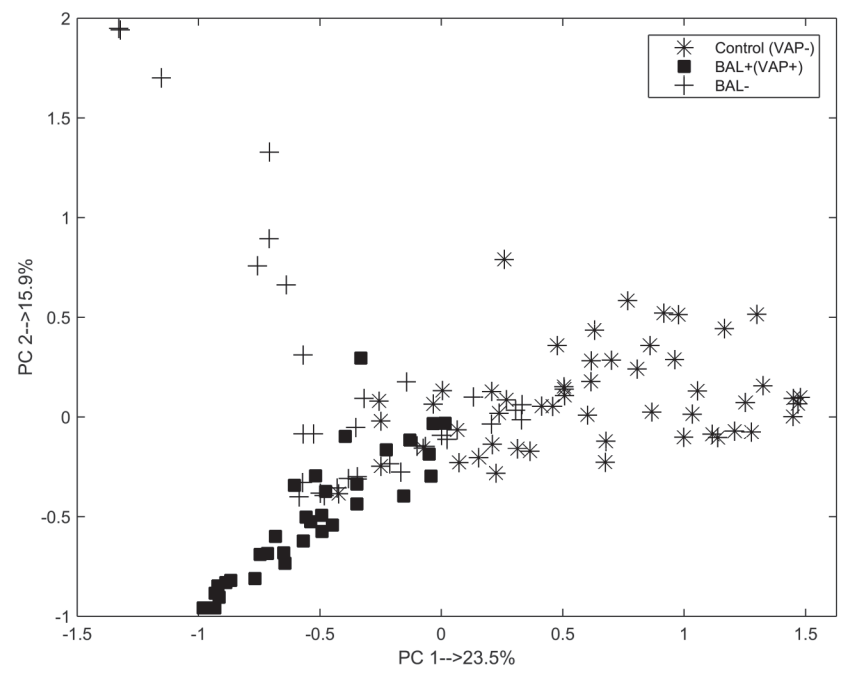

PCA plot performed on proximity matrix obtained from RF models

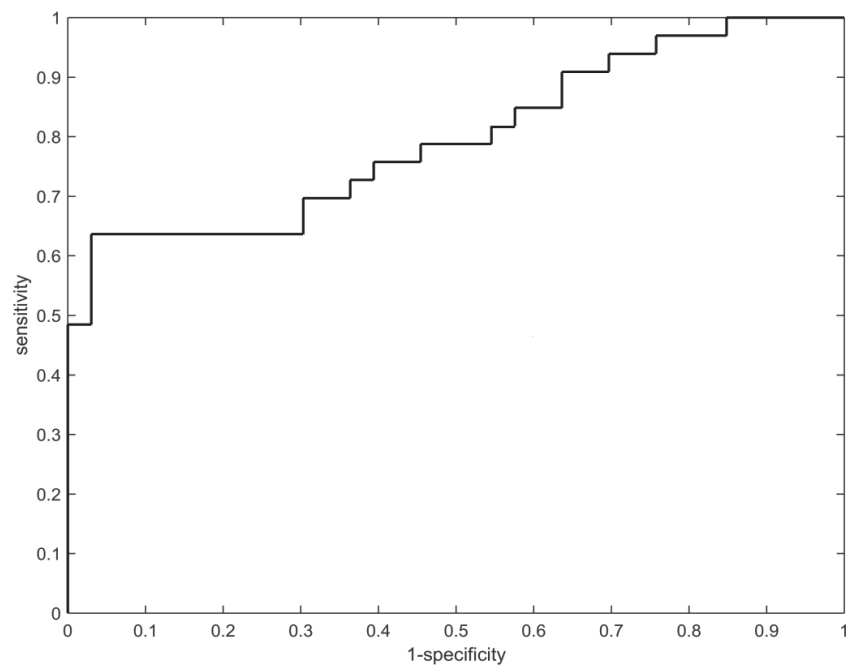

BAL+(VAP+)] versus [BAL-]: ROC-AUC $=0.78 ; 95 \% \mathrm{Cl}=0.68-0.89$; sensitivity: 0.69 , specificity: 0.71 
Chapter 7

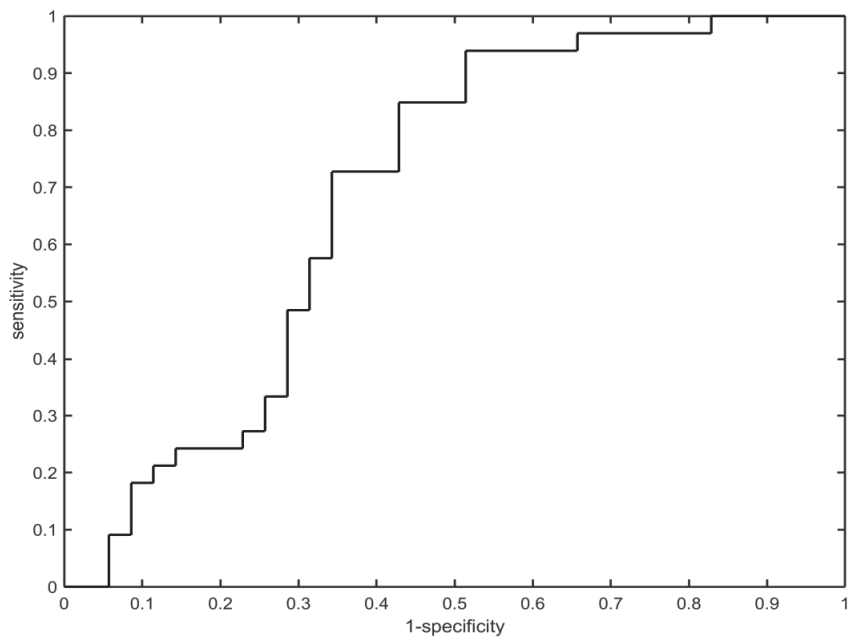

[BAL+(VAP+)] versus [control(VAP-)]: ROC-AUC $=0.70 ; 95 \% \mathrm{Cl}=0.60-0.81$; sensitivity: 0.72 , specificity: 0.66 


\section{References}

1. Wilson AD. Diverse applications of electronic-nose technologies in agriculture and forestry. Sensors 2013;13:2295-348.

2. de Meij TG, et al. Electronic nose can discriminate colorectal carcinoma and advanced adenomas by fecal volatile biomarker analysis: proof of principle study. International journal of cancer. Journal international du cancer 2014;134:1132-8.

3. Leunis $\mathrm{N}$, et al. Application of an electronic nose in the diagnosis of head and neck cancer. The Laryngoscope 2014;124:1377-81..

4. Bruins M, et al. Diagnosis of active tuberculosis by e-nose analysis of exhaled air. Tuberculosis 2013;93: 232-8.

5. Paff $\mathrm{T}$, et al. Exhaled molecular profiles in the assessment of cystic fibrosis and primary ciliary dyskinesia. Journal of cystic fibrosis 2013;12:454-60.

6. Fens $\mathrm{N}$, et al. Exhaled breath profiling enables discrimination of chronic obstructive pulmonary disease and asthma. American journal of respiratory and critical care medicine 2009;180:1076-82.

7. Montuschi P, Mores N, Trove A, Mondino C, Barnes PJ. The electronic nose in respiratory medicine. Respiration; international review of thoracic diseases 2013;85:72-84.

8. Humphreys $L$, et al. Electronic nose analysis of bronchoalveolar lavage fluid. European journal of clinical investigation 2011;41:52-8.

9. Hanson CW 3rd, Thaler ER. Electronic nose prediction of a clinical pneumonia score: biosensors and microbes. Anesthesiology 2005;102:63-8.

10. Hockstein NG, et al. Diagnosis of pneumonia with an electronic nose: correlation of vapor signature with chest computed tomography scan findings. The Laryngoscope 2004;114:1701-5.

11. Linssen CF, Bekers $O$, Drent M, Jacobs JA. C-reactive protein and procalcitonin concentrations in bronchoalveolar lavage fluid as a predictor of ventilator-associated pneumonia. Annals of clinical biochemistry 2008;45:293-8.

12. Linssen $\mathrm{CF}$, et al. Influence of antibiotic therapy on the cytological diagnosis of ventilator-associated pneumonia. Intensive care medicine 2008;34:865-72.

13. Breiman L. Random Forest. Machine Learning 2001;5-32.

14. Hanley JA, McNeil BJ. The meaning and use of the area under a receiver operating characteristic (ROC) curve. Radiology 1982;143:29-36.

15. Fagon JY. Diagnosis and treatment of ventilator-associated pneumonia: fiberoptic bronchoscopy with bronchoalveolar lavage is essential. Seminars in respiratory and critical care medicine 2006;27:34-44.

16. Torres A, El-Ebiary M. Bronchoscopic BAL in the diagnosis of ventilator-associated pneumonia. Chest 2000;117:198S-202S.

17. Chastre J, et al. Evaluation of bronchoscopic techniques for the diagnosis of nosocomial pneumonia. American journal of respiratory and critical care medicine 1995;152:231-40.

18. Marquette $\mathrm{CH}$, et al. Diagnostic tests for pneumonia in ventilated patients: prospective evaluation of diagnostic accuracy using histology as a diagnostic gold standard. American journal of respiratory and critical care medicine 1995;151:1878-88.

19. Sharpe JP, et al. Gender disparity in ventilator-associated pneumonia following trauma: identifying risk factors for mortality. The journal of trauma and acute care surgery 2014;77:161-5.

20. Bos LD, Sterk PJ, Schultz MJ. Volatile metabolites of pathogens: a systematic review. PLoS pathogens 2013;9:e1003311.

21. Laxminarayan $\mathrm{R}$, et al. Antibiotic resistance-the need for global solutions. The Lancet infectious diseases 2013;13:1057-98. 



\section{Chapter 8}

General discussion and summary 



\section{General discussion and summary}

The present thesis describes the search for new diagnostic modalities and techniques in ventilator-associated pneumonia (VAP), a common nosocomial infection in intensive care patients. All studies were conducted in a university hospital intensive care unit in the Netherlands. The diagnostic standard for VAP following clinical suspicion has been bronchoalveolar lavage (BAL) and subsequently microbiological culture with quantitative analysis for more than a decade. Hence a substantial database of BAL fluid analyses was available. Combined with clinical data this allowed further investigation of the diagnostic process of VAP.

\section{Alternative diagnoses in the putative ventilator-associated pneumonia patient not meeting lavage-based diagnostic criteria}

It has been known that on average in only a quarter of all patients clinically suspected of having VAP, bacterial pneumonia can be confirmed by BAL fluid analysis. ${ }^{1}$ The clinical picture of VAP can be mimicked by various other infectious and non-infectious diseases. ${ }^{2}$ Establishing a correct alternative diagnosis rapidly may be vital for initiating adequate treatment and benefiting patient outcome. Aim of the study was to determine the frequency of alternative diagnoses in putative VAP patients with negative lavage results. For this purpose data of BAL fluid analyses and clinical data of patients were retrospectively analysed. Results delivered numerous different alternative diagnoses of a wide clinical spectrum. The most frequently found alternative diagnoses and recommended diagnostic tests in the further workup are summarized in Table 8.1. A generally applicable diagnostic flowchart could not be deduced from the analysis. Diagnostic work-up has therefore to be individualized and guided by repeated clinical assessment. A frequent finding in our study was the presence of Herpes simplex virus DNA in BAL fluid. However, the clinical significance has been debated whether Herpes simplex virus has a genuine pathogenic role or is only a bystander. ${ }^{3}$ It was previously demonstrated that Herpes simplex DNA can be detected in the lower airways in about $30 \%$ of critically ill ventilated patients correlated to the severity of illness. More severe illness may lead to immune suppression, viral reactivation and shedding of microorganisms from the throat. No relationship between HSV-1 viral load and pulmonary injury or additional mortality could be established. This suggests a lack of pulmonary pathogenicity. ${ }^{4}$ Other studies contradict these data claiming some of HSV-1 positive critically ill patients may have evidence of viral pneumonia. ${ }^{5}$ If HSV-1 has a genuine pathogenic role, then treatment with acyclovir should result in better outcome. A recent study could establish a better mortality outcome when patients with HSV-1 positivity in BAL fluid were treated with acyclovir. ${ }^{6}$ Although the exact significance of HSV pneumonia remains to be established, treatment should be 
considered if no other likely causes of respiratory failure in severely ill patients can be identified.

Table 8.1 Frequent alternative diagnoses in patients with negative bacterial growth BAL result and recommended diagnostic tests

\begin{tabular}{|c|c|}
\hline Alternative diagnoses & recommended diagnostic tests \\
\hline Non-bacterial infectious pneumonia & $\begin{array}{l}\text { PCR for presence of viruses, Pneumocystis } \\
\text { jirovecii, fungi in BAL fluid; Galactomannan }\end{array}$ \\
\hline Non-infectious pneumonitis & computed tomography; lung biopsy \\
\hline $\begin{array}{l}\text { Cardiovascular (heart failure, pulmonary embolism, } \\
\text { endocarditis) }\end{array}$ & echocardiography; computed tomography \\
\hline Different septic focus (abdominal, urogenital, cerebral) & repeated blood culture, computed tomography \\
\hline
\end{tabular}

\section{Candida pneumonia in critically ill ventilated patients}

Whereas the role of bacteria in the etiology of VAP has been established and diagnostic cut-off values have been defined, less is known about the role of fungi in nosocomial pneumonia. Candida species are the most common isolated yeasts in critically ill patients but the clinical significance and pathogenic potency are still argued. ${ }^{7-9}$ Candida spp. isolation in the respiratory tract was associated with prolonged stay and increased risk of VAP. ${ }^{10}$ The presence of Candida spp. in respiratory secretions of patients with VAP could be associated with longer mechanical ventilation, prolonged stay and worse outcome. ${ }^{7,11}$ Respiratory tract colonization with Candida spp. can originate from the oropharyngeal cavity and upper respiratory tract in severely ill patients with diminished immune response. ${ }^{12}$ But many believe Candida does not directly contribute to respiratory disease and is merely a marker for severity of illness. ${ }^{4} \mathrm{~A}$ recent analysis investigated immune competent patients with nosocomial intensive-care unit acquired pneumonia with or without Candida spp. isolation in the respiratory tract. Although patients with Candida spp. had higher severity scores and organ dysfunction on admission and at onset of pneumonia, there were no differences in the systemic inflammatory response, length of stay and mortality. Antifungal therapy did not significantly influence outcome. ${ }^{11}$ Candida pneumonia as a clinical entity is questioned altogether. ${ }^{13}$ Specific cut-off values for fungi in BAL fluid are lacking. Only histopathology could establish the definitive diagnosis. Less invasive diagnostic strategies lack specificity and have been insufficiently validated. In our study we linked microbiological data from the BAL database to clinical information and available autopsy data. Critically ill patients with respiratory failure with no other microbiological or clinical explanation than exclusive presence of Candida species in bronchoalveolar lavage fluid were described. Reviewing 701 included BAL specimens and subsequently linking it to the clinical cases, five patients $(0.7 \%)$ could be identified with possible Candida pneumonia. It definitely is a rare entity but clinical evidence suggests that the 
condition can occur under certain circumstances. [Table 8.2] In cases of serious respiratory failure, radiographic and laboratory evidence for pneumonia and no other growth than Candida in the BAL fluid Candida pneumonia should be considered and subsequently treated.

Table 8.2 Risk factors under which Candida pneumonia might occur in critically ill patients

\begin{tabular}{ll}
\hline Risk factor for Candida pneumonia & \\
\hline Increased Candida load & $\begin{array}{l}\text { diverticulum of the oesophagus, } \\
\text { diabetes mellitus, nicotine and alcohol abuse, } \\
\text { aspiration of gastric fluids } \\
\text { cancer, immunosuppressive drugs, malnutrition }\end{array}$ \\
$\begin{array}{l}\text { Immunosuppression } \\
\text { Broad spectrum antibiotic treatment }\end{array}$ & \\
\hline
\end{tabular}

\section{Acanthamoeba polyphaga mimivirus as a respiratory pathogen in critically ill ventilated patients}

An investigation of a pneumonia outbreak with no clear causative agent led to the discovery of Acanthamoeba polyphaga Mimivirus (APMV) named so due to its mimicry of a bacterium by its size and appearance in Gram staining. Viruses belonging to the Mimiviridae family potentially cause community-acquired and healthcare-associated pneumonia. ${ }^{14}$ The clinical significance of APMV in the etiology of VAP has been suggested in earlier studies. APMV is known to induce histological evidence of pneumonia with the formation of diffuse alveolar damage in mice. Since the virus is able to induce pneumonia in mice, it was hypothesized that it would also be able to induce pneumonia in humans. Evidence of APMV as a respiratory pathogen in humans has mainly been based on serologic studies. It was shown that a fifth of intensive care patients with a suspicion of VAP are seropositive for APMV and this was associated with an increased duration of mechanical ventilation and ICU stay. ${ }^{15,16}$ However, the mere presence of antibodies only showed that the individual had been into contact with the virus, but did not always imply disease. Therefore we looked for the presence of the virus in patients with a clinical suspicion of VAP. We were unable to detect APMV DNA in BAL fluid and therefore concluded that APMV does not cause VAP.

\section{Clinical course and complications following diagnostic bronchoalveolar lavage}

Bronchoscopic BAL from the presumed site of infection with cytological analysis and quantitative microbiological culture of the lavage fluid has been established as a diagnostic standard for VAP. ${ }^{17-19}$ However, BAL is an invasive diagnostic technique 
carried out in vulnerable ventilated patients. Studies concerning the safety of bronchoscopic diagnostic techniques in critical care patients were small in size, differed in patient population, setting, applied diagnostic techniques and length of observation. ${ }^{20-27}$ The present study was the largest analysis of the clinical course and complications in patients following bronchoscopic BAL in the diagnosis of VAP. Frequently occurring haemodynamic and respiratory instability could be attributable to diagnostic BAL but no cases of severe cardiac rhythm disturbances, bleeding, pneumothorax or procedure related death were observed. [Table 8.3] The study did not allow to define clear-cut clinical criteria for withholding BAL because the limited number of patients with severe acidosis $(\mathrm{pH}<7.25)$, hypercapnia (PaCO2 $\geq 7.5 \mathrm{kPa} / 56 \mathrm{mmHg})$ and hypoxia $(\mathrm{PaO} 2 \leq 8 \mathrm{kPa} / 60 \mathrm{mmHg}$ or $\mathrm{PaO} 2 / \mathrm{FiO} 2$ ratio $\leq 13 \mathrm{kPa} / 100 \mathrm{mmHg})$.

Table 8.3 Summary of the clinical course and complications occurring within 24 hours following diagnostic FFB and BAL

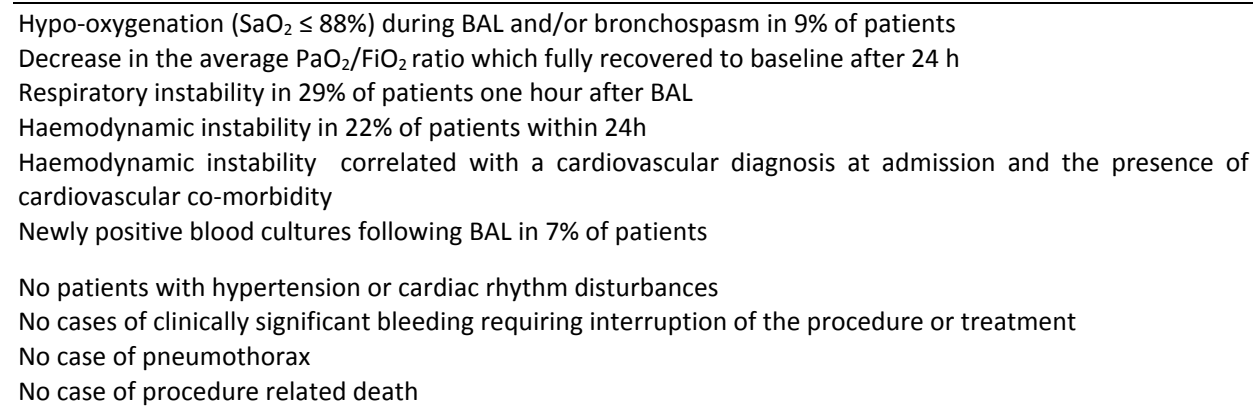

\section{Diagnosis of ventilator-associated pneumonia from exhaled breath analysis}

Bronchoscopic BAL is invasive and has its limitations in patients with severe pulmonary disease, high respiratory support settings and coagulation abnormalities. Analysis of BAL is laborious, costly and time-consuming before definitive results are available and the diagnosis of VAP can be confirmed or rejected. Therefore, it has been of interest to find new methods that allow a fast, reliable, non-invasive diagnosis of VAP. Exhaled breath analysis is an emerging and promising technique that may be able to meet some of these criteria. It is based on the analysis of volatile organic compounds (VOCs) present in exhaled breath. VOCs originate from both exogenous and endogenous sources. VOCs are produced by biological processes including oxidative stress and inflammation in the human body ${ }^{28,29}$ as well as by invading microorganisms ${ }^{30}$. Upon their production, VOCs are excreted into the blood after which they diffuse into the 
lungs where they are exhaled. Two different techniques of exhaled breath analysis in VAP were studied. Gas chromatography coupled with mass spectrometry (GC-MS) can directly detect VOCs. It separates molecules according to their volatility and interaction with the stationary phase of an absorbing column. During mass-spectrometry components are fragmented into charged particles, carried through an electromagnetic field and quantitatively detected. ${ }^{31,32}$ Electronic nose (e-nose) technology with hybrid metal oxide semiconductor sensors cannot directly detect different VOCs. E-noses are artificial sensor systems with an algorithm for pattern recognition. Changes in temperature-time-conductivity curves caused by presumed differences in the VOC composition of exhaled breath in patients with and without VAP were analysed. The results were compiled in Table 8.4 and compared with demands for an ideal diagnostic technique for VAP and the current diagnostic standard, the bronchoscopic BAL analysis. Exhaled breath analysis with GC-MS could not identify VOCs that exclusively appear in patients with VAP. But it could be demonstrated that it is possible to distinguish ICU patients with VAP from patients without VAP based on a profile of only 12 VOCs. However, the diagnostic sensitivity and specificity are insufficient for current clinical application. In the present study, the applied e-nose sensors lacked the clinically required diagnostic sensitivity and specificity in the direct exhaled breath detection of patients with VAP. Both studies had a relatively small number of subjects to test for specific strains of bacteria. As VAP is generally caused by an array of bacteria, there were only a few patients per bacterial strain available at most, hindering the use of multivariate statistics to identify strain-specific VOCs in vivo.

The selected VOCs to discriminate between VAP(+) and VAP(-) critically ill patients were associated with inflammation and activation of the immune system (Acrolein) or with activation of the metabolism (Ethanol, Aceton) in general. As two groups of comparably ill ICU patients were investigated, it might be difficult to discriminate with parameters that react to activation of inflammatory cascades in the body between subjects with and without additional presence of VAP. The majority of VOCs were (branched) alkanes (heptane, 2-methylbutane, dodecane, tetradecane and tetradecanal). Alkanes are present in the environment and are inhaled on a daily basis. After ingestion, the compounds are broken down in the liver by cytochrome P450 enzymes (CYP). The activity of these enzymes decreases with aging, but also with disease, implicating reduced CYP activity in severely ill patients. ${ }^{33}$ Differences in these VOCs could be caused by variations in age and severity of illness, inflammation and metabolic state.

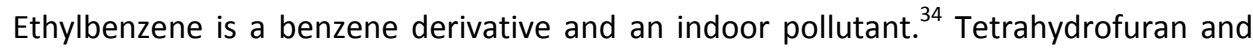
carane are also environmental pollutants without known endogenous source. Benzene and its derivatives are also broken down in the liver by CYP enzymes, which may have an altered activity in critically ill patients, resulting in different exhaled abundances of ethylbenzene. Thus, different concentrations in exhaled breath could likely reflect differences in exogenous source or liver metabolism. 
Table 8.4 Comparison between an ideal diagnostic technique for VAP and bronchoalveolar lavage (BAL), electronic nose (e-nose) and gas chromatography-mass spectrometry (GC-MS)

\begin{tabular}{|c|c|c|c|}
\hline Ideal technique & BAL & e-nose & GC-MS \\
\hline Non-invasive sampling & $\begin{array}{l}\text { invasive technique, requires } \\
\text { bronchoscopy and lavage } \\
\text { with frequent respiratory } \\
\text { and haemodynamic } \\
\text { deterioration }\end{array}$ & $\begin{array}{l}\text { non-invasive exhaled } \\
\text { breath collection }\end{array}$ & $\begin{array}{l}\text { non-invasive exhaled } \\
\text { breath collection }\end{array}$ \\
\hline Feasible in all patients & $\begin{array}{l}\text { contraindicated in patients } \\
\text { with coagulation } \\
\text { abnormalities }\end{array}$ & no restrictions & no restrictions \\
\hline Point-of-care results & no & potentially possible & no \\
\hline $\begin{array}{l}\text { Short duration until results } \\
\text { available }\end{array}$ & days & $<1 \mathrm{~h}$ & hours \\
\hline Not labour-intensive & $\begin{array}{l}\text { laborious, requires } \\
\text { bronchoscopy, lavage, } \\
\text { cellular analysis and } \\
\text { microbiological culturing }\end{array}$ & $\begin{array}{l}\text { non-laborious, could } \\
\text { become automated }\end{array}$ & $\begin{array}{l}\text { laborious, requires } \\
\text { exhaled breath sampling, } \\
\text { carbon element fixation, } \\
\text { lab analysis }\end{array}$ \\
\hline Inexpensive & $\begin{array}{l}\text { no; requires manpower } \\
\text { during sampling and } \\
\text { analysis, expensive } \\
\text { equipment, single use } \\
\text { material necessary } \\
\end{array}$ & $\begin{array}{l}\text { no; limited durability of } \\
\text { current sensors }\end{array}$ & $\begin{array}{l}\text { no; requires manpower } \\
\text { during analysis, } \\
\text { expensive equipment }\end{array}$ \\
\hline Strain specific diagnosis & yes & not yet available & not yet available \\
\hline Antibiogram available & yes & no & no \\
\hline High sensitivity / specificity & $42-93 / 45-100 \%{ }^{1}$ & $76 / 56 \%^{2}$ & $76 / 73 \%^{2}$ \\
\hline
\end{tabular}

${ }^{1}$ compared to histopathology; ${ }^{2}$ compared to BAL

In general, exhaled breath data contain several sources of variance, which include information of interest with regard to the examined disease, but also irrelevant variance associated with biological variation and noise. ${ }^{35,36}$ Ideally, in diagnostic exhaled breath analysis all sources of exogenous compounds should be eliminated and VOCs derived from the environment should be excluded from the data analysis and evaluation of biomarkers. ${ }^{33}$ Selected VOCs should have at least a $15 \%$ higher concentration in exhaled breath than in ambient air, the use of plastic for breath sampling should be reduced and exogenous compounds derived from room air, consumer products, food, analytical devices as well as compounds associated with cigarette smoking should all be excluded. ${ }^{37}$ Furthermore, exhaled breath collection and data processing methodologies could be more standardised. ${ }^{35}$ These measures could reduce inconsistency in results derived from exhaled breath analysis in the detection of respiratory diseases and thus facilitate the development of true volatile biomarker profiles. The availability of biomarker VOCs could enable the development of more specific electronic nose sensors to transfer exhaled breath analysis of respiratory disease towards the bedside. Further developments could focus on integrated devices for an early prediction of pneumonia development in ventilated patients. Ideally, it should be also possible to follow the response to therapeutic interventions to give guidance in antibiotic stewardship. 


\section{References}

1 Schnabel RM, Scholte JB, Van Der Velden KE, Roekaerts PM, Bergmans DC. Ventilator-associated pneumonia rates after introducing selective digestive tract decontamination. Infectious diseases 2015;47:650-3.

2 Meduri GU. et al. Causes of fever and pulmonary densities in patients with clinical manifestations of ventilator-associated pneumonia. Chest 1994;106:221-35.

3 Simoons-Smit AM, Kraan EM, Beishuizen A, Strack van Schijndel RJ, Vandenbroucke-Grauls CM. Herpes simplex virus type 1 and respiratory disease in critically-ill patients: Real pathogen or innocent bystander? Clinical microbiology and infection 2006;12:1050-9.

4 Assink-de Jong $\mathrm{E}$, et al. Clinical correlates of herpes simplex virus type 1 loads in the lower respiratory tract of critically ill patients. Journal of clinical virology 2013;58:79-83.

5 Luyt $\mathrm{CE}$, et al. Herpes simplex virus lung infection in patients undergoing prolonged mechanical ventilation. American journal of respiratory and critical care medicine 2007;175:935-42.

6 Traen S, et al. Is acyclovir effective among critically ill patients with herpes simplex in the respiratory tract? Journal of clinical virology 2014;60:215-21.

7 Delisle MS, et al. Impact of Candida species on clinical outcomes in patients with suspected ventilatorassociated pneumonia. Canadian respiratory journal 12011;8:131-6.

8 Hamet $\mathrm{M}$, et al. Candida spp. airway colonization could promote antibiotic-resistant bacteria selection in patients with suspected ventilator-associated pneumonia. Intensive care medicine 2012;38:1272-9.

9 Delisle MS, et al. The clinical significance of Candida colonization of respiratory tract secretions in critically ill patients. Journal of critical care 2008;23:11-7.

10 Azoulay $\mathrm{E}$, et al. Candida colonization of the respiratory tract and subsequent pseudomonas ventilatorassociated pneumonia. Chest 2006;129:110-7.

11 Terraneo S, et al. Impact of Candida spp. isolation in the respiratory tract in patients with intensive care unit-acquired pneumonia. Clinical microbiology and infection 2015; pii: S1198-743X(15)00817-4.

12 Heo SM, Sung RS, Scannapieco FA, Haase EM. Genetic relationships between Candida albicans strains isolated from dental plaque, trachea, and bronchoalveolar lavage fluid from mechanically ventilated intensive care unit patients. Journal of oral microbiology 2011;3.

13 Meersseman W, et al. Significance of the isolation of Candida species from airway samples in critically ill patients: a prospective, autopsy study. Intensive care medicine 2009;35:1526-31.

14 Kutikhin AG, Yuzhalin AE, Brusina EB. Mimiviridae, Marseilleviridae, and virophages as emerging human pathogens causing healthcare-associated infections. GMS hygiene and infection control 2014;9:Doc16.

15 La Scola B, Marrie TJ, Auffray JP, Raoult D. Mimivirus in pneumonia patients. Emerging infectious diseases 2005;11:449-52.

16 Vincent $A$, et al. Clinical significance of a positive serology for mimivirus in patients presenting a suspicion of ventilator-associated pneumonia. Critical care medicine 2009;37:111-8.

17 Fagon JY, et al. Invasive and noninvasive strategies for management of suspected ventilator-associated pneumonia. A randomized trial. Annals of internal medicine 2000;132:621-30.

18 Shorr AF, Sherner JH, Jackson WL, Kollef $\mathrm{MH}$. Invasive approaches to the diagnosis of ventilatorassociated pneumonia: a meta-analysis. Critical care medicine 2005;33:46-53.

19 Fagon JY. Diagnosis and treatment of ventilator-associated pneumonia: fiberoptic bronchoscopy with bronchoalveolar lavage is essential. Seminars in respiratory and critical care medicine 2006;27:34-44.

20 Trouillet $\mathrm{JL}$, et al. Fiberoptic bronchoscopy in ventilated patients. Evaluation of cardiopulmonary risk under midazolam sedation. Chest 1990;97:927-33.

21 Montravers P, Gauzit R, Dombret MC, Blanchet F, Desmonts JM. Cardiopulmonary effects of bronchoalveolar lavage in critically ill patients. Chest 1993;104:1541-7.

22 Steinberg KP, et al. Safety of bronchoalveolar lavage in patients with adult respiratory distress syndrome. The American review of respiratory disease 1993;148:556-61.

23 Bauer TT, et al. Effects of bronchoalveolar lavage volume on arterial oxygenation in mechanically ventilated patients with pneumonia. Intensive care medicine 2001;27:384-93. 
24 Chou MY, Ou CY, Chen CW. Alterations in respiratory mechanics in mechanically ventilated patients following bronchoalveolar lavage. Journal of the Formosan Medical Association = Taiwan yi zhi 2009;108:704-12.

25 Estella A. Effects on respiratory mechanics of bronchoalveolar lavage in mechanically ventilated patients. Journal of bronchology \& interventional pulmonology 2010;17:228-31.

26 Estella A. [Analysis of 208 flexible bronchoscopies performed in an intensive care unit]. Medicina intensiva / Sociedad Espanola de Medicina Intensiva y Unidades Coronarias 2012;36:396-401.

27 Turner JS, Willcox PA, Hayhurst MD, Potgieter PD. Fiberoptic bronchoscopy in the intensive care unit--a prospective study of 147 procedures in 107 patients. Critical care medicine 1994;22:259-64.

28 Miekisch W, Schubert JK, Noeldge-Schomburg GF. Diagnostic potential of breath analysis--focus on volatile organic compounds. Clinica chimica acta; international journal of clinical chemistry 2004;347: 25-39.

29 Boots AW, et al. The versatile use of exhaled volatile organic compounds in human health and disease. Journal of breath research 2012;6:027108.

30 Bos LD, Sterk PJ, Schultz MJ. Volatile metabolites of pathogens: a systematic review. PLoS pathogens 2013;9:e1003311.

31 Hübschmann. Handbook of GC/MS: Fundamentals and Applications. Wiley. 2008.

32 Santos FJ, Galceran MT. Modern developments in gas chromatography-mass spectrometry-based environmental analysis. Journal of chromatography. A 2003;1000:125-51.

33 Kwak J, Preti G. Volatile disease biomarkers in breath: a critique. Current pharmaceutical biotechnology 2011;12:1067-74.

34 Midorikawa K, et al. Metabolic activation of carcinogenic ethylbenzene leads to oxidative DNA damage. Chemico-biological interactions 2004;150:271-81.

35 Pereira J, et al. Breath analysis as a potential and non-invasive frontier in disease diagnosis: an overview. Metabolites 2015;5:3-55.

36 Smolinska A, et al. Current breathomics--a review on data pre-processing techniques and machine learning in metabolomics breath analysis. Journal of breath research 2014;8:027105.

37 Bajtarevic A, et al. Noninvasive detection of lung cancer by analysis of exhaled breath. BMC cancer 2009;9:348. 
Valorisation addendum 



\section{Valorisation addendum}

\section{Relevance}

Ventilator-associated pneumonia (VAP) is a nosocomial infection affecting the lungs. It is responsible for substantial healthcare costs and additional hospital mortality. The present thesis addresses new aspects with regard to causative microorganisms, diagnostic algorithms and novel non-invasive diagnostic techniques.

The knowledge of the pathogenic potency of a microorganism is essential to understand the infectious disease process, to develop a diagnostic strategy and therapy. This can benefit patient outcome. It is of interest to identify pathogenic microorganisms. In this thesis the potential role of Acanthamoeba polyphaga mimivirus (APMV) has been investigated. It has been demonstrated that APMV is not present in BAL lavage fluid and not a cause of VAP. Furthermore, the role of Candida as a causative microorganism of ICU pneumonia was investigated. Although rarely occurring, certain clinical circumstances were defined in which Candida pneumonia should be considered and treated.

Diagnostic algorithms give guidance to physicians in a complex decision making process stratifying the likelihood of diagnoses and the invasiveness of necessary diagnostic techniques. These must hold to the old Hippocratic paradigm not to harm patients in the first place. If it concerns invasive diagnostic techniques the expected benefits ought to outweigh the risks to justify application. In the present thesis the diagnostic tool fibreoptic bronchoalveolar lavage (BAL) in critical ill mechanically ventilated patients was investigated. BAL has been routinely performed in patients with clinical suspicion of VAP to confirm the diagnosis. In all patients with a negative BAL for bacterial growth possible alternative diagnoses accountable for their clinical symptoms were analysed. Other infectious causes like viral infections or Pneumocystis jirovecii infections, but also non-infectious causes like heart-failure or malignancies, were frequently found. With this information, therapy can be adequately adjusted. Next to the utility of BAL the clinical course and complications of the procedure in critical ill mechanically ventilated patients were analysed. It could be demonstrated in the present thesis that BAL is frequently followed by haemodynamic and respiratory instability and should be conducted under careful supervision by experienced physicians.

Exhaled breath analysis is a new diagnostic modality in respiratory medicine. It carries no procedural risks even in critical ill mechanically ventilated patients. In the studies of the present thesis exhaled breath was directly analysed in order to identify patients with VAP. Two different techniques were applied. Gas chromatography-mass spectrometry (GC-MS) directly analyses the presence of volatile organic compounds (VOCs) in breath and changes related to disease state. GC-MS is a complex and expensive technology. The advantage is the possibility to develop certain VOC profiles as markers of infectious diseases. Electronic noses (e-nose) indirectly analyse patterns 
of VOCs. The advantage of e-nose is their smaller size, portability and usability with potentials for point-of-care applications.

\section{Target groups}

The results from the studies are of interest for clinicians in intensive care - and respiratory medicine. A broad spectrum of professionals is involved in the development of exhaled breath analysis devices and their clinical application such as biologists, biochemist, physicians, physiologists and engineers.

\section{Innovation and implementation}

Point-of-care devices examining exhaled breath could be used for the diagnosis of respiratory disease and infections. It could support the discrimination of a bacterial lung infection from other respiratory conditions and the decision making on the necessity of antibiotic treatment. This could contribute to the reduction of antibiotic use. Exhaled breath analysis could be used for a fast discrimination of different forms of pneumonia as pneumococcal pneumonia, legionella or pneumonia caused by Pneumocystis jiroveci to initiate the right antimicrobial therapy. Devices that analyse exhaled breath could be integrated in respirators to detect a developing VAP early and subsequently to monitor the efficacy of antibiotic treatment. 
Acknowledgements 



\section{Acknowledgements}

This thesis could not have been accomplished without the support of many people who created the right environment, gave their inspiration and shared their knowledge.

I am grateful to all who influenced and shaped me to become a clinician during my first steps in medicine. I thank all professionals from the Maastricht University Hospital and the Catharina Hospital Eindhoven who helped me to develop clinical skills and competences as a doctor during my specialisation in anaesthesiology.

When I started my training in intensive care medicine at Maastricht University Hospital I met Dennis Bergmans. He became to me a highly regarded colleague and an enthusiastic doctorate advisor who introduced me to scientific methods, reasoning and writing. He had paved the way for this thesis by his own research on ventilatorassociated pneumonia. I am grateful to my thesis supervisor Paul Roekaerts who efficiently coached me with dedication and passion.

I thank all members of the scientific assessment commission for their judgement and the endorsement of this thesis.

A lot of research has been done in excellent collaboration with the department of microbiology. I thank Kitty Linssen for sharing microbiological data and contributing her broad knowledge on bronchoalveolar lavage. I owe thanks to Marijke Vanspauwen who was leading in the investigation of MIMI virus. Ellen Stobberingh had a large share in the draft of the exhaled breath studies. The experience, skills and the dedicated work of Marie-Louise Boumans in the microbiology laboratory were essential to accomplish the study results. Many thanks for the always pleasant and instructive cooperation.

The exhaled breath studies using gas chromatography - mass spectrometry were carried out in efficient collaboration with the department of toxicology. I owe special thanks to Frederik Jan van Schooten, Jan Dallinga and Agnes Boots for guidance, help and advice. Rianne Fijten was an enthusiastic and talented co-worker in our common project. I am honoured that she will back me as a paranymphe at the doctoral thesis defence together with Jan Willem Sels whom I know since our first clinical experiences in intensive care medicine more than a decade ago. I owe special thanks to Agnieszka Smolinska for her statistical advice and assistance.

I thank Kim van der Velden, Rik Schoemakers, Ruth Kaufmann and Aart Osinski for the hard work during their scientific projects as final year medical students that supported the studies of my thesis. 
My co-authors of the several publications Annelies Verbon, Guy Oudhuis, Nele Guion, Gernot Rohde, Catherine Bruggeman, Marjolein Drent and Walther van Mook were very supportive with help and advice. It was a pleasure to work and write together. I thank Miranda Hendrikx and ICT analyst Jerry Townsend for their assistance in data entry and retrieval and the statistician Bjorn Winkens for his competent support.

Special thanks to all my colleagues from the department of intensive care medicine, nurses, secretaries, residents, fellows and medical staff. This work could not have been accomplished without the support of colleagues who took over clinical tasks to enable research activities, their practical help and advice, encouragement and motivation. I thank Jan Scholte, co-researcher within the department, for all rewarding discussions. Thanks to the professionalism and assistance of Tiny Wouters the fine layout of the thesis could have been accomplished. The artist Meinhard Bärmich resumed the thesis with a twinkle in his eyes in a wonderful cartoon.

My parents Bernd and Rita provided me a caring, stable and open-minded home, encouraged curiosity in all aspects of life and eagerness to study. I am very grateful to them for their support and love.

The joy and love of my little family with my partner Jessica Holtkamp and our daughter Sarah encouraged me in all difficult moments. I thank Jessica for her unconditional support, to help me through this project with her distinctive patients and confidence. 
Curriculum Vitae 



\section{Curriculum Vitae}

Ronny Schnabel was born on June $23^{\text {rd }} 1974$ in Görlitz, Germany. After completing secondary education in 1992 he fulfilled his community service (in lieu of military service) in Germany. He worked for the aid organisation "Arbeiter-Samariter-Bund" (Görlitz) in home-care and for the ambulance service. In 1994 he went to the Johannes Gutenberg-University of Mainz, Germany, to study medicine. As a medical student he conducted research in the laboratory of Prof. S. Bhakdi at the department of medical microbiology and wrote a MD thesis titled: "Membrane insertion of the heptameric staphylococcal alpha-toxin pore. A domino-like structural transition that is allosterically modulated by the target cell membrane." During his final year he worked as an elective student at St. Helier Hospital, London, UK. He graduated from medical school in 2001 and gathered clinical experience in medicine, A\&E and intensive care in Aachen, Heerlen and Eindhoven before he started his specialisation in anaesthesiology and intensive care medicine at the Maastricht University Medical Centre+ in 2004. Since 2009 he has been working as a member of staff at the same hospital. Ronny lives with his partner Jessica Holtkamp and his daughter Sarah in Maastricht. 

List of publications 



\section{List of publications}

Membrane insertion of the heptameric staphylococcal alpha-toxin pore. A domino-like structural transition that is allosterically modulated by the target cell membrane Valeva A, Schnabel R, Walev I, Boukhallouk F, Bhakdi S, Palmer M; J Biol Chem. 2001; 276:14835-41

Intracardiac entrapment of a pulmonary artery catheter

Schnabel R , van Zundert A; Acta Anaesth Scand. 2007;51:781-2

Two cases of acquired methemoglobinemia

Hall A, Stessel B, Bergmans D, Schnabel R; Acta Anaesth Belg. 2012;63:97-100

Alternative diagnosis in the putative ventilator-associated pneumonia patient not meeting the diagnostic bronchoalveolar lavage criteria

Schoemakers RJ, Schnabel R, Oudhuis GJ, Linssen CF, van Mook WN, Verbon A, Bergmans DC; Scand J Infect Dis. 2014;46:868-74

Candida pneumonia in ICU?

Schnabel R, Linssen CF, Guion N, van Mook WN, Bergmans DC; Open Forum Infect Dis. 2014;1(1)

Mimivirus is not a frequent cause of ventilator-associated pneumonia in critically ill patients

Vanspauwen MJ, Schnabel R, Bruggeman CA, Drent M, van Mook WN, Bergmans DC, Linssen CF; J Med Virol. 2013;85:1836-41

Ventilator-associated pneumonia rates after introducing selective digestive tract decontamination

Schnabel R, Scholte JB, Van Der Velden KE, Roekaerts PM, Bergmans DC; Infect Dis (Lond). 2015;47:650-3

Clinical course and complications following diagnostic bronchoalveolar lavage in critically ill mechanically ventilated patients

Schnabel RM, van der Velden K, Osinski A, Rohde G, Roekaerts PMHJ, Bergmans DCJJ; BMC Pulm Med 2015;15:107

Analysis of volatile organic compounds in exhaled breath to diagnose ventilatorassociated pneumonia

Schnabel R, Fijten R, Smolinska A, Dallinga J, Boumans ML, Stobberingh E, Boots A, Roekaerts P, Bergmans D, van Schooten FJ; Sci Rep 2015;5:17179 
Electronic nose analysis of exhaled breath to diagnose ventilator-associated pneumonia Schnabel R, Boumans MLL, Smolinska A, Stobberingh EE, Kaufmann R, Roekaerts PMHJ, Bergmans DCJJ; Respir Med 2015;109:1454-9 
Abbreviations 



\section{Abbreviations}

\begin{tabular}{|c|c|}
\hline ANOVA & analysis of variance \\
\hline APACHE & acute physiology and chronic health evaluation \\
\hline APMV & acanthamoeba polyphaga mimivirus \\
\hline ARDS & adult respiratory distress syndrome \\
\hline ASP & antibiotic stewardship program \\
\hline ATRA & all trans retinoic acid \\
\hline$A \cup C$ & area under the curve \\
\hline BAL & bronchoalveolar lavage \\
\hline BALF & bronchoalveolar lavage fluid \\
\hline BOOP & bronchiolitis obliterans with organizing pneumonia \\
\hline CAP & community acquired pneumonia \\
\hline $\mathrm{cfu}$ & colony forming units \\
\hline $\mathrm{CDC}$ & Center of Disease Control \\
\hline ChEBI & chemical entities of biological interest \\
\hline CMV & cytomegalovirus \\
\hline COPD & chronic obstructive pulmonary disease \\
\hline CPIS & clinical pulmonary infection score \\
\hline CT & computed tomography \\
\hline CYP & cytochrome P450 \\
\hline DNA & deoxyribonucleic acid \\
\hline e-nose & electronic nose \\
\hline $\mathrm{FiO}_{2}$ & fraction of inspired oxygen \\
\hline FFB & flexible fibreoptic bronchoscopy \\
\hline GC-MS & gas chromatography - mass spectrometry \\
\hline GC-tof-MS & gas chromatography-time of flight-mass spectrometry \\
\hline GE & genome equivalent \\
\hline HAP & hospital acquired pneumonia \\
\hline HIV & human immunodeficiency virus \\
\hline hMPV & human metapneumovirus \\
\hline HSV & herpes simplex virus \\
\hline $\mathrm{ICO}$ & intracellular organisms \\
\hline ICU & intensive care unit \\
\hline KEGG & Kyoto encyclopaedia of genes and genomes \\
\hline kPA & kilo Pascal \\
\hline MANOVA & multivariate analysis of variance \\
\hline MAP & mean arterial pressure \\
\hline MDR & multi drug resistant \\
\hline$\mu \mathrm{g} / \mathrm{kg} / \mathrm{min}$ & microgram / kilogram / minute \\
\hline $\mathrm{mmHg}$ & millimetre of mercury \\
\hline
\end{tabular}




$\begin{array}{ll}\text { MRI } & \text { magnetic resonance imaging } \\ \text { NIP } & \text { non-infectious pneumonitis } \\ \text { NYHA } & \text { New York heart association } \\ \text { OR } & \text { odds ratio } \\ \text { PCA } & \text { principal component analysis } \\ \text { PCR } & \text { polymerase chain reaction } \\ \text { PEEP } & \text { positive end-expiratory pressure } \\ \mathrm{paCO}_{2} & \text { partial pressure of carbon dioxide in the arterial blood } \\ \text { pH } & \text { power of hydrogen } \\ \text { pO } & \text { partial pressure of oxygen } \\ \text { RF } & \text { random forest } \\ \mathrm{ROC}_{\mathrm{RNA}} & \text { receiver operating characteristic } \\ \mathrm{RNA} & \text { ribonucleic acid } \\ \mathrm{RSV} & \text { respiratory syncytial virus } \\ \mathrm{RT}-\mathrm{PCR} & \text { real time polymerase chain reaction } \\ \text { SaO } & \text { oxygen saturation } \\ \mathrm{SD} & \text { standard deviation } \\ \mathrm{SOFA} & \text { sequential organ failure assessment } \\ \text { SPp } & \text { species } \\ \text { TRP } & \text { transient receptor potential } \\ \text { VAP } & \text { ventilator-associated pneumonia } \\ \text { VOC } & \text { volatile organic compound }\end{array}$




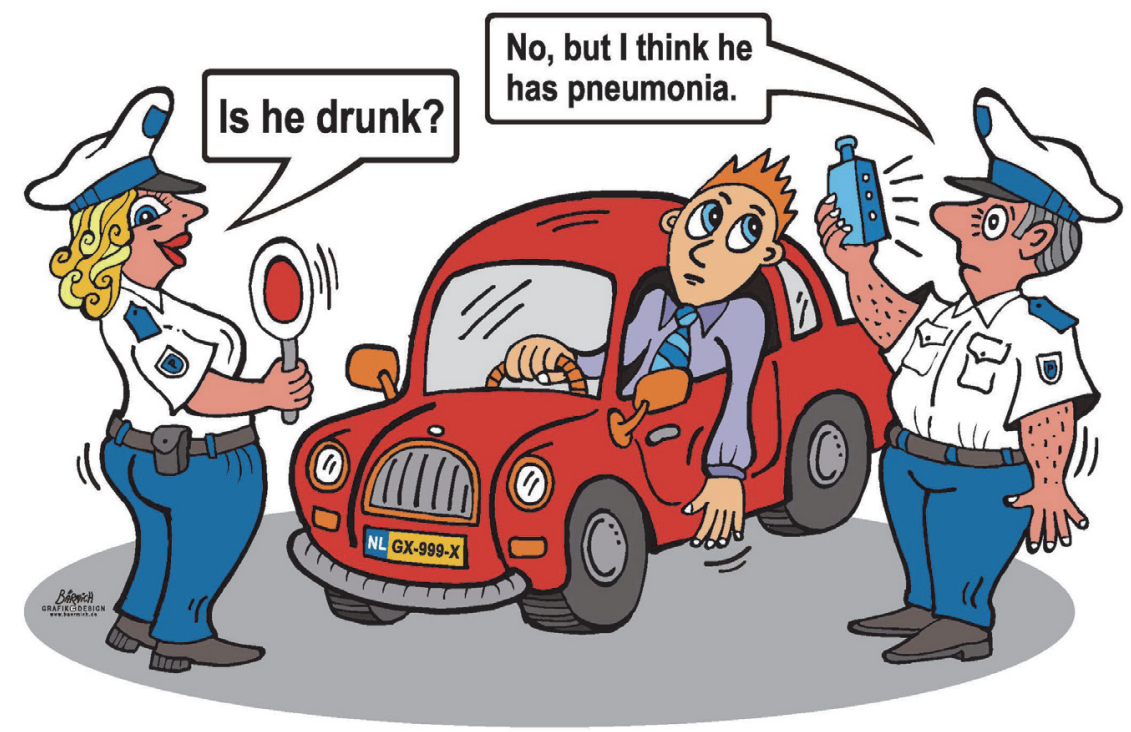


